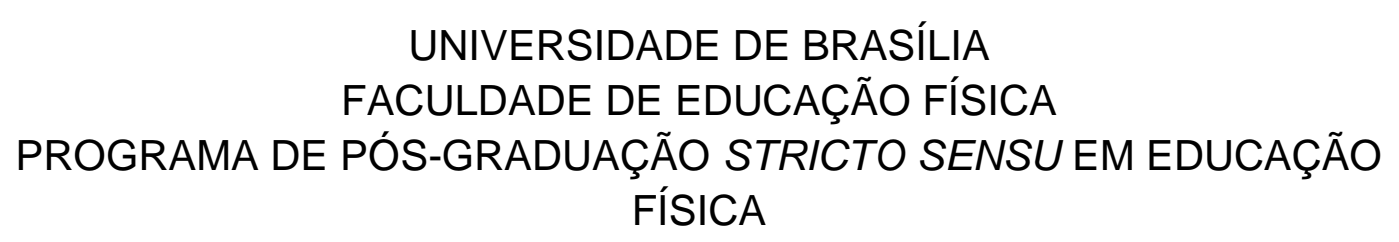

FÍSICA

\title{
EFEITOS DE DIFERENTES MÉTODOS DE TREINAMENTO RESISTIDO SOBRE A REATIVIDADE DA PRESSÃO ARTERIAL AO ESTRESSE MENTAL EM MULHERES IDOSAS HIPERTENSAS
}

Rafael Gauche

BRASÍLIA

2015 
EFEITOS DE DIFERENTES MÉTODOS DE TREINAMENTO RESISTIDO SOBRE A REATIVIDADE DA PRESSÃO ARTERIAL AO ESTRESSE MENTAL EM MULHERES IDOSAS HIPERTENSAS

\section{RAFAEL GAUCHE}

Dissertação apresentada à Faculdade de Educação Física da Universidade de Brasília, como requisito parcial para obtenção do grau de Mestre em Educação Física. 
Ficha catalográfica elaborada automaticamente, com os dados fornecidos pelo(a) autor(a)

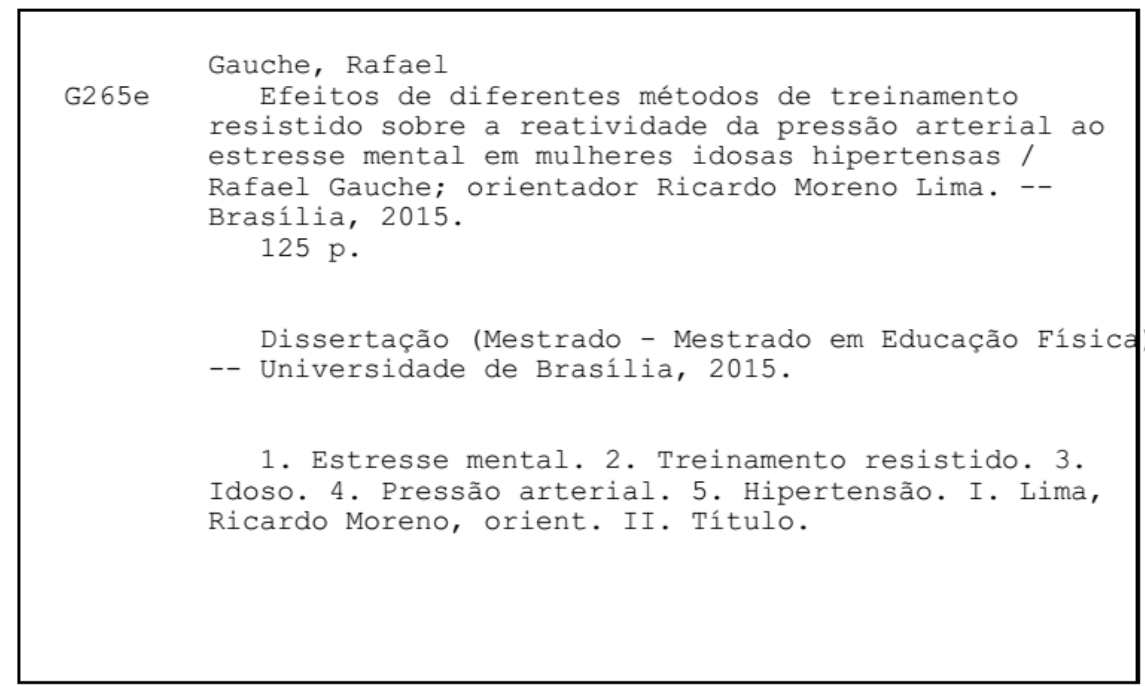




\section{DEDICATÓRIA}

À minha mãe, anjo encarnado na Terra, pelo amor e dedicação infinitos. Meu eterno amor e gratidão.

Ao meu pai, modelo de dedicação, trabalho e estudo. Obrigado por servir de exemplo no caminho acadêmico. 


\section{AGRADECIMENTOS}

A Deus, inteligência suprema, pela vida e pela oportunidade que tive de aprofundar meus estudos e chegar aonde cheguei. À Doutrina Espírita, por me proporcionar a força e a segurança moral necessárias ao sucesso nesta jornada.

Ao Mestrando Éberson, que considero Mestre há 15 anos, por tanto contribuir na formação dos meus valores e caráter, me ensinando o que é ser um verdadeiro capoeira!

À professora Dra. Marisete Pereira Safons, por abrir as portas para mim no Grupo de Estudos e Pesquisas sobre Atividade Física para Idosos GEPAFI. Meu agradecimento pelo acolhimento, atenção e doçura. À Juliana, Bruna e Fabiany, trabalhadoras incansáveis do GEPAFI, por me receberem tão bem. À Juliana, especialmente, pelos exemplos de simplicidade e humildade que julgo essenciais para todos nós.

Ao professor Dr. Ricardo Moreno Lima, pela confiança depositada na minha capacidade, pela gentileza, educação, pelas orientações e conselhos. Principalmente por tratar todos os seus alunos de graduação, mestrado ou doutorado com a mesma atenção, estima e respeito, me ensinando o que é ser um verdadeiro educador!

Aos meus colegas de Mestrado, André, Flávio, Sílvia, e a todos os participantes do Grupo de Estudos em Fisiologia do Exercício e Saúde GEFS. Muito obrigado pela companhia e auxílio.

À Carol, por ter me auxiliado e orientado tantas vezes e por ter me suportado nas horas de estresse, todo carinho e gratidão.

Às minhas voluntárias do GEPAFI, do Serviço de Convivência e Fortalecimento de Vínculos do Riacho Fundo II e demais voluntárias, pela gentileza e disposição em ajudar.

Ao Clayton, amigo e companheiro de trabalho, que tanto me ajudou na seleção das voluntárias.

Ao professor Dr. Lauro Casqueiro Vianna, pelas orientações e por suas perguntas difíceis de responder, que sempre me incentivaram a estudar e aprender mais, elevando meu nível de conhecimento.

À minha mãe, por se colocar à disposição para ajudar desde o início do meu curso de Mestrado e por ler e revisar cuidadosamente cada palavra desta dissertação.

$\mathrm{E}$ a todos aqueles que contribuíram, direta ou indiretamente, para que eu chegasse ao fim de mais esta etapa de aprendizagem. Muito obrigado! 


\section{SUMÁRIO}

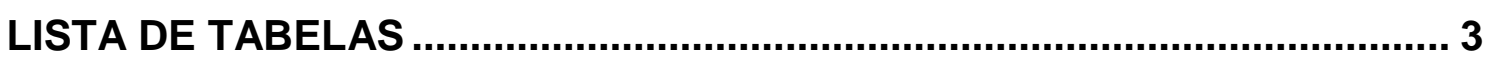

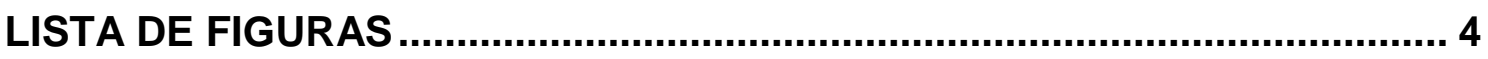

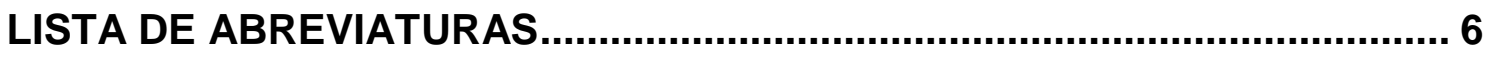

RESUMO

ABSTRACT

1. INTRODUÇÃO

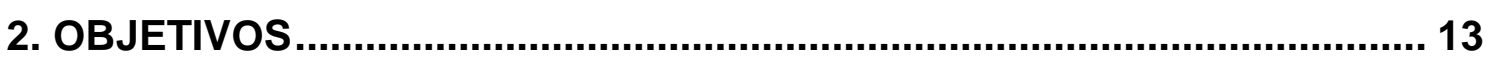

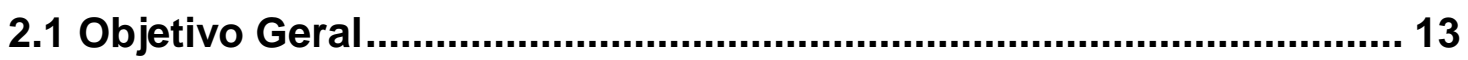

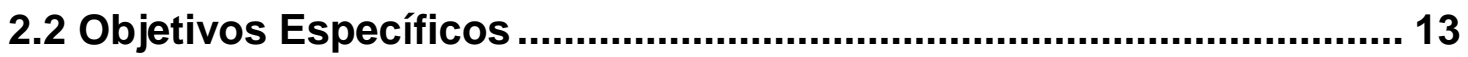

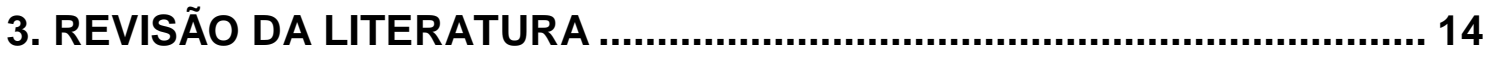

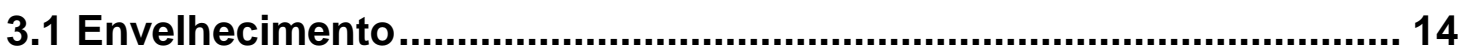

3.1.1 Dados epidemiológicos ......................................................... 14

3.1.2 Alterações fisiológicas e na composição corporal.......................... 16

3.1.3 Alterações estruturais no sistema cardiovascular .......................... 17

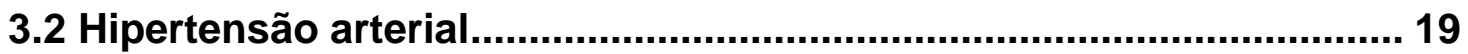

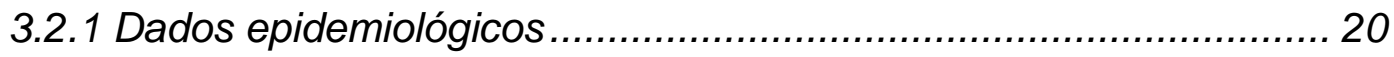

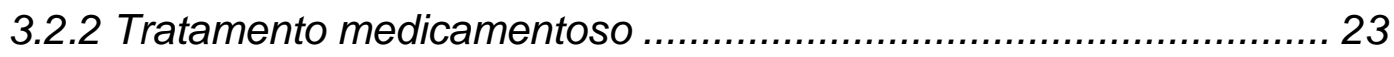

3.2.3 Tratamento não medicamentoso e treinamento resistido ................ 25

3.2.3.1 Exercício resistido e hipotensão pós-exercício................... 26

3.3 Modulação autonômica do sistema nervoso ………........................... 31

3.3.1 Variabilidade da frequência cardíaca........................................... 31

3.3.2 Exercício resistido e variabilidade da frequência cardíaca ............. 34

3.4 Reatividade da pressão arterial ao estresse mental ............................ 37

3.4.1 Exercício resistido e variabilidade da frequência cardíaca .............. 45

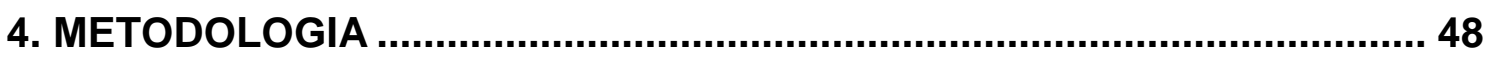

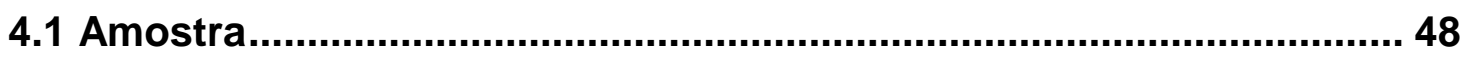

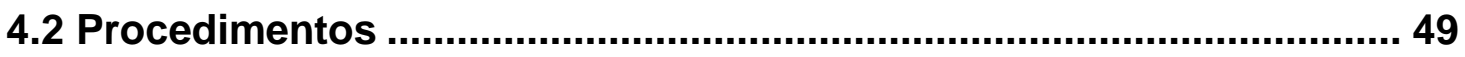

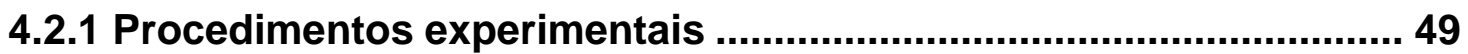

4.2.2 Sessões de familiarização e determinação....................................... 51 


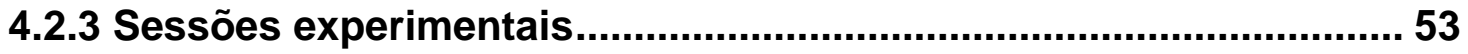

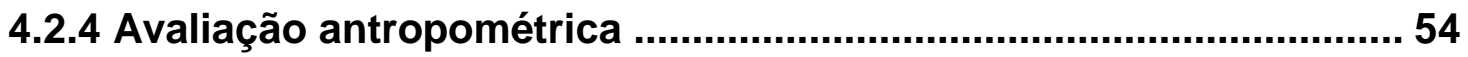

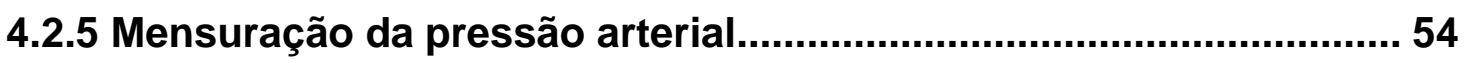

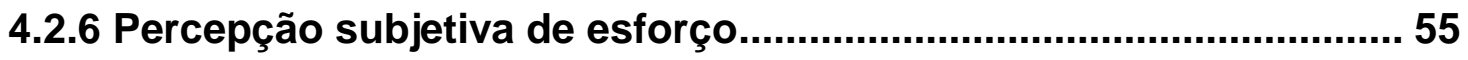

4.2.7 Modulação autonômica do sistema nervoso .................................. 59

4.2.8 Reatividade da pressão arterial ao estresse mental ....................... 61

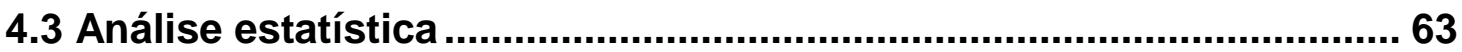

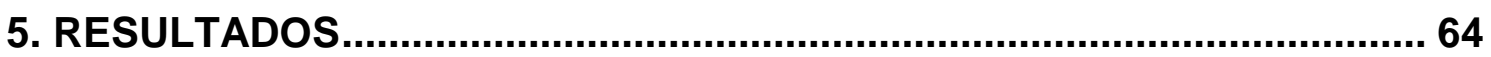

5.1 Características dos sujeitos e das sessões experimentais ............... 64

5.2 Efeitos agudos do exercício resistido sobre a pressão arterial.......... 67

5.3 Efeitos agudos do exercício resistido sobre a modulação autonômica 70

5.4 Efeitos agudos do exercício resistido sobre a reatividade da pressão

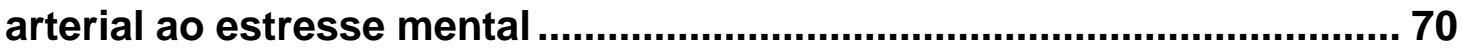

5.5 Efeitos agudos do exercício resistido na modulação autonômica

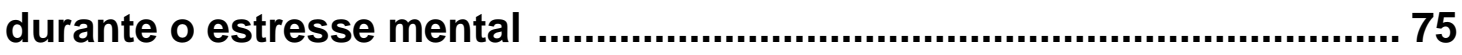

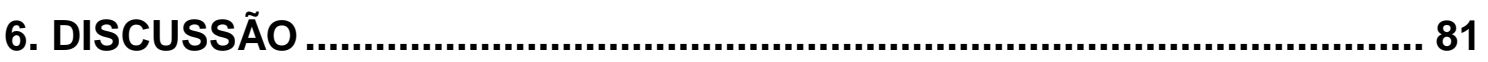

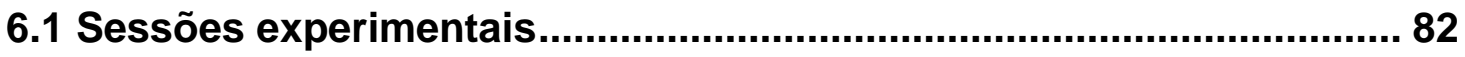

6.2 Efeitos agudos do exercício resistido sobre a pressão arterial.......... 84

6.3 Efeitos agudos do exercício resistido sobre a modulação autonômica

6.4 Efeitos agudos do exercício resistido sobre reatividade da pressão arterial ao estresse mental e modulação autonômica ............................. 90

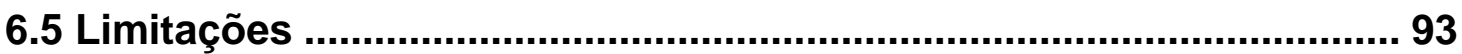

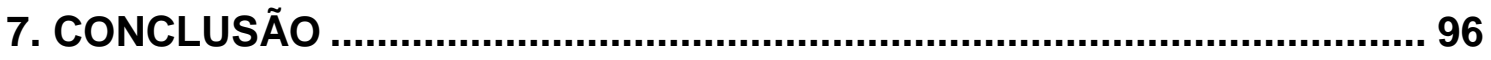

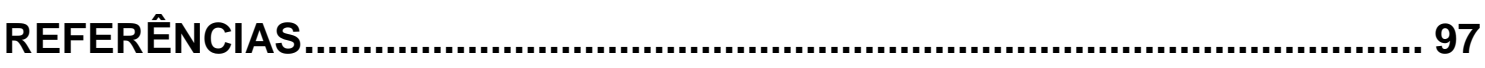

LISTA DE ANEXOS 


\section{LISTA DE TABELAS}

Tabela 1. Características dos sujeitos $(n=10)$ 64

Tabela 2. Distribuições de frequência e percentual de informações de saúde 65

Tabela 3. Cargas e volume total dos exercícios resistidos. 66

Tabela 4. Variáveis hemodinâmicas e autonômicas de repouso no dia das sessões experimentais (média $\pm \mathrm{EP}$ ) 66

Tabela 5. Quadro comparativo das características das sessões experimentais (média \pm EP) 67

Tabela 6. Média \pm EP dos componentes da análise espectral da VFC antes e após as sessões de exercício resistido tradicional (ERT) e exercício resistido em circuito (ERC) 71

Tabela 7. Valores absolutos das leituras de PA durante o teste de Stroop (média \pm EP)

Tabela 8. Média \pm DP dos componentes da análise espectral da VFC no repouso e durante o estresse mental, antes e após as sessões de exercício resistido tradicional (ERT) e exercício resistido em circuito (ERC) 


\section{LISTA DE FIGURAS}

Figura 1. Prevalência de hipertensão em adultos por idade e sexo. Reproduzido, com autorização, de Aronow, Fleg (90) ................................. 21

Figura 2. Pressão arterial sistólica e diastólica por idade e raça ou etnicidade em homens e mulheres acima de 18 anos de idade na população americana. Reproduzido, com autorização, de Chobanian, Bakris (91) ......................... 22

Figura 3. Ilustração esquemática da interação entre fatores ambientais e individuais que podem mediar os efeitos do estresse mental na doença cardiovascular. Reproduzido, com autorização, de Pickering (188) ................ 38

Figura 4. Fluxograma de recrutamento e seleção amostral ......................... 49

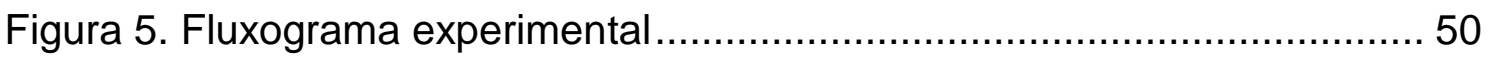

Figura 6. Exercícios resistidos executados nas sessões de familiarização e experimentais (numerados pela ordem de execução) ................................. 52

Figura 7. Escala de percepção subjetiva de esforço "OMNI-RES". Versão traduzida para a língua portuguesa ................................................... 56

Figura 8. Escala de percepção subjetiva de esforço Category Ratio (Borg CR10) modificada por Foster, Florhaug (258). Versão traduzida para a língua portuguesa

Figura 9. Esquema de aplicação do teste de Stroop. Abaixo, registro fotográfico de uma voluntária durante a realização do teste. 61

Figura 10. Escala de estresse percebido. Versão traduzida para a língua portuguesa

Figura 11. Média \pm EP da pressão arterial sistólica (PAS), diastólica (PAD), média (PAM) e frequência cardíaca (FC) antes e após as sessões de exercício resistido tradicional (ERT) e exercício resistido em forma de circuito (ERC) ... 68

Figura 12. Média $\pm E P$ da pressão arterial sistólica (PAS), diastólica (PAD) e média (PAM) expressa em $\Delta \mathrm{mm} \mathrm{Hg}$ (ie., valor da PAS em cada tempo pósexercício - PAS pré-exercício), antes e após as sessões de exercício resistido tradicional (ERT) e exercício resistido em circuito (ERC)

Figura 13. Comportamento da PA pré-teste e a cada minuto durante o estresse mental (painel A) e valores de reatividade da pressão arterial sistólica (PAS) ao estresse mental antes e após as sessões de exercício resistido tradicional (ERT) e exercício resistido em circuito (ERC; painel B). Dados apresentados como média \pm EP.

Figura 14. Comportamento da PA pré-teste e a cada minuto durante o estresse mental (painel A) e valores de reatividade da pressão arterial diastólica (PAD) 
ao estresse mental antes e após as sessões de exercício resistido tradicional (ERT) e exercício resistido em circuito (ERC; painel B). Dados apresentados como média \pm EP 74

Figura 15. Comportamento da PA pré-teste e a cada minuto durante o estresse mental (painel A) e valores de reatividade da pressão arterial média (PAM) ao estresse mental antes e após as sessões de exercício resistido tradicional (ERT) e exercício resistido em circuito (ERC; painel B). Dados apresentados como média $\pm \mathrm{EP}$ 74

Figura 16. Média \pm EP dos valores de reatividade da frequência cardíaca (FC) ao estresse mental antes e após as sessões de exercício resistido tradicional (ERT) e exercício resistido em circuito (ERC). 75

Figura 17. Análise espectral da VFC de um sujeito em repouso e durante 0 teste de estresse mental (Stroop). A série temporal dos intervalos RR pode ser visualizada no painél superior, com as setas da esquerda e direita indicando $o$ início e final do estímulo estressor, respectivamente. Nos painéis inferiores, saída da análise autorregressiva do Software Kubios HRV 2.2 de um sujeito em repouso (direita) e durante o teste de Stroop (esquerda) ............................... 78

Figura 18. Média \pm EP dos valores de RMSSD em repouso e durante 0 estresse mental, antes e após as sessões de exercício resistido tradicional (ERT) e exercício resistido em circuito (ERC) 79

Figura 19. Média \pm EP dos valores de entropia amostral (SampEn) em repouso e durante o estresse mental, antes e após as sessões de exercício resistido tradicional (ERT) e exercício resistido em circuito (ERC) 80 


\section{LISTA DE ABREVIATURAS}

ACCF/AHA: American College of Cardiology Foundation

AHA: American Heart Association

DASH: Dietary Approaches to Stop Hypertension

ER: Exercício resistido

ERC: Exercícios resistidos em forma de circuito

ERT: Exercícios resistidos de forma tradicional

FC: Frequência cardíaca

GEFS: Grupo de Estudos em Fisiologia do Exercício e Saúde

GEPAFI: Grupo de Estudos e Pesquisas sobre Atividade Física para Idosos

HA: Hipertensão arterial

HF: High frequency

HPE: Hipotensão pós-exercício

IMC: Índice de massa corporal

IPAQ: International Physical Activity Questionnaire

LF: Low frequency

nu: Normalized units

OMNI-RES: Omnibus Resistance Exercise Scale

PA: Pressão arterial

PAD: Pressão arterial diastólica

PAM: Pressão arterial média

PAR-Q: Physical Activity Readiness Questionnaire 
PAS: Pressão arterial sistólica

PSE: Percepção subjetiva de esforço

RM: Repetição(ões) máxima(s)

RMSSD: Square root of the mean of the sum of the squares of differences between adjacent $N N$ intervals

RPA: Reatividade da pressão arterial

SampEn: Sample Entropy

TCLE: Termo de consentimento livre e esclarecido

TP: Total Power

TR: Treinamento resistido

VFC: Variabilidade da frequência cardíaca

VLF: Very low frequency 


\title{
RESUMO
}

\author{
EFEITOS DE DIFERENTES MÉTODOS DE TREINAMENTO RESISTIDO \\ SOBRE A REATIVIDADE DA PRESSÃO ARTERIAL AO ESTRESSE MENTAL \\ EM MULHERES IDOSAS HIPERTENSAS
}

\author{
Autor: RAFAEL GAUCHE \\ Orientador: RICARDO MORENO LIMA
}

OBJETIVO: Verificar as respostas hemodinâmicas e autonômicas ao exercício resistido em idosas hipertensas medicadas, comparando-se os métodos tradicional e de circuito. METODOLOGIA: Dez mulheres idosas (71,1 $\pm 5,5$ anos; 1,5 \pm 0,1 m; 56,1 \pm 9,8 kg; 24,2 $\pm 3,9$ IMC) com hipertensão controlada participaram do estudo. As voluntárias foram submetidas a 4 sessões de familiarização e determinação de carga, e a 2 sessões experimentais de exercício resistido (tradicional e circuito). A carga foi determinada por meio da escala de percepção de esforço OMNI-RES, com o protocolo experimental composto por 3 séries de 12 repetições em 7 exercícios. A pressão arterial, a variabilidade da frequência cardíaca (VFC) e a reatividade pressórica ao estresse mental (teste de Stroop) foram avaliadas antes e após as sessões experimentais. Um teste $\mathrm{t}$ pareado foi utilizado para as comparações das variáveis hemodinâmicas e autonômicas de repouso e demais características das sessões experimentais. Análises de variância de medidas repetidas foram executadas para verificação dos efeitos dos dois métodos de exercício resistido na pressão arterial, VFC e reatividade da pressão arterial ao estresse mental. A significância estatística adotada foi de $p<0,05$. RESULTADOS: O exercício resistido não promoveu alterações na pressão arterial pós-exercício para dos métodos estudados, em relação aos valores de repouso. Uma depressão vagal foi observada durante 15 minutos para a análise realizada no domínio de frequência da VFC, não confirmada por análise no domínio de tempo. A complexidade da frequência cardíaca foi reduzida por 45 minutos após 0 exercício, sem diferença entre as sessões. Pela primeira vez, foi verificada uma atenuação na reatividade da pressão arterial ao estresse mental após o exercício resistido, sem diferença entre os métodos estudados. Essa atenuação pode ser justificada, em parte, por uma redução na ativação simpática durante o estresse mediada pelo exercício. CONCLUSÕES: O exercício resistido é uma ferramenta eficaz na redução da reatividade pressórica ao estresse mental, o que pode estar associado a uma redução aguda no risco cardiovascular. Esses resultados apresentam implicação clínica de relevância, e se agregam a evidências prévias que recomendam essa modalidade de treino como importante componente de um programa de treinamento físico para idosos e para portadores da HA.

Palavras-chave: Treinamento de resistência. Pressão arterial. Estresse psicológico. Idoso. Hipertensão. 


\begin{abstract}
EFFECTS OF DIFFERENT METHODS OF RESISTANCE TRAINING ON BLOOD PRESSURE REACTIVITY TO MENTAL STRESS IN ELDERLY HYPERTENSIVE WOMEN
\end{abstract}

\author{
Author: RAFAEL GAUCHE \\ Advisor: RICARDO MORENO LIMA
}

OBJECTIVES: Verify the hemodynamic and autonomic responses to resistance exercise in elderly hypertensive women in use of medication, comparing traditional vs circuit-weight methods. METHODOLOGY: Ten elderly women (71,1 \pm 5,5 years; 1,5 \pm 0,1 $\mathrm{m} ; 56,1 \pm 9,8 \mathrm{~kg} ; 24,2 \pm 3,9 \mathrm{BMI})$ with controlled hypertension participated in the study. Volunteers were subjected to 4 familiarization and load determination sessions, and to 2 resistance exercise experimental sessions (traditional and circuit). Load was determined with the perceived exertion OMNI-RES scale, with the experimental protocol consisting in 3 series of 12 repetitions in 7 exercises. Blood pressure, heart rate variability (HRV) and blood pressure reactivity (Stroop color-word test) were evaluated before and after experimental sessions. A paired t-test was used for comparison of hemodynamic and autonomic variables at rest, and for further experimental sessions characteristics. Repeated analysis of variance were utilized to verify the effects of the 2 resistance exercise methods employed on blood pressure, HRV and blood pressure reactivity to mental stress. Significance level was set at $p<0.05$. RESULTS: No changes on blood pressure were observed after exercise in any resistance exercise method employed, in relation to rest values. A vagal depression was observed during 15 minutes by frequency domain analysis of HRV, not confirmed by analysis in time domain. Heart rate complexity was reduced by 45 minutes post-exercise, with no difference between sessions. It was demonstrated, for the first time and similarly for both methods, that resistance exercise attenuated blood pressure reactivity to mental stress. This attenuation may be justified, in part, by an exercise-mediated reduction in sympathetic activation during stress. CONCLUSIONS: Resistance exercise is an effective tool to reduce blood pressure reactivity to mental stress, which could therefore be associated with an acute reduction on cardiovascular risk. This result presents relevant clinical implications, joining previous evidence that recommend this training modality as an important component of an exercise program designed for the elderly and hypertensive subjects.

Keywords: Resistance training. Arterial pressure. Psychological stress. Aged. Hypertension. 


\section{INTRODUÇÃO}

Respostas hiper-reativas da pressão arterial (PA) durante a ocorrência de eventos estressantes podem representar um risco elevado para o desenvolvimento de doenças e eventos cardiovasculares, como o acidente vascular encefálico (1), doença cerebrovascular silenciosa (2), e mortalidade cardiovascular (3). Como a reatividade da pressão arterial (RPA) ao estresse mental demonstrou ser exacerbada em indivíduos idosos (4), essa exposição acentuada pode representar uma potencialização do risco cardiovascular nessa população.

Foi demonstrado que sessões de exercício aeróbio $(5,6)$ podem atenuar a RPA ao estresse mental, servindo como uma ferramenta de redução do risco cardiovascular. Hamer, Taylor (7), em meta-análise que incluiu resultados de 15 estudos, demonstraram reduções médias de 3,0 e 3,9 mm Hg na RPA sistólica e diastólica, respectivamente, após uma sessão de exercício aeróbio, ratificando a importância dessa prática na atenuação da RPA ao estresse. A despeito de apenas um estudo incluir o exercício resistido (ER) como parte de uma sessão de exercícios (8), demonstrando uma redução significativa na RPA, os efeitos do ER per se ainda são desconhecidos.

Estudos prévios demonstraram que a atenuação da RPA foi decorrente de reduções na resistência vascular periférica (9), ou no volume de ejeção e débito cardíaco $(5,10)$. Fatores como a responsividade $\beta$-adrenérgica e as catecolaminas circulantes foram alvo de estudos prévios $(6,11,12)$. O envolvimento do sistema nervoso também foi apontado como um dos possíveis mecanismos de redução da RPA (6). Nessa direção, Brownley, Hinderliter (6) demonstraram que $64 \%$ da atenuação observada na RPA média, após uma sessão de exercício aeróbio, foi justificada por meio de uma redução na reatividade simpática durante o estresse mental.

Outra forma pela qual a realização de uma sessão de ER pode estar associada a uma redução no risco cardiovascular é por meio da redução da PA em relação ao seu valor pré-exercício, fenômeno conhecido como "hipotensão pósexercício" (HPE) (13). Devido à elevação no risco cardiovascular que acompanha o 
processo de envelhecimento $(14,15)$, bem como à presença de patologias como a hipertensão arterial (HA), indivíduos que se encontram em tais condições podem se beneficiar de forma mais evidente, em termos clínicos, ao experimentar esse fenômeno desencadeado pelo ER. Como muitos indivíduos portadores de hipertensão fazem uso de medicações que reduzem os níveis de PA, é possível que os benefícios do ER nessa população estejam minorados, já que há uma relação entre o nível de PA pré-exercício e a magnitude do fenômeno da hipotensão pósexercício $(16,17)$. Apesar de escassos, estudos prévios demonstraram que o ER pode induzir alterações benéficas na pressão arterial pós-exercício em indivíduos idosos portadores de hipertensão arterial (18-20); entretanto, não há unanimidade nesse achado (21).

A par dos potenciais benefícios que podem advir da realização de uma sessão de ER, uma das preocupações associadas à sua execução se justifica pelas alterações provocadas na atividade nervosa pós-ER $(22,23)$. Há uma elevação no risco de morte súbita após um episódio de esforço vigoroso (24), o que se dá, principalmente, por meio de uma redução na ativação vagal $(25,26)$. Enquanto uma supressão vagal foi observada após a realização de uma sessão de ER em indivíduos idosos normotensos (27) e em hipertensos não-medicados (28), os efeitos dessa modalidade de exercício ainda são desconhecidos na população de hipertensos em uso de medicação anti-hipertensiva. A utilização de medicamentos representa uma condição importante, pois seu uso pode estar associado a modificações na modulação autonômica $(29,30)$ que podem alterar seu comportamento após uma sessão de ER.

A realização de sessões de ER em forma de circuito representa prática comum em grupos de indivíduos idosos $(31,32)$. Entretanto, apenas dois estudos compararam os efeitos do método de circuito com a forma tradicional $(33,34)$, sem observar diferenças entre esses arranjos para o comportamento da pressão arterial pós-ER, sendo ambos realizados com jovens normotensos. No único estudo realizado que comparou os métodos supracitados para a modulação autonômica, avaliada por meio da VFC, Anunciação, Poton (33) observaram um aumento no balanço simpatovagal maior no método de circuito. Entretanto, não houve controle 
em relação à hora de realização da sessão, o que pode comprometer os resultados, tendo em vista que VFC é passível de sofrer variações vinculadas ao ritmo circadiano (35).

Dessa forma, o objetivo do presente estudo é verificar as respostas hemodinâmicas e autonômicas após o exercício resistido, no repouso e durante o estresse mental, em um grupo de mulheres idosas com hipertensão e em uso de medicação, comparando-se os métodos tradicional e de circuito. 


\section{OBJETIVOS}

\subsection{Objetivo geral}

Verificar os efeitos de diferentes métodos de treinamento resistido sobre a reatividade da pressão arterial ao estresse mental em mulheres idosas hipertensas.

\subsection{Objetivos específicos}

- Verificar e comparar os efeitos agudos do exercício resistido tradicional com o método de circuito nas respostas pressóricas por 60 minutos pós-exercício;

- Verificar e comparar os efeitos agudos do exercício resistido tradicional com o método de circuito nas respostas autonômicas por 60 minutos pós-exercício;

- Verificar e comparar os efeitos agudos do exercício resistido tradicional com o método de circuito na modulação autonômica durante o estresse mental; 


\section{REVISÃO DE LITERATURA}

\subsection{Envelhecimento}

É possível, com relativa facilidade, identificar os processos que caracterizam o envelhecimento após uma simples observação de indivíduos idosos. Considerandose a grande variabilidade no fenótipo do envelhecimento (36) - assim como no desenvolvimento individual -, é importante ressaltar que as variações biológica e social que permeiam a existência dos indivíduos tornam a reação ao processo de envelhecimento como algo individualizado, que extravasa limites estritamente cronológicos (37).

De acordo com Kirkwood (36), o envelhecimento pode ser definido como um "processo de declínio de função, progressivo e generalizado, resultando em um aumento na vulnerabilidade frente aos desafios ambientais e um risco aumentado de doenças e morte" (p. 438). Não obstante, o envelhecimento, em sua complexidade, consiste em um processo razoavelmente heterogêneo, assim como o são as mudanças estruturais e funcionais que acompanham esse processo (38), o que justifica as diferenças observadas entre o envelhecimento cronológico e o fisiológico (39).

\subsubsection{Dados epidemiológicos}

A estimativa da Organização das Nações Unidas para a população mundial de idosos (i.e., 60 ou mais anos) equivale a 841 milhões de indivíduos no ano de 2013, com expectativa de que essa população aumente para 2 bilhões em 2050, e para próximo de 3 bilhões no ano de 2100 , representando mais de $50 \%$ do aumento populacional mundial estimado para o referido período (40). É esperado que a população relativa de idosos em relação à população mundial cresça de 12\% (2013) para $21 \%$ e $29 \%$ nos anos de 2050 e 2100 , respectivamente (40).

Fatores como a redução na fertilidade global, avanços na disponibilidade de fármacos que permitem maior eficácia no tratamento de doenças infectocontagiosas 
e crônico-degenerativas, desenvolvimento e aprimoramento dos métodos diagnósticos e cirúrgicos - levando a aumentos na expectativa de vida - são algumas das possíveis explicações para a distribuição populacional e as estimativas supracitadas (41).

Para o Brasil, os dados apresentam uma tendência semelhante. A população brasileira de idosos compreende mais de 22 milhões de indivíduos, devendo atingir 73 milhões em 2060 (42). Dados das tábuas de mortalidade do Instituto Brasileiro de Geografia e Estatística indicam uma expectativa de vida da população brasileira correspondente a 74,9 anos (71,3 para homens e 78,6 para mulheres) no ano de 2013 (43), valores que devem ultrapassar os 81 anos em 2060 (44). Para o ano de 2100, a estimativa da Organização das Nações Unidas para a expectativa de vida no Brasil é de 88,3 anos (40). Os dados apresentados indicam um aumento no envelhecimento populacional, caracterizado por um aumento relativo e absoluto na população de idosos, sinalizando para um processo de transição demográfica.

Apesar das projeções apontarem para um envelhecimento populacional, o quadro de saúde e prática regular de atividade física da população brasileira apresenta-se como preocupante. De acordo com a Pesquisa Nacional de Amostra por Domicílios de 2008 sobre o panorama de saúde brasileiro (45), dos indivíduos com 65 anos ou mais: a) 42,8\% consideravam sua saúde regular e 14,8\% a consideravam ruim ou muito ruim; b) $30,4 \%$ apresentavam restrições na realização de atividades da vida diária; c) 79,1\% apresentavam pelo menos uma doença crônica; d) 16,3\% praticaram exercício físico ou esporte nos 3 meses anteriores à pesquisa; para indivíduos de 60-64 anos, esse valor foi de 21,3\%. Dados recentes da Pesquisa Nacional de Saúde (46) apontam para uma redução no percentual de indivíduos que praticam a quantidade recomendada semanal de atividade física (150 minutos de atividade física de intensidade leve a moderada, ou 75 minutos de atividade física de intensidade vigorosa) com o avançar da idade, que caiu de 35,3\% para $13,6 \%$ entre indivíduos de $18-24$ e 60 ou mais anos, respectivamente; adicionalmente, $62,7 \%$ dos indivíduos com 60 ou mais anos foi declarado como insuficientemente ativo, na mesma pesquisa (46). A baixa prevalência de indivíduos 
que apresentaram um estilo de vida ativo indica a necessidade de criação de estratégias de incentivo à prática regular de exercícios físicos e adoção de um estilo de vida mais saudável.

Modificações no estilo de vida podem ser benéficas para a população de idosos. Lin, Huang (47) observaram a relação entre atividade física e mortalidade em 876 idosos e identificaram que um estilo de vida ativo está associado a um menor risco de mortalidade nessa população. Gregg, Cauley (48) examinaram a relação entre atividade física e mortalidade em mais de 7500 mulheres idosas, demonstrando que o aumento e a manutenção dos níveis de atividade física nessa população podem prolongar a longevidade. Adicionalmente, a prática regular de atividade física está associada a uma série de benefícios para a saúde, diminuindo o risco de desenvolvimento de doenças crônicas que podem comprometer a qualidade de vida dos indivíduos idosos (49).

\subsubsection{Alterações fisiológicas e na composição corporal}

O processo de envelhecimento vem acompanhado por diversas mudanças fisiológicas que atingem órgãos, tecidos e funções, refletindo na independência para realização de atividades da vida diária de indivíduos idosos (49). Entre essas alterações, destacam-se as que ocorrem na composição corporal e no metabolismo, no sistema muscular e no sistema cardiovascular dessa população.

Para a composição corporal, é possível destacar uma redução na densidade mineral óssea, aumentos na massa gorda e no percentual de gordura abdominal, aumentos no percentual de gordura corporal total $(50,51)$, além de reduções na taxa metabólica de repouso (52). Em relação à massa magra, a despeito de alguns estudos transversais $(50,51)$ demonstrarem uma redução com o processo de envelhecimento, estudos prospectivos apresentaram variações no comportamento dessa variável, observando que ela pode aumentar, se manter ou diminuir $(53,54)$. 
As alterações provocadas pelo processo de envelhecimento na força, massa e qualidade muscular (razão entre a força muscular máxima e a massa muscular) merecem especial destaque. Vários estudos prospectivos avaliaram força e massa muscular em indivíduos idosos (53-55). Delmonico, Harris (53), após acompanharem o comportamento da força, massa e qualidade muscular em 1678 indivíduos por um período de 5 anos, observaram que mesmo com um aumento, manutenção ou diminuição da massa muscular, houve decréscimo na força muscular, alterações que indicam um decréscimo na qualidade muscular. Adicionalmente, a potência muscular também parece sofrer alterações com o envelhecimento $(56,57)$. Reid, Pasha $(56)$ estudaram as mudanças na potência muscular após um período de três anos em indivíduos idosos, observando uma redução média de 8,5\% nessa variável. Este processo fisiológico é de grande relevância para a população de idosos, já que a potência muscular apresenta um declínio mais pronunciado que a força muscular com o passar dos anos, além de se associar de maneira mais forte com atividades funcionais (49).

As modificações supracitadas no sistema muscular apresentam consequências deletérias para a realização das atividades da vida diária e diminuição da capacidade funcional (58), além de estarem vinculadas à ocorrência de doenças crônico-degenerativas (59) e mortalidade (60), causando impacto financeiro significativo no sistema público de saúde (61).

Por essa razão, o treinamento resistido (TR) tem sido incluído como um importante componente de recomendações de exercício físico $(62,63)$ que visam à promoção e manutenção da saúde, tanto para adultos quanto para idosos, devido aos benefícios que pode proporcionar em termos de força, potência e massa muscular (64).

\subsubsection{Alterações estruturais no sistema cardiovascular}

O sistema cardiovascular também sofre diversas alterações em decorrência do processo de envelhecimento, modificações que se estendem aos níveis estrutural, 
funcional e molecular, comprometendo o coração, os vasos sanguíneos e o controle reflexo desse sistema (38).

Entre as modificações estruturais no coração, é possível observar um aumento no seu peso, uma redução no número de células auto excitáveis do nodo sinusal, um aumento no tamanho dos miócitos acompanhado por uma redução no seu número (38), além de um acúmulo de tecido conjuntivo e depósitos de cálcio na estrutura cardíaca e no sistema de condução dos impulsos nervosos para o coração $(14,15)$.

As alterações no leito vascular compreendem aumentos na espessura e rigidez arteriais causados pela perda de tecido elástico, além de aumento de tecido conjuntivo e deposição de cálcio nessa estrutura (15). Esse processo também atinge as arteríolas, levando a um aumento na resistência vascular total (14). Foi demonstrado um aumento progressivo na velocidade de onda de pulso (um indicador da rigidez arterial) com o envelhecimento (65), variável pode refletir um aumento na pressão arterial sistólica (PAS), um aumento na pressão de pulso (i.e., PAS - PA diastólica; PAD), e alterações nas propriedades da parede vascular (14) - todos fatores de risco cardiovascular.

Estudos epidemiológicos apontam o espessamento da parede arterial como um forte preditor de acidente vascular encefálico e doença cardiovascular (66). Esse espessamento atinge principalmente a túnica íntima, como foi observado no estudo de Nagai, Metter (67), que constataram um aumento na espessura intimal-medial acompanhando o processo de envelhecimento. Essas mudanças estruturais também levam a uma diminuição na complacência arterial. Foi demonstrado um decréscimo de 25 a 45\% na complacência arterial da artéria carótida comparando-se indivíduos jovens com idosos de diferentes níveis habituais de atividade física (68).

O conjunto das alterações supracitadas leva a um aumento da PAS que, somado à perda de miócitos, pode ocasionar um processo de hipertrofia no ventrículo esquerdo. Esse processo foi observado por Fleg (69), que identificou um aumento de $30 \%$ na espessura da parede ventricular esquerda dos 25 aos 80 anos, em decorrência da maior demanda de trabalho imposta ao coração com o envelhecimento. Ademais, o envelhecimento está associado a um enchimento 
diastólico inicial diminuído, o que ocasiona uma contração atrial exagerada e sua consequente hipertrofia, adaptação que está associada a um maior risco de fibrilação atrial (15).

O processo de envelhecimento também se relaciona com alterações na atividade nervosa do coração. Nesse sentido, observam-se reduções na responsividade cronotrópica à estimulação beta-adrenérgica (70) e concomitante aumento no spillover de norepinefrina plasmática (71); aumento na atividade nervosa simpática muscular, que apresenta valores duas vezes maiores comparando-se indivíduos de 65 com de 25 anos de idade (71); redução da VFC (72) e consequente aumento no balanço simpatovagal (73), indicando aumento da atividade simpática, além de uma resposta atenuada da frequência cardíaca (FC) ao ciclo respiratório (73); e redução da sensibilidade dos barorreceptores perante as variações da PA, efeito decorrente, em parte, de uma complacência arterial central reduzida (74).

O aumento na atividade simpática observado com o envelhecimento está vinculado a um maior risco para o desenvolvimento de doenças cardiovasculares e metabólicas, além de estar relacionado com maior produção de espécies reativas de oxigênio, fator que se associa ao processo hipertrófico das células musculares lisas, espessamento da parede arterial e disfunção endotelial em indivíduos idosos (75). 0 conjunto de alterações supracitado pode oferecer um ambiente propício para o desenvolvimento de doenças como a aterosclerose e a hipertensão, além de favorecer a ocorrência de eventos como o acidente vascular encefálico, justificando mudanças no estilo de vida que levem a uma melhora na função fisiológica do sistema cardiovascular, como a prática regular de exercícios físicos (14).

\subsection{Hipertensão arterial}

A hipertensão arterial pode ser definida como a elevação sustentada dos níveis de PA, consistindo em uma patologia multifatorial (76). Essa patologia está associada ao aumento no risco cardiovascular, em decorrência de alterações funcionais e/ou estruturais em órgãos-alvo e de alterações metabólicas (76). Fatores 
genéticos, ambientais e comportamentais estão vinculados à gênese dessa patologia (77), e diversos modelos foram construídos na tentativa de melhor caracterizar e estudar a hipertensão (78). São considerados hipertensos os indivíduos que apresentem PAS $\geq 140$ e/ou PA diastólica (PAD) $\geq 90 \mathrm{~mm} \mathrm{Hg}(76,79)$.

As modificações hemodinâmicas presentes na HA estabelecida compreendem um aumento na resistência vascular periférica, com uma manutenção do índice cardíaco e volume de ejeção (80). As principais modificações estruturais e funcionais compreendem hipertrofia do ventrículo esquerdo, alargamento do átrio esquerdo e disfunção sistólica e diastólica do ventrículo esquerdo (81).

\subsubsection{Dados epidemiológicos}

Em 2000, a população estimada de adultos hipertensos compreendia 972 milhões de indivíduos, número que deve atingir 1,56 bilhão em 2025, o que representa um crescimento de $60 \%$ nessa população (82). Pereira, Lunet (83), em revisão sistemática sobre a prevalência da HA em nível mundial, observaram que $37,8 \%$ dos homens e $32,1 \%$ das mulheres apresentavam hipertensão. Não obstante, para o Brasil, dados publicados na Pesquisa Nacional de Saúde (46), referentes ao ano de 2013 , apontam que a prevalência da HA atinge $21,4 \%$ dos brasileiros, sendo maior no grupo de mulheres (24,2\% contra $18,3 \%$ para os seus congêneres do sexo masculino). Entretanto, deve-se ter cautela na interpretação desses dados, uma vez que a presença de hipertensão foi auto referida, e não foram realizadas avaliações da PA com equipamento específico para este fim nos entrevistados. Como o nível de conhecimento da própria patologia (i.e., saber-se portador da doença) é relativamente baixo nos países em desenvolvimento, e maior entre as mulheres do que entre os homens (52,7\% e 40,2\%, respectivamente) (83), é possível que a falta de controle para essas variáveis apresente um nível de prevalência subestimado, com as diferenças de gênero carecendo de confirmação por meio de instrumentos de medida adequados. De fato, estudos realizados utilizando-se de técnicas adequadas para mensuração da PA (84-86) demonstram níveis maiores de prevalência do que os apresentados na Pesquisa Nacional de Saúde (46). 
Segundo relatório da Organização Mundial de Saúde (87), as complicações decorrentes da HA contabilizam 9,4 milhões de mortes no mundo todo a cada ano. Ademais, a hipertensão arterial se responsabiliza por $45 \%$ das mortes por doença cardíaca, e $51 \%$ das mortes por acidente vascular encefálico (87). No Brasil, para o ano de 2007, as doenças cardiovasculares foram responsáveis por 1.157.509 internações e 308.466 óbitos, representando a principal causa de morte no nosso país (76). Em relação aos custos atinentes às internações, mais de 165 milhões de reais foram gastos com as 91.970 internações que ocorreram no ano de 2009, apenas no mês de novembro (76). Em 2005, o custo estimado para tratamento da HA nos sistemas de saúde público e privado brasileiros foi de $R \$ 1.631 .878 .387,19$, o equivalente a $0,08 \%$ do PIB do Brasil para o ano de 2005 (76). Desse valor, mais de $50 \%$ dos custos para o sistema público de saúde foram devidos a gastos com medicamentos (76).

Em idosos, a prevalência da HA se associa positivamente com a idade (Figura 1) (88). Segundo a $\mathrm{SBH}$, mais de $60 \%$ dos indivíduos com mais de 65 anos apresentam quadro de hipertensão (76), números demonstrados em estudos recentes realizados em diversos estados federativos do Brasil $(86,89)$.

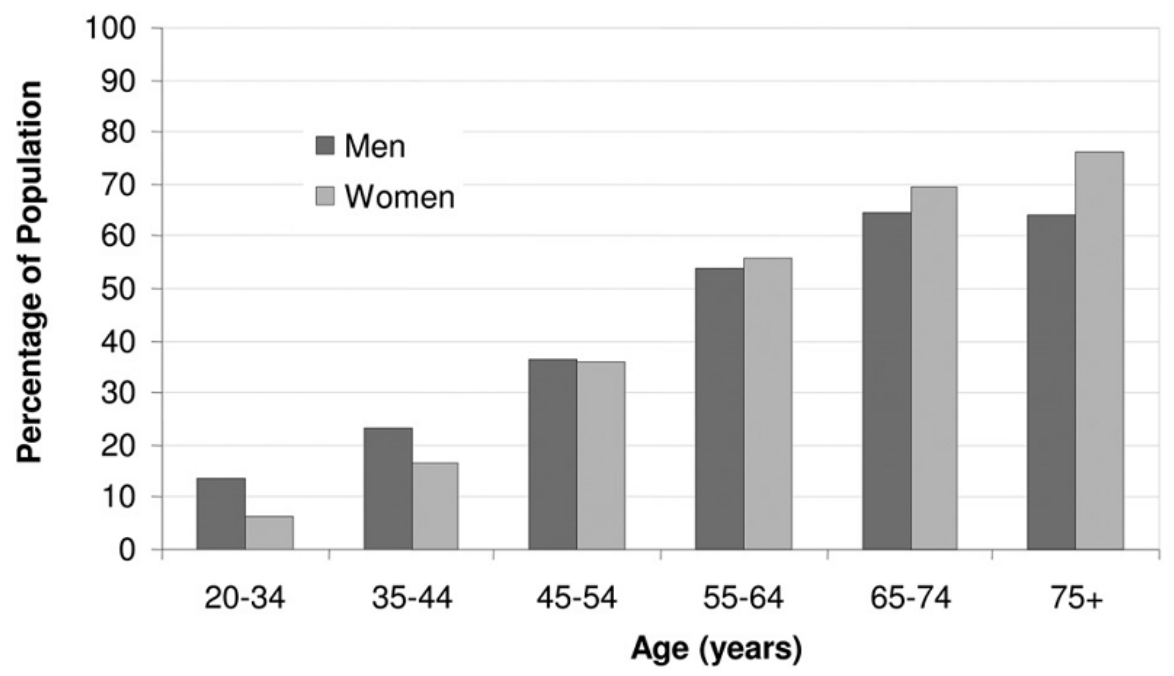

Figura 1. Prevalência de hipertensão em adultos por idade e sexo. Reproduzido, com autorização, de Aronow, Fleg (90). 
A hipertensão sistólica isolada representa a forma mais comum de HA, já que enquanto a PAS aumenta progressivamente com o envelhecimento, a PAD apresenta um declínio progressivo após os 60 anos de idade, concomitante a um aumento na pressão de pulso (i.e., diferença entre a PAS e a PAD; Figura 2) (14).
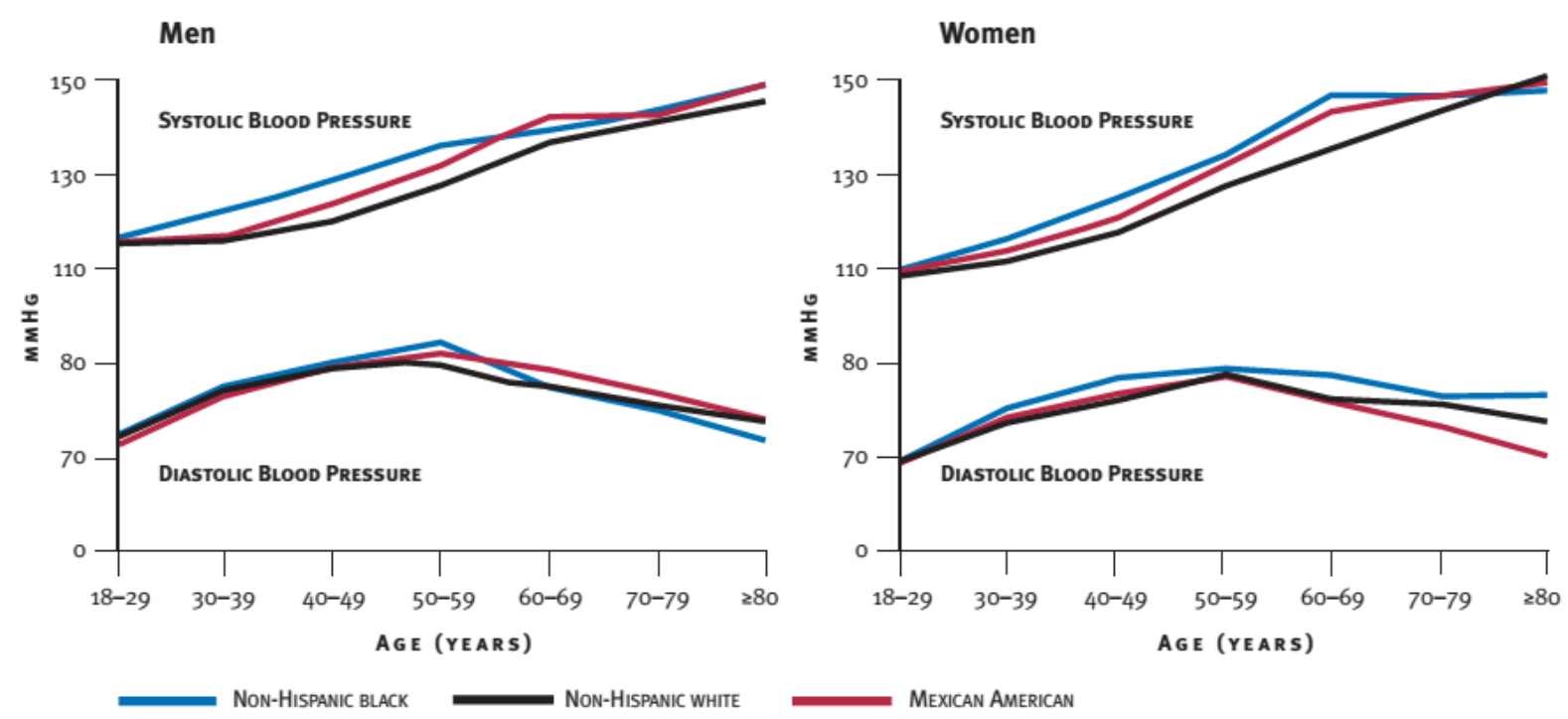

Figura 2. Pressão arterial sistólica e diastólica por idade e raça ou etnicidade em homens e mulheres acima de 18 anos de idade na população americana. Reproduzido, com autorização, de Chobanian, Bakris (91).

Elevações na PA podem representar um aumento no risco de doença cardiovascular (92, 93). De acordo com Franklin, Larson (92), em indivíduos com 60 anos de idade ou mais, a PAS e a pressão de pulso, especificamente, representam fortes preditores de doença cardiovascular. Adicionalmente, Lewington, Clarke (94) demonstraram que a partir de $115 / 75 \mathrm{~mm} \mathrm{Hg}$, cada aumento de 20/10 mm Hg na PAS/PAD representa um risco dobrado de mortalidade vascular para indivíduos com 60-69 anos; para indivíduos mais velhos, o risco ainda existe, mas de maneira atenuada. É importante ressaltar que a mortalidade por doenças cardiovasculares em indivíduos do sexo feminino apresenta um grande aumento a partir dos 60 anos em relação aos do sexo masculino, o que indica um risco cardiovascular potencializado em mulheres idosas (95). 
O quadro supracitado reitera a necessidade de se adotarem medidas profiláticas e terapêuticas no controle dos níveis de PA, em especial nos indivíduos idosos.

\subsubsection{Tratamento medicamentoso}

A redução na morbidade e mortalidade se configura como o principal objetivo a ser atingido com o tratamento da HA (76). O tratamento medicamentoso dessa doença compreende a utilização de anti-hipertensivos para a redução da PA, diminuição de eventos fatais e não fatais associados à $P A$, e redução na taxa de mortalidade (76).

Entre os principais medicamentos anti-hipertensivos comercialmente disponíveis no Brasil (76), as evidências apontam para a eficácia de tratamentos com antagonistas dos canais de cálcio (96), inibidores da enzima conversora de angiotensina (97), bloqueadores do receptor AT1 da angiotensina II (98), diuréticos (99), inibidores adrenérgicos (100), e inibidor direto da renina (101) na diminuição dos níveis de PA.

A utilização de medicamentos anti-hipertensivos pode estar associada a alterações na modulação autonômica aferida pela VFC. Shehab, Elnour (102) observaram que a ingestão de valsartana, um bloqueador do receptor da angiotensina, provocou uma melhora da VFC mensurada por vários parâmetros do domínio de tempo em pacientes com falência cardíaca crônica. Contrariamente, De Tommasi, lacoviello (103) não observaram alterações significativas após 16 semanas de tratamento com esse medicamento, em 90 pacientes com a mesma patologia. Keković, Milovanović (104) observaram melhora na função autonômica cardiovascular após 1 mês de ingestão de losartana em 60 indivíduos hipertensos, para análise no domínio de tempo; entretanto, não foram observadas alterações no domínio de frequência ou complexidade da FC. Chern, Hsu (105) não observaram alteração na VFC de 30 portadores de HA, após 6 meses de tratamento com losartana, para análise no domínio de tempo. 
Osakwe, Jacobs (106), em estudo que investigou os efeitos combinados de diferentes medicações na VFC, demonstraram que a ingestão de hidroclorotiazida associada a um $\beta$-bloqueador reduziu o componente LF, enquanto a combinação de valsartana com anlodipino, um bloqueador dos canais de cálcio, não promoveu alterações na VFC de 156 indivíduos hipertensos. Após 4 semanas de ingestão de anlodipino, Sahin, Kosar (107) também não puderam observar alterações significativas na VFC, analisada tanto no domínio de tempo quanto no de frequência; resultados semelhantes foram observados por Pavithran, Prakash (108). Entretanto, os resultados apresentados por Karas, Lacourcière (29) apontam para um controle autonômico prejudicado após 8 semanas de ingestão de anlodipino, o que também foi observado por Milovanović, Trifunović (30) em indivíduos com predominância vagal no estado de repouso. Considerando a hidroclorotiazida (um diurético tiazídico), foram observadas melhoras na função autonômica cardiovascular após terapia combinada com esse medicamento (109), em concordância com os resultados de Osakwe, Jacobs (106). Entretanto, ingestões isoladas de hidroclorotiazida não promoveram alterações significativas na VFC após 8 semanas de tratamento em indivíduos com HA (108). Adicionalmente, Kakhramanova and Bakhshaliev (110) observaram melhoras na VFC em pacientes com HA e disfunção autonômica tratados com indapamida e lisinopril.

Em pacientes classificados com HA estágio 1 (i.e., PAS entre 140-159 e/ou PAD entre $90-99 \mathrm{~mm} \mathrm{Hg}$ ) e risco cardiovascular baixo a moderado, a monoterapia pode se configurar como opção inicial para tratamento da PA (76). Entretanto, a combinação de dois medicamentos como medida primária de tratamento pode ser mais interessante em comparação à monoterapia $(76,111,112)$, pelos benefícios que apresenta no controle da PA. Nesse contexto, importa ressaltar que a escolha farmacológica deve ser realizada considerando-se a presença de comorbidades, se o paciente apresenta níveis elevados do débito cardíaco ou da resistência vascular periférica e em qual extensão o paciente responde ao tratamento (77).

Segundo a Sociedade Brasileira de Hipertensão, muitos indivíduos hipertensos diagnosticados não se encontram em tratamento medicamentoso (76). A aderência 
ao tratamento - observada quando o comportamento do paciente está de acordo com a medicação prescrita (76) - apresenta-se como fator de importância nesse contexto, já que estudos realizados no Brasil indicam uma baixa adesão dos indivíduos hipertensos ao tratamento prescrito $(113,114)$. De acordo com Miranda et. al. (115), a aderência ao tratamento anti-hipertensivo apresenta-se como um dos maiores desafios no controle da PA, problema contumaz e frequente na população de idosos.

Considerando-se que a prevalência de doenças é maior nos indivíduos idosos, comparados aos jovens (45), há maior necessidade de associação do tratamento medicamentoso com mudanças no estilo de vida nessa população (115). Nesse sentido, a prática regular de exercícios físicos apresenta-se como ferramenta eficaz, tendo em vista os benefícios pode oferecer em vários fatores de risco cardiovascular (116).

\subsubsection{Tratamento não medicamentoso e treinamento resistido}

Modificações no estilo de vida podem representar o único tratamento necessário para prevenir e controlar a HA na população de idosos (90). Em indivíduos que encontram-se em terapia medicamentosa, a dose utilizada no controle da HA pode ser reduzida com essas modificações (90). Em documento consensual acerca da hipertensão no idoso, elaborado pela ACCF/AHA (90), as cinco modificações no estilo de vida essenciais para prevenção e tratamento da HA são a) redução de peso; b) adoção do plano de dieta DASH (Dietary Approaches to Stop Hypertension); c) redução na ingestão diária de sódio; d) moderação no consumo de álcool; e e) prática regular de atividades físicas.

Das estratégias supracitadas, a prática de exercícios físicos apresenta-se como a principal. O treinamento resistido, reconhecido em 1990 pelo American College of Sports Medicine como um importante componente em um programa global de condicionamento físico para adultos de todas as idades (117), tem sido 
recomendado como parte integrante de um programa de exercícios para indivíduos hipertensos (118).

Há evidências de que o treinamento resistido se associa a uma redução na PA de repouso em adultos e idosos (119-121). Em meta-análise recente, Cornelissen and Smart (119) observaram reduções de 3,1 na PAS e 3,4 na PAD de indivíduos com 50 anos ou mais submetidos a intervenções com o TR. Os efeitos em indivíduos com HA não foram tão evidentes, sendo mais expressivos em indivíduos préhipertensos. Adicionalmente, intensidades baixas e moderadas se associaram às maiores reduções. Nessa direção, Moraes, Bacurau (120) demonstraram reduções médias de 16 e $13 \mathrm{~mm} \mathrm{Hg}$ para PAS e PAD, respectivamente, em um grupo de homens hipertensos de meia-idade, submetidos a 12 semanas de TR realizado a $60 \%$ de 1 repetição máxima (RM). Indivíduos com experiência em TR também apresentam uma resposta pressórica ao ER menor em comparação aos seus congêneres destreinados, tanto para 1-RM quanto para um mesmo percentual de 1$\mathrm{RM}$ (122).

\subsubsection{Exercício resistido e hipotensão pós-exercício}

A despeito dos efeitos crônicos na redução e controle da PA após intervenções realizadas com o $\operatorname{ER}(19,123)$, a realização de apenas uma sessão dessa modalidade de exercício pode desencadear uma redução sustentada na PA para níveis inferiores aos observados antes de sua execução, fenômeno definido como "hipotensão pós-exercício" (13). Importa considerar que, enquanto o fenômeno da HPE foi demonstrado por vários autores $(16,19,21)$, há evidências de que o ER não induza a HPE ou aumente os níveis de PA pós-exercício (124-126). Não obstante, as evidências apontam para reduções na PA clínica e ambulatorial pós-ER, que podem durar até 2 e 10 horas, respectivamente $(23,127)$. A magnitude e duração da resposta hipotensora podem situar o indivíduo hipertenso em uma faixa de menor risco cardiovascular, já que reduções de apenas $3 \mathrm{~mm} \mathrm{Hg}$ representam uma redução no risco de doença arterial coronariana, acidente vascular encefálico e mortalidade por todas as causas de $5 \%, 8 \%$ e $4 \%$, respectivamente (128). 
Enquanto várias pesquisas objetivaram verificar a ocorrência da HPE, poucas foram realizadas com o objetivo de estudar seus mecanismos $(20,22,23,27,28,33$, 129-133). Estudos prévios demonstraram que a HPE se deu por um decréscimo no débito cardíaco, induzido por reduções no volume de ejeção que não foram compensadas pelos aumentos observados na resistência vascular periférica $(22,23$, 27). Entretanto, de Freitas Brito, de Oliveira (20) observaram que a HPE foi acompanhada por um aumento no fluxo sanguíneo e redução na resistência vascular do antebraço, sugerindo que a HPE seja mediada por vasodilatação. Por outro lado, Queiroz, Sousa (28) observaram que a HPE pode ocorrer tanto por reduções no débito cardíaco quanto na resistência vascular periférica, não apenas em indivíduos normotensos, mas também em hipertensos. Adicionalmente, Queiroz, Rezk (129) não observaram diferenças na ocorrência da HPE entre indivíduos do sexo masculino e feminino; entretanto, os autores demonstraram que a HPE ocorre por meio de mecanismos diferentes em indivíduos do sexo masculino (reduções no volume de ejeção e débito cardíaco) e feminino (reduções na resistência vascular periférica).

Com relação à modulação autonômica do sistema nervoso, apenas pesquisas que se valeram de análises da VFC - um índice de medida indireto - foram encontradas $(22,23,27,28,33,132)$. Na presença ou ausência de HPE, estudos prévios sinalizam para uma elevação da atividade simpática associada a uma redução da atividade parassimpática do sistema nervoso. Dessa forma, parece que a atividade nervosa eferente simpática não se apresenta como mecanismo responsável pela HPE, mas como uma alteração fisiológica compensatória para manutenção da PA em resposta à hipotensão, o que se dá por meio de aumentos na FC, como se pode observar nas evidências supracitadas. Considerando a atividade nervosa aferente, Queiroz, Kanegusuku (27) e Queiroz, Sousa (28) observaram reduções na sensibilidade barorreflexa pós-ER; dessa forma, a queda de PA após a realização de uma sessão de ER não representaria um estímulo adequado para provocar uma resposta excitatória no centro de controle cardiovascular, contrabalanceando a HPE com um aumento pressórico equivalente (13). 
Acerca das alterações periféricas locais, MacDonald, MacDougall (130) não puderam observar elevações significativas no peptídeo atrial natriurético pós-ER, mesmo na presença da HPE, bem como não puderam observar uma relação entre 0 volume plasmático e esta variável. Moreno, Cunha (133), em trabalho que analisou os efeitos do lactato e da influência da creatina na sua produção, em duas intensidades diferentes de ER, apontaram para uma possível influência desse metabólito na HPE. Contrariamente, Moraes, Bacurau (131) não encontraram correlação entre a concentração de lactato com a HPE, associação que também não pôde ser observada em relação ao óxido nítrico. Os mesmos autores, entretanto, apresentaram evidências interessantes de uma possível vasodilatação mediada pela ativação do sistema calicreína-cinina, que atuaria na redução da resistência vascular periférica.

A PA inicial dos sujeitos apresenta-se como variável de influência na resposta hipotensora observada após a prática de uma sessão de ER. Constatou-se que quanto maiores os níveis de PA observados em uma sessão controle, maiores as reduções observadas na PA pós-ER $(17,127)$. Ao verificar os efeitos de uma sessão de ER de intensidade moderada (50\% de 1-RM estimado) na forma de circuito em 16 mulheres normotensas e com hipertensão borderline (PAS de 130-159 mm Hg e PAD de $85-99$ ), Fisher (16) demonstrou que $71 \%$ dos sujeitos hipertensos borderline experimentaram um decréscimo consistente na PAS $(-7 \mathrm{~mm} \mathrm{Hg})$ em relação ao valor de repouso, quando apenas $33 \%$ dos indivíduos normotensos apresentaram decréscimo semelhante.

Mais recentemente, o estudo da HPE na população de indivíduos idosos foi alvo de várias pesquisas $(18,19,21,27,134-138)$, cujos resultados são de relevância clínica, considerando as elevações na PA e consequente aumento no risco cardiovascular que acompanham o processo de envelhecimento (14). Scher, Ferriolli (137) avaliaram as respostas hemodinâmicas pós-ER (realizado em forma de circuito) em amostra composta por 16 indivíduos idosos, hipertensos medicados, de ambos os sexos. Os autores observaram que o ER foi capaz de reduzir os níveis de PA durante 60 minutos pós-ER, em situação clínica. Esses resultados foram corroborados por vários autores, que demonstraram alterações positivas na PA após 
a realização de uma sessão de $E R$, em relação a uma sessão controle ou à PA préexercício $(18,19,21,27,134-138)$.

Considerando amostras compostas por hipertensos medicados, poucos estudos foram encontrados $(18-21,134,137)$, e em todos a PA foi reduzida após uma sessão de ER, seja em relação aos níveis pré-exercício, seja em relação a uma sessão controle, evidências que afirmam a importância do exercício físico como intervenção complementar ao tratamento medicamentoso da PA. Vale ressaltar, de Freitas Brito, de Oliveira (20), verificaram os efeitos de sessões de ER de diferentes volumes nas respostas hemodinâmicas de um grupo de 10 indivíduos idosos, hipertensos, e que estavam fazendo uso de inibidores da enzima conversora da angiotensina e diuréticos. Os autores observaram reduções na PAS e PAD que atingiram valores de até 26,5 e 13,8 $\mathrm{mm} \mathrm{Hg}$, respectivamente, para a sessão de maior volume.

Diversos estudos foram realizados com o intuito de estabelecer a influência das diferentes variáveis do ER na HPE, como intensidade (139-141), volume (18, 20, 137), intervalo de recuperação $(136,142)$ e ordem de execução dos exercícios $(21)$. Ainda não há consenso em relação à melhor forma de se prescrever o ER para a ocorrência da HPE. Em geral, com base nos resultados de revisão recente publicada acerca do assunto (143), conclui-se que a) ainda há indefinição acerca da melhor intensidade para a ocorrência da HPE, apesar de que intensidades moderadas estão associadas a respostas mais evidentes na PAD; b) sessões de maior volume aparentam ser mais eficazes na produção desse fenômeno; e c) há poucas evidências considerando o intervalo de recuperação e ordem de execução dos exercícios, mas é possível que intervalos maiores (e.g., 2 minutos) e exercícios realizados de forma intercalada entre membros superiores e inferiores provoquem uma diminuição mais acentuada da PA, devido a uma mobilização vascular acentuada e uma vasodilatação maior após a sessão de exercício.

A forma de execução dos exercícios também foi alvo de estudos prévios (33, 34). Uma forma comum de se prescrever exercícios resistidos, especialmente na população de idosos, é por meio do método de circuito. O método de circuito consiste 
na realização de exercícios resistidos para o corpo todo, geralmente com séries de 10-15 repetições, carga moderada (40-60\% de 1-RM), e descanso mínimo entre as estações do circuito (entre 15 a 30 segundos), apenas o suficiente para o indivíduo trocar de exercício (32). Evidências têm demonstrado benefícios significativos no sistema muscular, cardiovascular e na composição corporal após intervenções com essa modalidade de treino em indivíduos idosos de ambos os sexos (31, 144-146). Adicionalmente, o método de circuito demonstrou segurança e eficácia em sua aplicação em indivíduos portadores de condições cardíacas, como a doença arterial coronariana (147) e a hipertensão arterial (146).

A despeito das alterações benéficas na PA demonstradas após intervenções com o ER em forma de circuito $(8,131,137,148,149)$, apenas 2 estudos que compararam esses arranjo com o método tradicional foram encontrados $(33,34)$. Anunciação, Poton (33) compararam o método tradicional com o de circuito em diferentes volumes de trabalho ( 1 vs. 3 séries) em 10 adultos jovens normotensos. Os autores encontraram maior resposta hipotensora nos exercícios de maior volume, independentemente da forma de execução. Entretanto, as sessões experimentais foram realizadas em períodos diferentes do dia, o que pode ter interferido nos resultados. Simao, Fleck (34), em estudo que avaliou os efeitos de diferentes intensidades, volumes e metodologias de treino resistido (i.e., tradicional e circuito) na resposta pressórica pós-exercício em jovens normotensos, concluíram que não há diferenças entre o método tradicional e 0 de circuito. Entretanto, não houve randomização das sessões e o protocolo de circuito apresentou um intervalo exagerado de recuperação entre cada exercício (2 minutos).

Tendo em vista a popularidade do método de circuito entre a população de idosos e considerando a alta prevalência de hipertensão arterial nessa população, fatores esses somados à escassez de evidências que compararam esse arranjo de ER com o método tradicional, mais estudos são necessários na verificação das respostas cardiovasculares pós-exercício, especificamente com a população de idosos e portadores de HA. 


\subsection{Modulação autonômica do sistema nervoso}

\subsubsection{Variabilidade da frequência cardíaca}

O sistema cardiovascular apresenta propriedades de auto-organização que atuam na manutenção da homeostase (150). O atingimento do equilíbrio dinâmico realizado pelo sistema cardiovascular ocorre por meio do controle autonômico da FC, PA e outros fatores, reagindo rapidamente a uma gama de estímulos externos e internos (150). Uma das maneiras de se mensurar o controle autonômico do sistema cardiovascular, pela FC, é por meio da análise de suas flutuações, mensuradas batimento a batimento (i.e., intervalos consecutivos dos picos de onda $\mathrm{R}$ ), que podem ser definidas como "variabilidade da frequência cardíaca" $(151,152)$. A VFC representa uma medida indireta da modulação autonômica que permite discriminar a contribuição simpática da parassimpática na regulação cardiovascular, com uma alta variabilidade representando uma boa capacidade de adaptação e um bom funcionamento dos mecanismos de controle autonômico (150).

Considerando-se os métodos lineares de análise da VFC - domínio de tempo e domínio de frequência -, a análise espectral no domínio de frequência apresentase como método mais adequado para análises de curto período (i.e., 2-5 minutos) (153). Estudos que demonstraram oscilações cíclicas na FC relacionadas com o ciclo respiratório $(154,155)$, associados a estudos que observaram abolição do componente de alta frequência (High frequency, HF; faixa de $0,15 \mathrm{a} 0,4 \mathrm{~Hz}$ ) por meio de bloqueio vagal $(156,157)$, sugerem que o componente supracitado seja mediado pelo sistema nervoso parassimpático. A importante contribuição do sistema nervoso simpático para o componente de baixa frequência (Low frequency, LF; faixa de 0,04 a $0,15 \mathrm{~Hz}$ ) foi identificada por meio da observação de variações cíclicas na VFC em associação com a atividade barorreflexa (158). A constatação de alterações nesse componente por meio de bloqueio simpático $(156,157)$, somada à correlação do componente LF com a atividade muscular nervosa simpática (159), corroboram a contribuição do sistema nervoso simpático para esta faixa de frequência. Entretanto, como existem indícios de participação do sistema nervoso parassimpático no componente LF - demonstrada por bloqueio vagal - $(156,157)$, o balanço simpato- 
vagal (razão LF/HF) tem sido utilizado como indicador da predominância simpática/parassimpática na modulação da FC.

Sabe-se que a VFC se associa com uma série de condições clínicas, como infarto do miocárdio, falência cardíaca congestiva, fibrilação atrial, síncope, vasovagal, neuropatia diabética, doença de Parkinson, dentre outras (151). Yoo, Lee (160) demonstraram uma correlação positiva entre variáveis da VFC, avaliados tanto no domínio de tempo quanto no de frequência, e o Framminghan Risk Score, um método de avaliação que compreende vários fatores de risco cardiovascular, utilizado na predição do desenvolvimento de doença arterial coronariana. Esses resultados indicam que a VFC é uma ferramenta útil na avaliação do risco para essa patologia. Nessa direção, Gujjar, Sathyaprabha (161) observaram que o componente LF demonstrou ser um preditor independente de mortalidade em pacientes que sofreram acidente vascular encefálico severo, após controle de fatores de confundimento. Índices da VFC no domínio de tempo (162) e frequência (163) também foram associados com a ocorrência de mortalidade em indivíduos que sofreram infarto do miocárdio; esse risco pode ser até 5,3 vezes maior em indivíduos com uma VFC baixa.

A HA, especificamente, foi alvo de diversas pesquisas que observaram seu relacionamento com a VFC (164-169). Estudos demonstraram que indivíduos hipertensos de ambos os sexos apresentam VFC reduzida quando comparados aos seus congêneres normotensos (166-169), enquanto outros não puderam observar uma associação entre essas variáveis $(164,165)$.

Não obstante Guzzetti, Piccaluga (170) apontarem a análise espectral dos intervalos $\mathrm{RR}$ como uma técnica satisfatória para acompanhar as alterações progressivas no balanço simpato-vagal em indivíduos com $\mathrm{HA}$, é possível que a hiperatividade simpática seja fundamental na etiopatogenia dessa doença apenas em seus estágios iniciais, com mecanismos estruturais e funcionais contribuindo na manutenção dos altos níveis de PA observados nesta condição, conforme sugerido por Montano, Porta (151). De fato, Schroeder, Liao (166) identificaram uma tendência à convergência dos valores de VFC de indivíduos normotensos e hipertensos com o 
passar do tempo, bem como Fagard, Stolarz (165) observaram alterações dos componentes HF, LF e do balanço simpato-vagal apenas na hipertensão de "avental branco", sem diferenças entre normotensos e indivíduos com HA.

É possível que a elevação prolongada da PA, somada a uma atividade parassimpática reduzida e uma atividade simpática elevada, levem a uma normalização do débito cardíaco e a um aumento na resistência vascular e na atividade parassimpática, com consequente diminuição da atividade simpática, explicando os resultados supracitados (166). Como hipóteses adicionais para justificar a ausência de diferenças na VFC de indivíduos normotensos e com HA, Fagard, Stolarz (165) sugeriram que: a) o estímulo simpático pode diferir entre coração e vasos sanguíneos, já que ambos são controlados por nervos diferentes, com uma hiporegulação das respostas cardíacas acompanhando uma hiperregulação das respostas vasculares; b) a análise de poder espectral da VFC mensura a resposta do nodo sinusal à descarga simpática, e não a descarga em si, o que pode sofrer influência de uma responsividade reduzida à estimulação betaadrenérgica.

Foi demonstrado que tanto o componente HF quanto o LF estão associados aos níveis de PA $(165,167,171,172)$, relação mais evidente em medidas convencionais (clínicas) do que em ambulatoriais (171). Em estudo conduzido por Singh, Larson (167), cada decremento de 1 desvio-padrão no componente LF se associou a um aumento na PAS e PAD de 1,95 e 0,83 $\mathrm{mm} \mathrm{Hg}$ em homens, e 0,70 e $0,26 \mathrm{~mm} \mathrm{Hg}$ em mulheres, respectivamente. Adicionalmente, há evidências indicando que a VFC pode predizer o desenvolvimento da HA em indivíduos de ambos os sexos $(166,172)$, ou apenas em homens, mas não em mulheres (167).

A VFC também parece ser alterada com o envelhecimento, diminuindo significativamente nesse processo (73, 173-175). Liao, Barnes (174) observaram um decréscimo tanto no componente HF quanto no LF com o passar da idade, sem diferenças entre indivíduos jovens e idosos para o balanço simpato-vagal (LF/HF), em análise realizada com 1984 indivíduos com 44-65 anos de idade, resultados corroborados, posteriormente, por Agelink, Malessa (173), em estudo conduzido com 
uma amostra de 309 indivíduos estratificada em várias faixas etárias. Já Melo, Santos (73), ao estudar 41 homens, jovens e idosos, também observaram uma redução na VFC, acompanhada por uma redução no componente HF (unidades normalizadas - normalized units, nu) e um aumento no componente LF (nu), com consequente aumento na razão LF/HF. Adicionalmente, Stein, Barzilay (176) verificaram um decréscimo na VFC mais acentuado entre os 65-69 anos, que foi mais discreto entre os 70-74 anos, e se tornou mínimo em indivíduos com 75 ou mais anos.

Importa ressaltar, considerando a interação entre envelhecimento e $H A$, que devido aos efeitos do envelhecimento na VFC, as alterações provocadas na modulação autonômica pela HA apresentam uma influência limitada em indivíduos idosos, pois estes já apresentam uma modulação autonômica alterada em decorrência do processo de envelhecimento (164).

\subsubsection{Exercício resistido e variabilidade da frequência cardíaca}

Considerando os efeitos agudos do ER na modulação autonômica nervosa, a maioria dos estudos observou um aumento na atividade simpática e uma redução na atividade parassimpática em relação a uma sessão controle ou aos níveis préexercício $(22,23,27,28,33,132,177-181)$. Entretanto, Okuno, Pedro (182) e Lima, Forjaz (183) não observaram alterações na modulação autonômica após sessões de ER realizadas a $50 \%$ de 1-RM, em comparação ao repouso; ausência de reposta também foi observada em indivíduos com doença arterial periférica (184). Conforme sugerido por Heffernan, Kelly (177), é possível que as alterações na modulação autonômica pós-ER ocorram devido a modificações no volume plasmático, a reconfiguração ou alterações na sensibilidade dos barorreceptores, a alterações na atividade vagal pelo metaborreceptores, e/ou a variações no volume corrente, que afetariam a flutuação respiratória e retorno venoso, com consequente modificação no estiramento do nodo sinusal. Nessa direção, Queiroz, Kanegusuku (27) e Queiroz, Sousa (28) demonstraram redução da sensibilidade barorreflexa após a realização 
de uma sessão de ER, justificando, em parte, as elevações na FC observadas nesses estudos.

De um ponto de vista clínico, as alterações na modulação autonômica após uma sessão de exercícios podem se apresentar como deletérias, por situarem o indivíduo em uma situação aumentada de risco cardiovascular (24, 25). Digno de nota, o risco de morte súbita é aumentado em 17 vezes durante e até 30 minutos após um episódio de esforço vigoroso, como o exercício (24). Não obstante as alterações na modulação autonômica pós-ER indicarem a possibilidade de um risco cardiovascular potencializado, com duração de até 75 minutos (22), as evidências sugerem uma manutenção na VFC de repouso após intervenções longitudinais com o ER em adultos jovens saudáveis, e uma melhora na atividade parassimpática em adultos de meia idade com disfunção autonômica (185).

Considerando os efeitos do ER na modulação autonômica de indivíduos idosos, apenas um estudo foi encontrado. Queiroz, Kanegusuku (27) observaram o comportamento da VFC em 16 indivíduos idosos de ambos os sexos, normotensos, e com experiência em ER. Após a realização de uma sessão de ER, que consistiu em 3 séries de 8-RM em 9 exercícios, foi observado um aumento no componente LF e no balaço simpatovagal em comparação ao repouso e à sessão controle. Além disso, foi observada uma manutenção do delta da variância total e do componente HF $\left(m s^{2}\right)$, variáveis que se elevaram na situação controle, sugerindo uma depressão vagal associada ao ER.

Apenas o estudo de Queiroz, Sousa (28) foi realizado com o objetivo de verificar se há diferenças na resposta da modulação autonômica em indivíduos normotensos e hipertensos. Após a realização de 3 séries em 7 exercícios, com repetições executadas até a diminuição da velocidade de movimento do exercício e carga de $50 \%$ de 1-RM, não foram observadas diferenças na modulação autonômica comparando-se indivíduos normotensos e hipertensos grau 1 e 2. Ambos os grupos apresentaram reduções na VFC e no componente HF (un), seguidas por aumentos no componente LF (un) e no balanço simpato-vagal. Importa ressaltar que os indivíduos hipertensos não ingeriram medicamento no período do estudo, mas um 
tratamento placebo. A condução de estudos com indivíduos medicados e que controlem para a classe de medicação utilizada no controle da HA poderá demonstrar o comportamento dessas variáveis sob a influência do medicamento, uma situação comum entre indivíduos portadores de HA (83); sua realização também se justifica pelas influências da medicação na modulação do sistema nervoso autônomo $(186,187)$.

Considerando as variáveis do ER, estudos foram conduzidos avaliando intensidade $(22,182,183)$, volume (33), estado de treinamento (179), segmento corporal (179), métodos de ER (178, 180, 182), e forma de execução da sessão (33). Os resultados publicados indicam que: a) uma maior intensidade pode estar vinculada a uma depressão mais evidente no componente HF e um aumento maior no componente LF $(182,183)$, ou não exercer influência na modulação autonômica (22); b) sessões de maior volume estão associadas a aumentos mais pronunciados no balanço simpato-vagal (33); c) o estado de treinamento não exerce influência no comportamento da VFC quando analisada no domínio de frequência (179); d) sessões realizadas com membros superiores podem gerar uma supressão vagal atenuada quando comparadas a sessões realizadas com membros inferiores ou com o corpo todo, considerando análises realizadas no domínio de frequência (179); e) não há diferenças na modulação autonômica em sessões realizadas ou não até a falha concêntrica (180), ou entre o método tradicional e o de cluster (178), mas a oclusão vascular pode ocasionar aumentos e reduções mais pronunciadas para os componentes LF e HF, respectivamente (182).

Apenas um estudo foi realizado comparando-se a forma de execução nas respostas autonômicas agudas após o ER (33). Em estudo conduzido por Anunciação, Poton (33), foram verificados os efeitos do ER comparando-se a forma de execução tradicional com o formato de circuito, em volumes de trabalho diferentes (1 e 3 séries), em 10 homens saudáveis. Séries de 18 repetições com $40 \%$ de 1-RM foram realizadas, em 8 exercícios. Para as sessões de volume mais baixo (1 série), não foram observadas elevações significativas no balanço simpato-vagal (LF/HF); não obstante, esta variável apresentou um aumento significativo em ambos os protocolos de maior volume em relação ao repouso, e foi significativamente maior na 
sessão de circuito, em comparação à tradicional. Importa ressaltar que há falta de informação quanto ao período de descanso entre exercícios no método de circuito, que os intervalos entre cada volta (3-5 minutos) foram relativamente longos e que os dados foram coletados em períodos diferentes do dia. Como a VFC é passível de sofrer variações vinculadas ao ritmo circadiano (35), há necessidade de confirmação de resultados.

A forma de execução em circuito é comumente utilizada em grupos de indivíduos idosos (31), o que indica uma demanda por estudos conduzidos com essa população específica. É possível que essas respostas sejam diferentes nessa população, pois indivíduos idosos apresentam alterações na modulação do sistema nervoso em decorrência do envelhecimento (174).

\subsection{Reatividade da pressão arterial ao estresse mental}

O estresse mental, que se caracteriza por uma interação adversa entre o indivíduo e seu meio, pode ser definido como uma "ameaça" percebida. Tem, portanto, uma essência subjetiva, podendo se originar de diversas fontes extrínsecas (terremotos, desastres naturais) e intrínsecas (meio psicológico individual, incluindo personalidade e humor) que se traduzem em respostas fisiológicas relativas à percepção de estresse individual e à suscetibilidade fisiológica ao estresse (Figura 3) (188).

Uma das formas de se verificar e quantificar os efeitos do estresse mental em parâmetros cardiovasculares é por meio da realização de testes laboratoriais [e.g., testes aritméticos, de discurso, teste de Stroop (Color-Word Interference Test)], desenvolvidos no intuito de simular situações estressantes e com a vantagem de padronizar as condições laboratoriais na avaliação das funções cardiovasculares (189). Tem sido demonstrado que testes laboratoriais de estresse mental provocam respostas rápidas e consistentes na PA. Nessa direção, Carter and Ray (190), reunindo resultados de uma série de estudos prévios que utilizaram testes aritméticos para provocar o estresse mental, demonstraram que as elevações 
observadas na PA média para homens e mulheres foram, respectivamente, de $\Delta 16 \mathrm{e}$ $\Delta 12 \mathrm{~mm} \mathrm{Hg}$, diferenças de gênero que parecem desaparecer comparando-se homens e mulheres idosos (191-193).

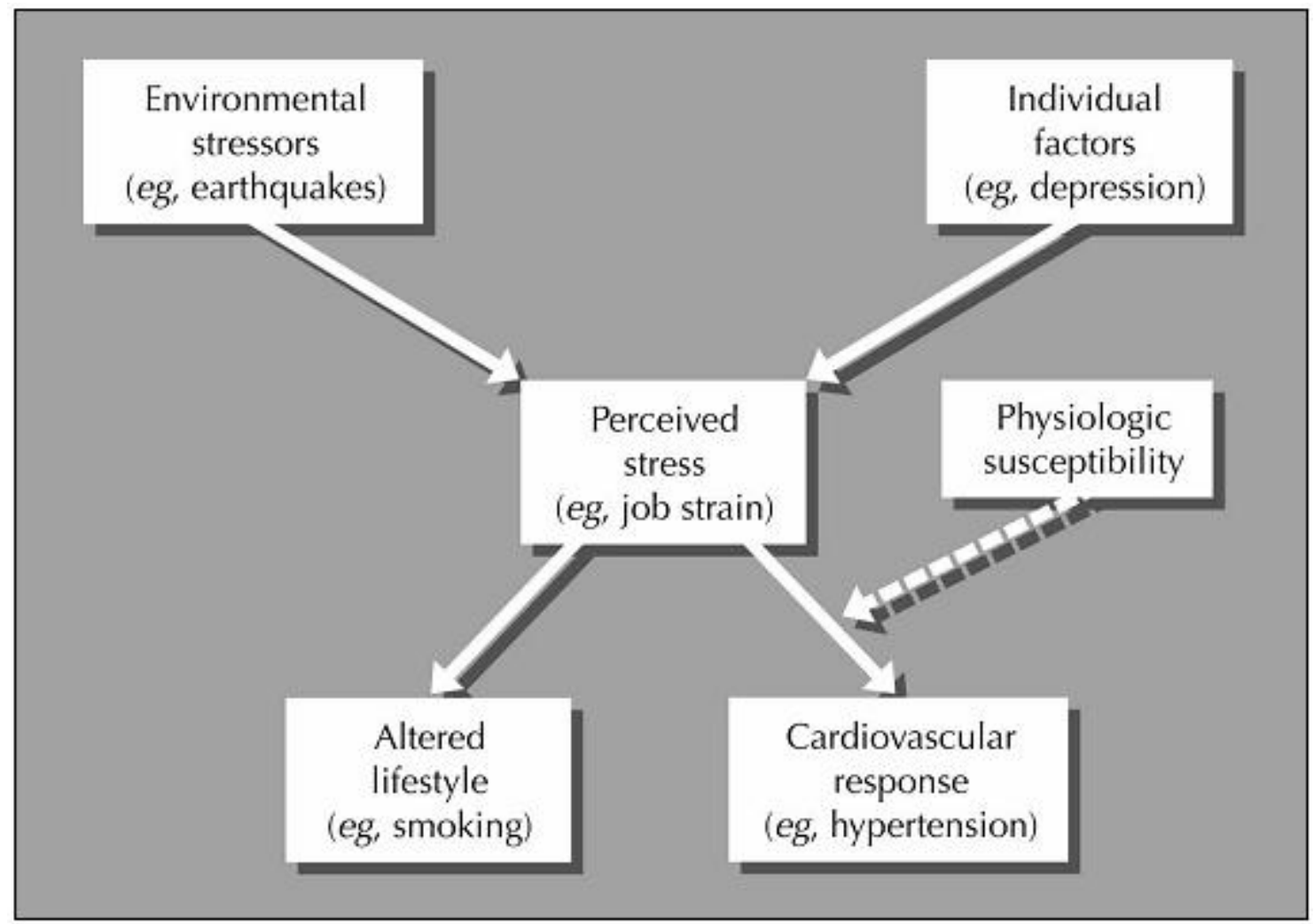

Figura 3. llustração esquemática da interação entre fatores ambientais e individuais que podem mediar os efeitos do estresse mental na doença cardiovascular. Reproduzido, com autorização, de Pickering (188).

Não obstante situações de estresse representarem acontecimentos naturais da vida, e as respostas fisiológicas ao estresse serem essenciais à homeostasia e sobrevivência (194), diversas evidências ligam o estresse mental ao desenvolvimento de doenças e à incidência de eventos cardiovasculares (188, 189). Alterações emocionais e eventos estressantes estimulam áreas de processamento central no córtex e tronco encefálico, podendo desencadear um distúrbio no equilíbrio 
eletrofisiológico do coração que favorece a ocorrência de arritmias que podem levar à morte (195).

Kamarck, Everson (196) identificaram uma associação entre RPA e espessura intimal-medial das artérias carótidas comuns (um marcador de aterosclerose) em 901 homens de meia idade (42-60 anos), apontando para uma espessura adicional de 0,02 a 0,03 mm para cada $\mathrm{mm} \mathrm{Hg}$ de elevação na PA durante o estresse mental. Esses dados são de relevância clínica considerável, já que cada incremento de 0,1 $\mathrm{mm}$ na espessura intimal-medial da carótida se associou de forma prospectiva a uma elevação de $11 \%$ no risco de infarto agudo do miocárdio em um período de 3 anos (197).

Everson, Lynch (1) demonstraram que respostas exageradas na PA ao estresse mental contribuem para um risco aumentado de acidente vascular encefálico. Cada aumento de $1 \mathrm{~mm} \mathrm{Hg}$ na PAS durante uma situação de estresse (antecipação ao exercício) correspondeu a $1 \%$ de aumento no risco de acidente vascular encefálico após 11 anos de acompanhamento, risco que foi 58\% maior nos indivíduos hiper-reativos, após controle de diversas covariáveis. Carroll, Ginty (3), após acompanhar 431 indivíduos de ambos os sexos por período de 16 anos, verificaram que a RPA está associada à mortalidade cardiovascular; para cada 1 desvio-padrão de aumento na reatividade da PAS e PAD, um aumento de 3 e 5\% no risco de mortalidade cardiovascular foi identificado, respectivamente.

Adicionalmente, há evidências de que a RPA se associe com a doença cerebrovascular silenciosa (2) e calcificação das artérias coronárias (198). Vale ressaltar, foi demonstrado que o estresse mental pode provocar uma disfunção endotelial transitória, representando uma conexão entre o estresse mental e a aterogênese (199). Chida and Steptoe (189), em conformidade com os estudos supracitados, demonstraram que a reatividade exacerbada da PA ao estresse mental se relaciona com o estado de risco cardiovascular futuro, em meta-análise que incluiu dados de 36 estudos referentes ao assunto.

Estudos indicam a existência de uma associação entre a RPA durante testes de estresse mental (realizados em laboratório) e a gênese da hipertensão arterial 
(200-202). Entretanto, esses achados não são unanimes (203, 204). Tais divergências podem ser explicadas por diferenças na suscetibilidade genética individual e fatores ambientais a que o indivíduo pode se encontrar exposto (205). Não obstante as divergências supracitadas, de acordo com meta-análise realizada por Chida and Steptoe (189), indivíduos mais reativos apresentam um risco 23\% maior de desenvolver hipertensão do que seus congêneres menos reativos.

Também foi demonstrado que a RPA é útil na predição da progressão da HA (206). Armario, del Rey (206), após acompanharem 89 indivíduos com hipertensão estágio 1, durante período de 5 anos, demonstraram que a hiper-reatividade da PA a dois testes de estresse (teste aritmético e entrevista) está associada à progressão da HA. Um risco relativo 4,5 vezes maior de a $\mathrm{HA}$ progredir foi identificado nos indivíduos que apresentaram uma resposta exacerbada ao estresse mental.

As respostas básicas do sistema cardiovascular ao estresse mental são aumentos na PA, no débito cardíaco (mediado principalmente por aumentos na FC) e no fluxo sanguíneo do antebraço, e vasoconstrição renal e esplâncnica (207-211). Destes, a PA representa a principal variável modulada durante o estresse, já que alterações induzidas farmacologicamente no débito cardíaco (bloqueio $\beta$ adrenérgico) ou tônus vascular (inibição da síntese de óxido nítrico) geram respostas compensatórias para manter os mesmos níveis absolutos de PA durante a ocorrência de eventos estressantes $(207,210)$.

As catecolaminas parecem ser um mecanismo importante nas respostas cardiovasculares observadas no estresse mental, considerando que elevações nos níveis arteriais de epinefrina e norepinefrina foram observadas durante a aplicação de estímulos estressores $(6,207,210,212)$, bem como aumentos no spillover da norepinefrina, tanto no nível total quanto no nível cardíaco (213). A sensibilidade dos receptores $\beta$-adrenérgicos também foi evidenciada como um dos mecanismos responsáveis pelas respostas supracitadas $(6,210)$. Outro possível mecanismo, cuja importância está razoavelmente bem estabelecida, é o óxido nítrico. Vários estudos que bloquearam a síntese dessa substância observaram atenuação nas respostas da PA, vasodilatadoras e na resistência vascular, situando o óxido nítrico como 
importante na mediação das respostas cardiovasculares ao estresse (207, 214-216). Nesse sentido, o aumento da PA e fluxo sanguíneo estimularia mecanorreceptores vasculares devido a elevações no estresse de cisalhamento, com aumento na síntese de óxido nítrico e consequente vasodilatação (217).

Considerando a atividade muscular nervosa simpática, há muita discussão e controvérsia quanto ao papel do sistema nervoso nas respostas ao estresse mental. Diversas pesquisas foram realizadas e incrementos, diminuição, ou manutenção dessa variável $(209,218-220)$ foram demonstrados, variação presente também em segmentos corporais diferentes $(218,220)$. Callister, Suwarno (221) avaliaram a atividade muscular nervosa simpática em 12 sujeitos em dois testes de estresse mental (Stroop e aritmético) com níveis de dificuldade diferentes, no intuito de solucionar as controvérsias apresentadas na literatura científica. Os autores atribuíram as divergências da atividade simpática à percepção de estresse, determinada, em grande parte, pela dificuldade absoluta dos testes empregados. Entretanto, estudos posteriores refutaram essa hipótese (190, 219, 220). Carter and Ray (190), em estudo compreensivo com dados de 82 sujeitos, observaram que não há um padrão definido de resposta para a atividade neural muscular simpática, o que não afeta a resposta da PA ao estresse. Tanto em indivíduos classificados como "responsivos" (positivos ou negativos) quanto como "não-responsivos" (sem alterações na atividade simpática), houve aumento expressivo na RPA ao estresse mental (teste aritmético), sem diferenças entre os grupos. Adicionalmente, não foi observada associação entre a percepção de estresse e a resposta simpática ou da PA.

A VFC também tem sido utilizada no estudo dos mecanismos de regulação cardiovascular ao estresse mental, por representar um método não invasivo eficaz de avaliação da regulação neural desse sistema. Aumentos no componente LF associados a reduções no componente HF foram demonstrados (191, 222, 223); entretanto, esses achados são inconsistentes, com estudos apontando para uma manutenção nos componentes absolutos $\operatorname{LF}$ e $\operatorname{HF}(224,225)$, elevações no componente HF (226), reduções no componente LF (227), e reduções nos componentes LF e HF $(228,229)$. É possível que as contradições supracitadas 
repousem na relação próxima que a VFC apresenta com o sistema respiratório, cuja modulação depende das condições de realização do teste de estresse mental utilizado $(224,225)$. Bernardi, Wdowczyk-Szulc (225) demonstraram que 0 comportamento das faixas de baixa e alta frequência da VFC pode depender do fato de o teste de estresse mental ser realizado de forma silenciosa (os sujeitos dão as respostas silenciosamente, por escrito ou pressionando teclas de computador) ou verbalizada (os sujeitos dão as respostas em voz alta), discrepâncias que parecem influenciar mais o componente HF, o que se justifica por alterações na frequência respiratória durante o teste. De fato, os autores demonstraram que há um decréscimo no componente HF apenas no teste realizado de forma silenciosa, sem diferenças nesse componente durante o teste realizado de forma verbalizada, corroborando os achados de Sloan, Korten (224).

Vuksanović and Gal (226), no intuito de tentar explicar as discrepâncias apresentadas pela análise espectral durante o estresse mental, observaram que há indivíduos que respondem com elevações ou reduções no componente HF, justificando as discrepâncias apresentadas na literatura. Os autores só observaram alterações significativas no componente HF durante o estresse mental ao separar os indivíduos na dependência da resposta apresentada, com um aumento no balanço simpato-vagal evidente apenas no grupo que apresentou redução da banda HF. Não foram observadas alterações no componente LF em nenhum grupo ou na análise com os grupos combinados. Resultados semelhantes foram observados por Visnovcova, Mestanik (227) no componente LF, que apresentou aumento e diminuição durante os testes de Stroop e de aritmética, respectivamente, sugerindo que diferentes testes podem gerar respostas discrepantes.

Resultados de análise não-linear da VFC no estresse mental, apresentados por Visnovcova, Mestanik (227), apontaram para uma redução na complexidade da FC (Symbolic dynamics) em 70 jovens de ambos os sexos, submetidos a dois estressores diferentes. Esses resultados foram apoiados, em parte, pelos apresentados por Vuksanović and Gal (226), que demonstraram redução na complexidade da FC (Entropia amostral) apenas no grupo que teve o componente HF reduzido durante o estresse mental, sem alterações evidentes para o outro grupo. 
Estudos realizados comparando indivíduos hipertensos e normotensos apresentaram resultados divergentes na RPA. Enquanto há evidências que demonstram uma resposta hiper-reativa nos indivíduos com hipertensão $(230,231)$, outras não observaram diferenças absolutas na resposta da PA ao estresse mental entre essas duas condições (232-234). Entretanto, ao considerar os valores percentuais de aumento da RPA (i.e., considerando o valor de PA pré-teste), Lindvall, Kahan (233) e Tsai, Yucha (234) reportaram uma resposta atenuada na população de hipertensos, provavelmente decorrente de uma redução na complacência cardíaca e hipertrofia do ventrículo esquerdo nos pacientes com HA, resultando em um débito cardíaco reduzido durante o estresse mental. Adicionalmente, Cardillo, Kilcoyne (232) demonstraram uma resposta vasodilatadora atenuada durante 0 estresse mental em indivíduos hipertensos, em comparação aos seus congêneres normotensos, efeito mediado por uma atividade reduzida do óxido nítrico, dados que podem sugerir uma maior suscetibilidade a danos vasculares com a exposição repetida ao estresse mental nessa população.

Poucos estudos que tiveram como foco comparar as respostas ao estresse mental em indivíduos normotensos e hipertensos, por meio da VFC, foram encontrados (235, 236). Langewitz, Rüddel (235) demonstraram uma redução no componente HF - indicando uma redução do controle cardíaco parassimpático - e um aumento no balanço simpatovagal em indivíduos com HA. Ruediger, Seibt (236) observaram um aumento no componente LF e uma redução no componente HF (porção mediada pela respiração: 0,25 Hz) nos indivíduos hipertensos em comparação aos normotensos, durante a realização de testes aritméticos.

A resposta apresentada por indivíduos idosos ao estresse mental diverge da de indivíduos jovens. Não obstante existirem divergências na literatura, com estudos apresentando uma reatividade exacerbada $(192,193)$ ou ausência de diferenças/inconsistência de resultados entre os dois grupos $(237,238)$, resultados de estudos bem controlados demonstraram que indivíduos idosos apresentam uma hiper-reatividade para a PAS, mas não para a $\operatorname{PAD}(191,192,239,240)$. De fato, em meta-análise (4) que incluiu resultados de 31 estudos publicados com o objetivo de verificar a existência de diferenças entre essas populações, apenas a reatividade da 
PAS divergiu entre os grupos, com uma resposta exacerbada na PAS nos indivíduos idosos.

Steptoe, Moses (239), especificamente, compararam a RPA ao estresse mental (matrizes progressivas de Raven) em 84 mulheres, estratificadas em 3 grupos de idade (19-32, 33-43, e 44-60 anos). Os autores encontraram uma resposta exacerbada apenas para a PAS, no grupo de maior idade, e sugeriram que essa resposta pode ser dependente de reações autonômicas e neuroendócrinas específicas ao estresse, já que essa diferença não pôde ser observada durante o exercício. Adicionalmente, os resultados apresentados por Steptoe, Fieldman (193) indicam que as diferenças na RPA são mais evidentes em indivíduos do sexo feminino, em relação ao envelhecimento. Uma possível explicação para as divergências na RPA, com o avançar da idade, pode repousar na resposta vasodilatadora ao estresse mental, conforme demonstrado por Heffernan, Patel (238). Os autores compararam as respostas cardiovasculares ao estresse (teste aritmético) em 24 indivíduos jovens e idosos de ambos os sexos, e observaram uma redução na resposta vasodilatadora nos indivíduos mais velhos.

Adicionalmente, uma redução da sensibilidade $\beta$-adrenérgica durante 0 estresse mental foi observada por Johansson and Hjalmarson (192) em indivíduos idosos, o que pode estar vinculado ao aumento da atividade simpática que pode acompanhar o processo de envelhecimento (241). Corroborando essa assertiva, Esler, Thompson (213) demonstraram um aumento no spillover da norepinefrina advinda do coração em indivíduos idosos, em comparação a indivíduos adultos jovens. Adicionalmente, em análise dos intervalos RR durante o estresse mental, Uchino, Uno (191) demonstraram uma redução no controle parassimpático cardíaco durante o estresse mental em indivíduos idosos em comparação aos mais jovens. Finalmente, reduções na sensibilidade barorreflexa com 0 envelhecimento (possivelmente vinculadas ao aumento da rigidez arterial) e associadas ao estresse mental foram demonstradas em diversas pesquisas $(193,242)$. Dessa forma, a desregulação do sistema cardiovascular observada com 0 processo de envelhecimento, durante o estresse mental, pode explicar as diferenças na RPA supracitadas. A redução das habilidades fisiológicas para lidar com demandas 
ambientais pode contribuir para uma exacerbação dos processos patológicos relacionados ao estresse, no processo de envelhecimento.

3.4.1 Exercício resistido e atenuação da reatividade da pressão arterial ao estresse mental

Não foram encontradas evidências acerca dos efeitos agudos que o ER pode desencadear na reatividade pressórica durante o estresse mental, com exceção de um estudo que combinou exercícios resistidos com o aeróbio na mesma sessão (8), o que não permite uma avaliação dos efeitos isolados do ER na modulação dessa variável. Dessa forma, uma breve revisão dos efeitos agudos do exercício aeróbio na RPA e seus possíveis mecanismos será realizada, para fundamentação do problema de pesquisa.

Em geral, estudos têm demonstrado que uma única sessão de exercício aeróbio é capaz de provocar uma atenuação na RPA ao estresse mental (5, 6, 8-10, 12, 243-246), não obstante a existência de evidências contrárias a esses achados $(11,247-249)$. Ao limitar o indivíduo à exposição de descargas hipersimpáticas repetidas durante situações de estresse (7), o exercício pode apresentar-se como ferramenta eficaz de prevenção na ocorrência de eventos e incidência de doenças cardiovasculares.

Hamer, Taylor (7), em meta análise que incluiu os resultados de 15 estudos, demonstraram que o exercício aeróbio é capaz de promover uma redução significativa na reatividade pressórica equivalente a 3,0 e $3,9 \mathrm{~mm} \mathrm{Hg}$ para PAS e PAD, respectivamente. Adicionalmente, foi demonstrado que: a) o estado de treinamento individual não exerce influência na atenuação da RPA ao estresse mental por meio do exercício aeróbio (7); e b) há uma relação entre a magnitude da resposta com a dose de exercício utilizada (i.e., volume e intensidade), com uma maior dose evocando uma atenuação pressórica maior $(7,250,251)$.

Vários mecanismos podem estar associados à atenuação da reatividade pressórica mediada pelo exercício agudo. West, Brownley (9) observaram uma 
redução na resistência vascular periférica durante estímulos estressores (Cold pressor test e teste aritmético) após uma sessão de exercício aeróbio, mas não no volume de ejeção. Contrariamente, Neves, Carvalho (10), ao investigarem os efeitos de uma sessão de exercício aeróbio na reatividade cardiovascular, identificaram um menor volume de ejeção e débito cardíaco na situação pós-exercício, sem modificações na resistência vascular periférica. Em apoio a esses achados, Vianna, Silva (5) observaram que a atenuação da reatividade pressórica ao estresse mental foi provocada por reduções nos índices cardíaco e de volume de ejeção, e na contratilidade do ventrículo esquerdo, sem alterações na vasodilatação do antebraço.

Brownley et. al. (6) demonstraram aumentos significativos na responsividade dos receptores adrenérgicos $\beta 1$ e $\beta 2$ após uma sessão de exercício aeróbio (até 120 minutos pós-exercício), indicando uma reatividade pressórica atenuada por vasodilatação mediada pelos receptores adrenérgicos $\beta 2$. Adicionalmente, o exercício promoveu uma redução significativa nos níveis de norepinefrina e epinefrina durante um teste de discurso, com uma tendência à redução da norepinefrina durante um teste aritmético. Em suma, os resultados de Brownley, Hinderliter (6) indicam uma reatividade pressórica atenuada por meio de reduções na atividade simpática e potencialização da vasodilatação periférica. Péronnet, Massicotte (11) observaram uma redução nos níveis de epinefrina durante o estresse mental após uma sessão de exercício aeróbio, em comparação a uma sessão controle, sem verificarem uma atenuação na reatividade pressórica ao estresse mental. Já Ebbesen, Prkachin (12) não puderam observar diferenças nas catecolaminas circulantes durante 3 testes de estresse (Cold pressor test, Stroop e discurso), não obstante identificarem uma atenuação na reatividade pressórica após o exercício aeróbio, que perdurou por até 3 horas.

Além disso, é possível que mecanismos psicossociais também influenciem na atenuação da reatividade pressórica, conforme demonstrado por Bartholomew (243), que identificou que o tipo de feedback oferecido relativo ao desempenho obtido em um teste de consumo máximo de oxigênio (feedback de desempenho real, superestimado ou subestimado) foi capaz de modificar a ocorrência deste fenômeno. 
Curiosamente, o feedback que subestimou o desempenho foi capaz de eliminar os efeitos do exercício aeróbio na reatividade pressórica.

Não está claro se fatores como a idade ou a presença de patologias (e.g., hipertensão arterial) podem influenciar na atenuação da resposta pressórica mediada pelo exercício aeróbio. Entretanto, é possível que uma sessão de exercícios promova modificações nas diferenças observadas na reatividade cardiovascular entre normotensos e hipertensos, considerando que a realização de uma sessão de exercício aeróbio parece abolir tanto as diferenças observadas na resistência vascular do antebraço durante o estresse mental, em homens jovens com histórico familiar de hipertensão (247), quanto as diferenças no fluxo sanguíneo e condutância vascular do antebraço observadas entre indivíduos normotensos e pré-hipertensos de ambos os sexos (245).

Finalmente, no único estudo encontrado que incluiu exercícios resistidos como parte da sessão de exercícios (exercício concorrente), Moreira, Lima (8) verificaram uma atenuação na RPA mediada pelo exercício em 20 homens e mulheres saudáveis, durante um teste de estresse vascular (Cold pressor test) aplicado antes e 60 minutos após a realização da sessão. Entretanto, como os exercícios foram realizados na mesma sessão, ainda não se sabe se o ER per se pode provocar uma atenuação na RPA. Dessa forma, há uma lacuna a ser preenchida em relação aos possíveis efeitos do ER na reatividade pressórica ao estresse mental. 


\section{METODOLOGIA}

\subsection{Amostra}

Setenta e uma mulheres idosas ( $\geq 60$ anos de idde) portadoras de hipertensão arterial sistêmica foram convidadas a participar do estudo. Foram consideradas hipertensas as voluntárias diagnosticadas por médico especialista e que estivessem fazendo uso de medicação anti-hipertensiva. $O$ projeto foi divulgado por meio de cartazes e panfletos distribuídos nas oficinas do Grupo de Estudos e Pesquisas sobre Atividade Física para Idosos (GEPAFI) da Universidade de Brasília, no Serviço de Convivência e Fortalecimento de Vínculos da Secretaria de Estado de Desenvolvimento Humano e Social, em academias e instituições religiosas do Plano Piloto, por meio de contato telefônico com voluntárias que participaram de projetos prévios realizados pelo Grupo de Estudos em Fisiologia do Exercício e Saúde (GEFS) da UnB, e por meio de indicações.

Os critérios de exclusão aplicados na pesquisa foram a) saber ler; b) estar em terapia de reposição hormonal; c) apresentar outras doenças cardiovasculares além da hipertensão arterial; d) ser portador de diabetes mellitus; e) apresentar hiper/hipotireoidismo; f) ter histórico de arritmia ou eventos cardiovasculares; g) apresentar condições osteomioarticulares que pudessem ser agravadas com a realização dos exercícios resistidos utilizados na pesquisa, ou os limitassem; h) fazer uso de medicamentos inibidores adrenérgicos ou bloqueadores dos canais de cálcio não-diidropiridínicos; e i) obesidade, determinada por escore $>29,9$ no índice de massa corporal (IMC).

Com a aplicação dos critérios de exclusão, 14 sujeitos foram excluídos após contato telefônico, 46 após preenchimento de anamnese, e 1 após avaliação física preliminar (Figura 4). Dessa forma, um total de 10 mulheres idosas compôs a amostra do presente estudo. As voluntárias foram informadas sobre os riscos e benefícios do experimento e assinaram um termo de consentimento livre e esclarecido (TCLE; Anexo I) antes da participação no estudo. Os procedimentos desenvolvidos e executados neste estudo foram aprovados pelo Comitê de Ética e 
Pesquisa da Faculdade de Ciências da Saúde da Universidade de Brasília, de acordo com a Resolução n. 196/1996 do Conselho Nacional de Saúde - Protocolo 001/13 (Anexo II).

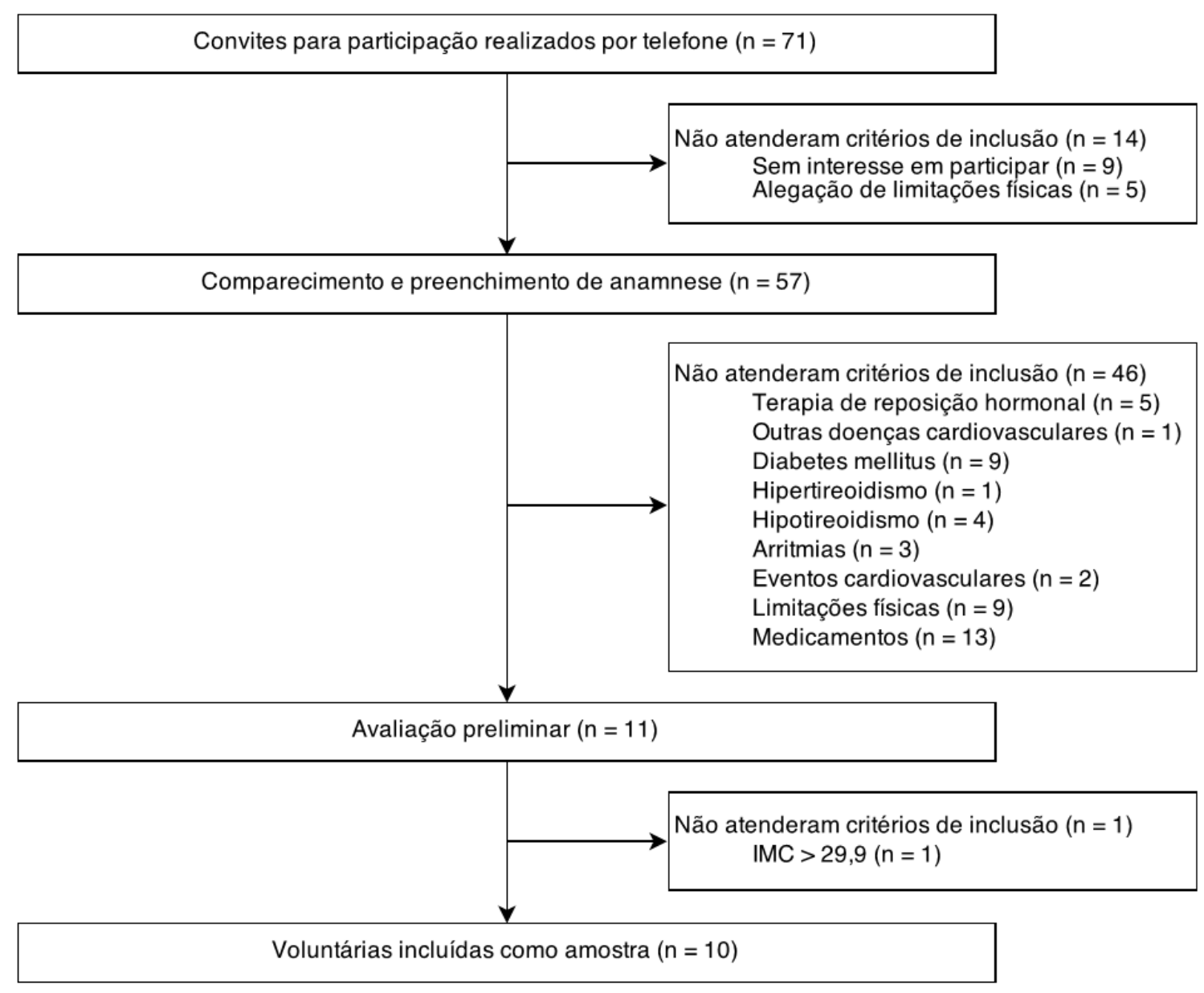

Figura 4. Fluxograma de recrutamento e seleção amostral.

\subsection{Procedimentos}

\subsubsection{Procedimentos experimentais}

Os procedimentos para avaliação e execução das sessões experimentais foram realizados em 6 visitas (Figura 5), no Laboratório de Treinamento Resistido da 
Faculdade de Educação Física da Universidade de Brasília. Na primeira visita, as voluntárias chegaram ao Laboratório e preencheram uma anamnese sobre hábitos de vida e saúde (Anexo III), o Questionário Internacional de Atividade Física e Saúde (International Physical Activity Questionnaire, IPAQ; Anexo IV), o Questionário de Prontidão para Atividade Física (Physical Activity Readiness Questionnaire, PAR-Q; Anexo V) e o TCLE. Após o preenchimento dos questionários, a PA das voluntárias foi mensurada e estas foram submetidas à avaliação antropométrica. Em seguida, foi realizada a primeira sessão de familiarização.

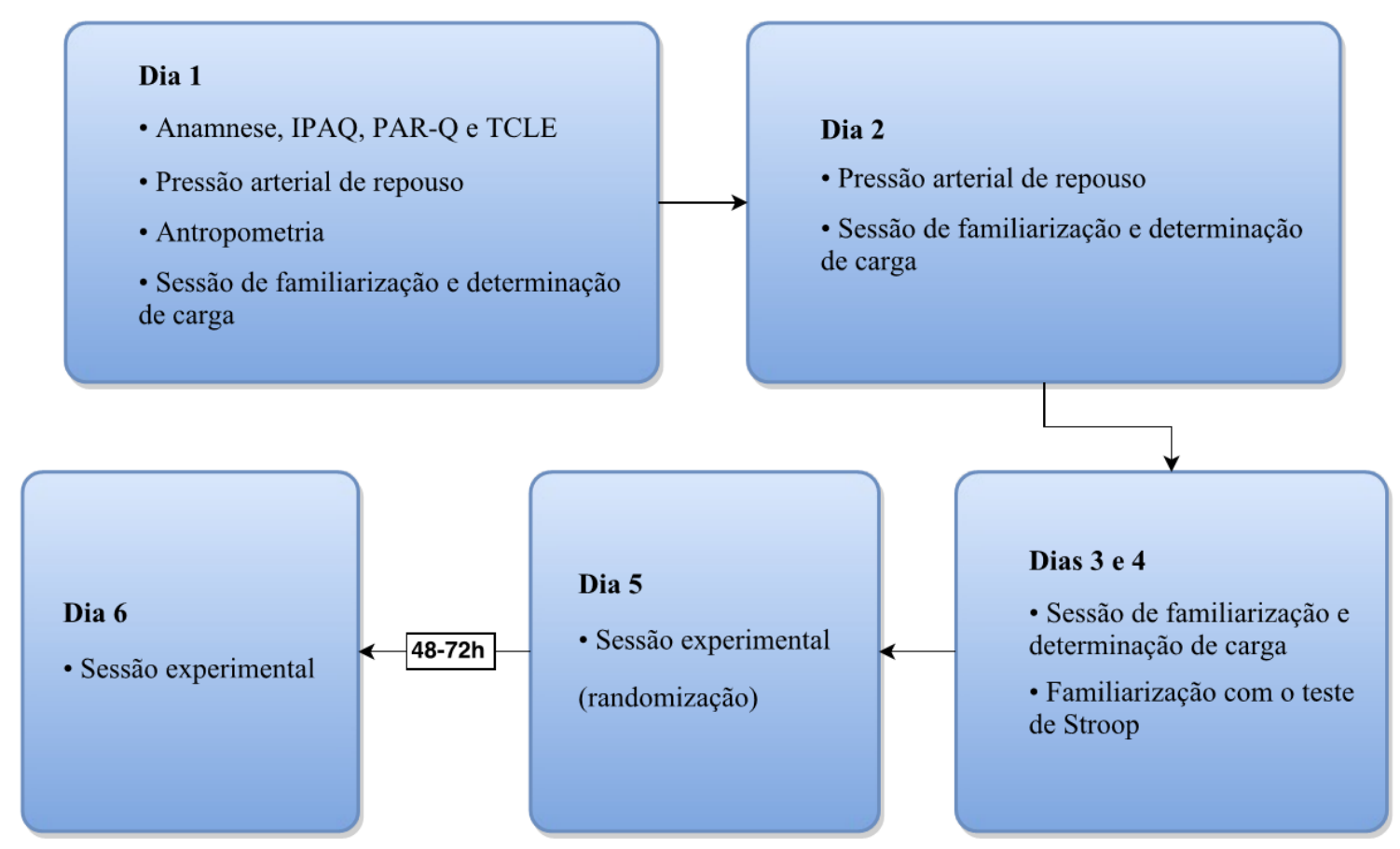

Figura 5. Fluxograma experimental.

Na segunda visita, as voluntárias chegaram ao Laboratório e tiveram sua PA aferida novamente, para caracterização da amostra, seguindo com a realização da segunda sessão de familiarização. As visitas 3 e 4 foram dedicadas à realização das duas últimas sessões de familiarização. 
As sessões experimentais foram realizadas nas visitas 5 e 6 (i.e., exercício resistido em forma tradicional ou de circuito) de forma randomizada, em até 7 dias após a última sessão de familiarização e determinação. Ao chegar ao laboratório, uma fita transmissora foi colocada nas voluntárias (para análise da $\mathrm{FC}$ ), que foram posicionadas em uma cadeira confortável, em seguida, para as avaliações de PA. Após as leituras de PA, o monitor cardíaco foi ligado, as voluntárias tiveram a VFC de repouso aferida e realizaram o teste de Stroop, para mensuração da RPA. Em seguida, as voluntárias realizaram um aquecimento de $\sim 5$ minutos e deram início à sessão experimental. Após a sessão experimental, as voluntárias foram novamente posicionadas na posição sentada, ingeriram $200 \mathrm{ml}$ de água, e permaneceram em repouso durante 60 minutos. Nesse período, 4 medidas de PA foram realizadas, uma a cada 15 minutos (i.e., 15, 30, 45 e 60 minutos após a sessão) e, após a última leitura, o teste de Stroop foi repetido. O monitor cardíaco permaneceu ligado até o final da visita, e os momentos utilizados para análise da VFC foram estratificados posteriormente, e 4 análises com 5 minutos de duração foram realizadas,

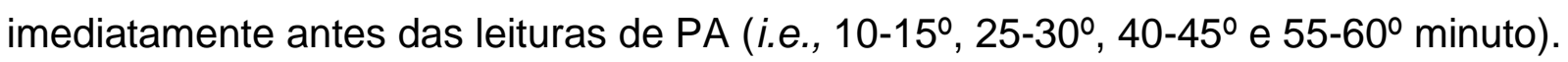
Trinta minutos após o fim de cada sessão experimental, a percepção subjetiva de esforço da sessão foi mensurada, para comparação do esforço percebido.

\subsubsection{Sessões de familiarização e determinação}

As quatro primeiras sessões foram realizadas com os objetivos de familiarizar as voluntárias com os exercícios e determinar as cargas utilizadas nas sessões experimentais. Os exercícios resistidos foram executados nessa ordem: leg-press, remada sentada (fechada, com pegada neutra), extensão de joelhos, supino sentado, flexão de joelhos, elevação lateral com halteres e flexão plantar sentada (Figura 6). Todos os ajustes das máquinas foram anotados para cada voluntária na primeira sessão de familiarização, e utilizados nas sessões posteriores. 

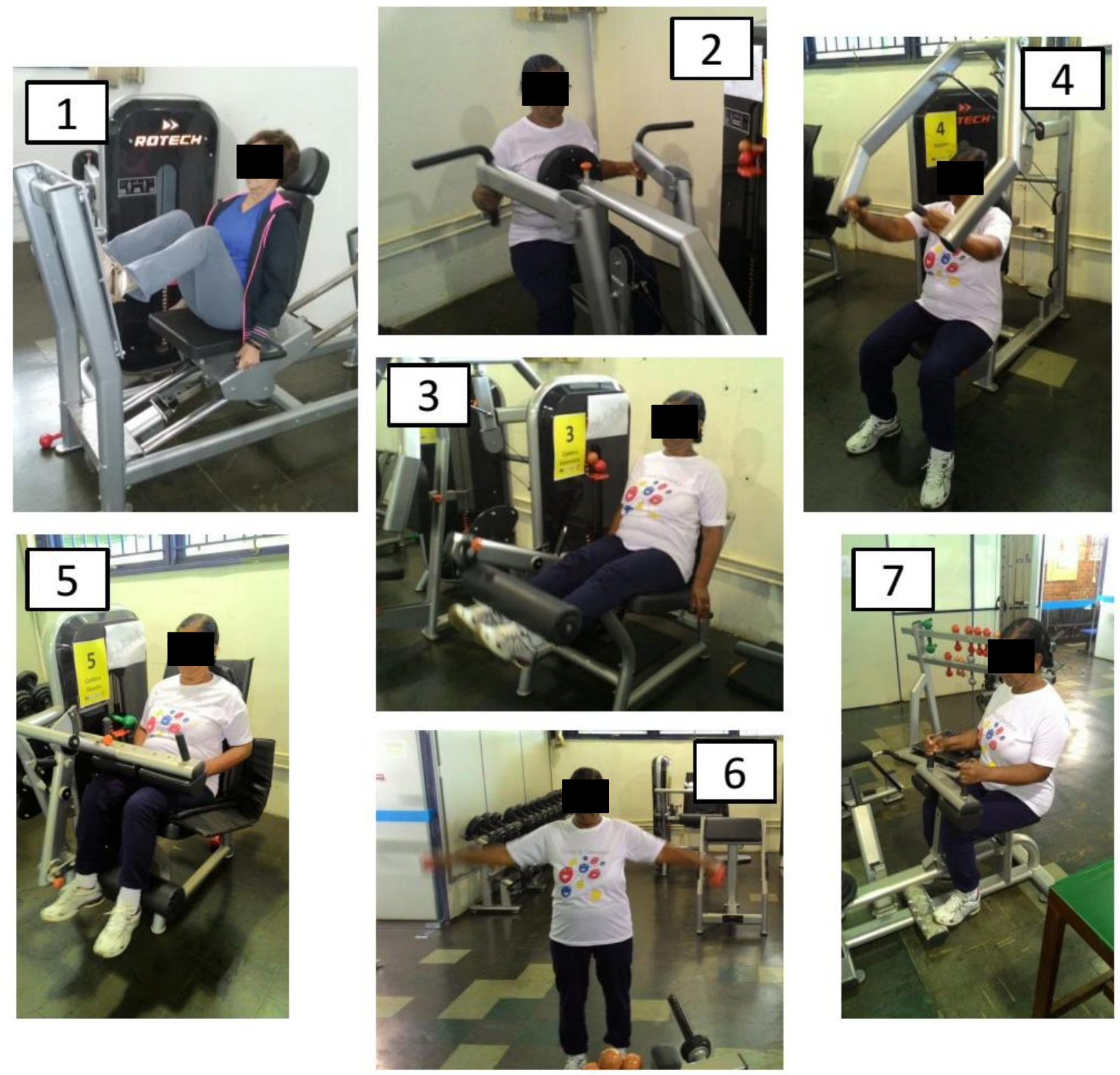

Figura 6. Exercícios resistidos executados nas sessões de familiarização e experimentais (numerados pela ordem de execução).

Inicialmente, as cargas de cada exercício foram determinadas com a utilização de uma escala de percepção de esforço (Omnibus Resistance Exercise Scale; nota 4 - “Um pouco difícil”). Após a determinação, os sujeitos realizaram a) uma série de 12 repetições em cada exercício, com $50 \%$ da carga estimada pela escala, na primeira sessão; b) duas séries de 12 repetições em cada exercício, com $60 \%$ da carga 
estimada pela escala, na segunda sessão; c) duas séries de 12 repetições em cada exercício, com 70\% da carga estimada pela escala, na terceira sessão; e d) três séries de 12 repetições em cada exercício, com $80 \%$ da carga estimada pela escala, na quarta sessão.

As cargas e séries foram aumentadas, progressivamente, a cada sessão, para otimizar o ajuste das cargas. A primeira sessão de familiarização foi realizada na forma de circuito, e as três seguintes foram randomizadas (Decision Analyst STATS $^{\mathrm{TM}}$ 2.0) para os arranjos tradicional e circuito, de forma que as voluntárias se familiarizassem com cada arranjo por duas vezes. Na última sessão de familiarização e determinação, os sujeitos foram apresentados ao teste de estresse mental (teste de Stroop) após os exercícios, e realizaram 1 minuto de teste para habituação com os procedimentos utilizados.

\subsubsection{Sessões experimentais}

Os sujeitos realizaram duas sessões experimentais: "Exercícios resistidos de forma tradicional" (ERT) e "Exercícios resistidos em forma de circuito" (ERC). As duas sessões foram realizadas no período matutino, com 48 a 72 horas de intervalo entre si. A ordem das sessões foi randomizada com software Decision Analyst STATS $^{\text {TM }}$ 2.0, e os mesmos exercícios das sessões de familiarização e determinação foram realizados, na mesma ordem. A carga utilizada nas sessões experimentais foi equivalente à média das cargas encontradas nas duas últimas sessões de familiarização e determinação, para cada exercício.

Na sessão ERT, os 7 exercícios foram realizados no modelo tradicional. Para tanto, 3 séries de 12 repetições foram realizadas em cada exercício, antes que os indivíduos trocassem de máquina, com intervalo de recuperação equivalente a 60 segundos entre séries e exercícios. Na sessão ERC, os indivíduos realizaram os exercícios na forma de circuito. Três voltas no circuito foram realizadas, com 1 série de 12 repetições executada em cada exercício, em cada volta. Um intervalo de 
repouso de 30 e 60 segundos entre exercícios e voltas, respectivamente, foi cronometrado. A realização da manobra de Valsalva foi desencorajada durante a realização dos exercícios. O tempo total da sessão, o tempo sob tensão (tempo total da sessão - intervalos de recuperação) e a FC foram computados para cada sessão.

Os sujeitos foram orientados a não ingerir substâncias que contivessem cafeína ou álcool e a não realizar atividades físicas vigorosas nas 24 horas que precedessem as sessões, e a dormir ao menos 6 horas na noite anterior ao dia das sessões experimentais. Adicionalmente, as voluntárias foram instruídas a realizar uma alimentação leve duas horas antes da execução de todos os protocolos experimentais, e a ingerir o medicamento anti-hipertensivo no horário usual.

\subsubsection{Avaliação antropométrica}

A avaliação antropométrica foi caracterizada por medidas de massa corporal e estatura. A mensuração da massa corporal foi realizada com uma balança digital com resolução de $0,1 \mathrm{~kg}$ (Toledo, Brasil), com os indivíduos descalços e usando roupas leves. Para a estatura, foi utilizado um estadiômetro fixado na parede (Cardiomed, Brasil; resolução de $0,1 \mathrm{~cm}$ ), e a leitura realizada durante expiração máxima dos sujeitos. O IMC foi calculado por meio da divisão da massa corporal pelo quadrado da estatura dos sujeitos $\left(\mathrm{kg} / \mathrm{m}^{2}\right)$.

\subsubsection{Mensuração da pressão arterial}

A monitoração clínica da PA foi realizada utilizando-se um dispositivo oscilométrico (BP 3AC1-1 PC, Microlife) aprovado pelos critérios de validação da European Society for Hypertension (informações sobre validação podem ser consultadas em http://www.dableducational.org/). Em todas as sessões, os sujeitos permaneceram sentados para as leituras de PA, com o braço repousando em uma mesa da altura da linha do coração. As medidas foram realizadas sempre no braço 
esquerdo, e seguiram as recomendações de Pickering (252). Os sujeitos foram orientados a manter o braço relaxado, as penas descruzadas e as costas apoiadas na cadeira, além de não conversarem durante as leituras.

Duas a três medidas de PA foram realizadas para caracterização da amostra em dois dias diferentes ( $1^{\underline{a}}$ e $2^{\underline{a}}$ visitas). Procedimento semelhante foi adotado no dia das sessões experimentais, no momento pré-exercício. Se uma diferença $>5 \mathrm{~mm} \mathrm{Hg}$ fosse observada entre as duas primeiras leituras, uma terceira era realizada. As leituras foram realizadas com intervalo de 5 minutos entre si, após os indivíduos repousarem por 5 minutos na posição sentada. As leituras no período de 60 minutos pós-ER foram realizadas nos minutos 15, 30, 45 e 60. As leituras de PA no teste de Stroop foram realizadas com um monitor auscultatório de coluna de mercúrio (Unitec Ind. Com. de aparelhos hospitalares LTDA.), sendo considerados como valores de PAS e PAD as leituras realizadas nos $1^{\circ}$ e $5^{\circ}$ sons de Korotkoff.

\subsubsection{Percepção subjetiva de esforço}

A definição das cargas utilizadas no estudo foi realizada por meio do uso da escala "Omnibus Resistance Exercise Scale" (OMNI-RES; Figura 7), desenvolvida por Robertson, Goss (253), com o intuito de avaliar a percepção subjetiva de esforço (PSE) na realização do ER. A escala original foi traduzida para a língua portuguesa para ser utilizada na pesquisa.

A escala foi afixada em todas as máquinas de $E R$, permitindo uma visualização permanente por parte dos sujeitos. A definição de PSE e instruções de utilização da escala foram adaptadas de Robertson, Goss (253) para melhor compreensão dos sujeitos. Estudos prévios demonstraram a aplicabilidade da escala OMNI-RES na população de mulheres idosas $(254,255)$. Adicionalmente, a escala OMNI-RES foi validada para o ER em forma de circuito, e demonstrou ser apropriada na manipulação da intensidade de esforço nesse tipo de método de ER (256). 


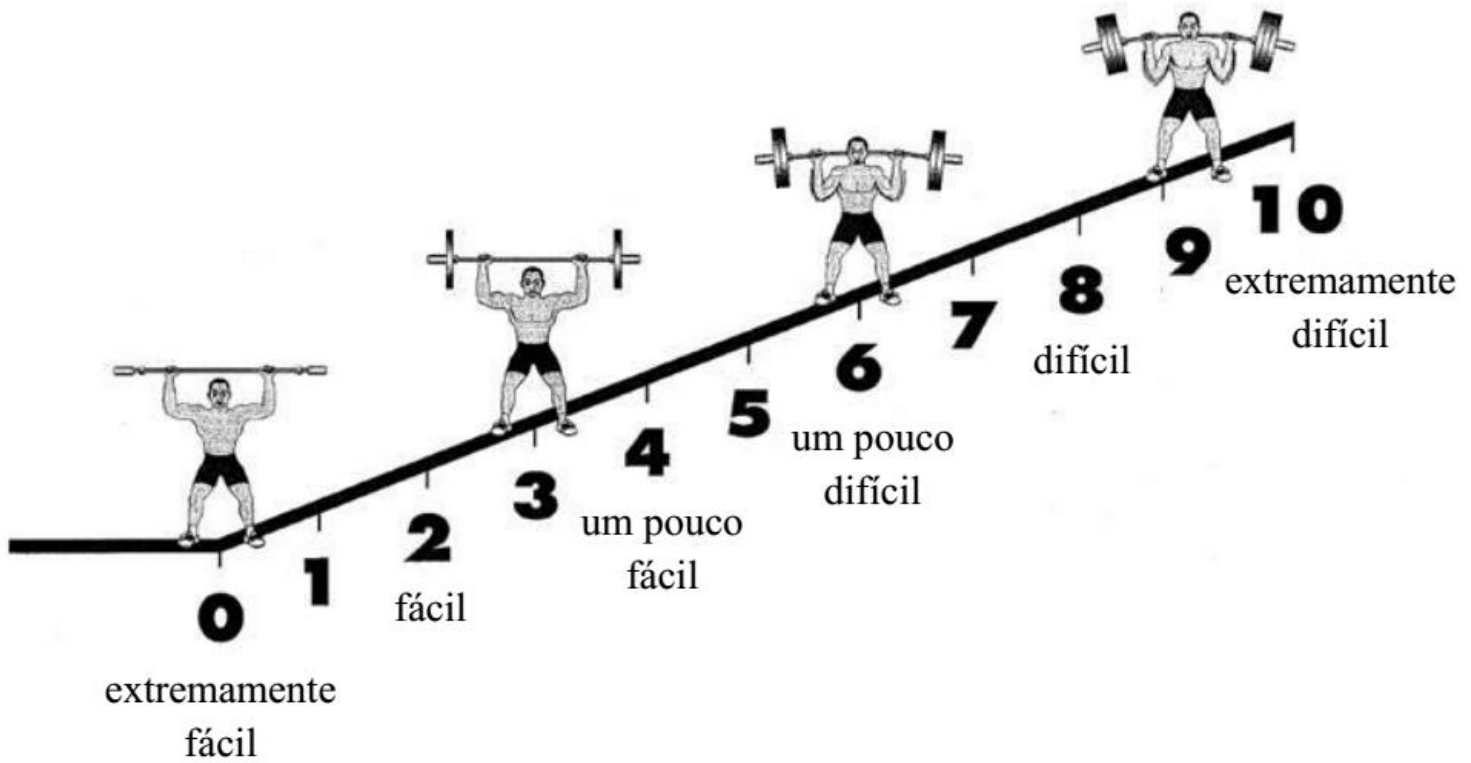

Figura 7. Escala de percepção subjetiva de esforço "OMNI-RES". Versão traduzida para a língua portuguesa.

A avaliação da PSE por meio da escala OMNI-RES foi determinada após a realização de 1 repetição em cada exercício, com intervalo de 1 minuto entre cada tentativa. Foi demonstrado que 1 repetição pode ser utilizada para identificar a intensidade de treino desejada, não sendo necessária a realização de várias repetições $(257,258)$. Após a realização de cada repetição, os sujeitos foram apresentados à escala e orientados a dar uma nota referente à PSE atingida com aquela carga. Os sujeitos foram instruídos a trocar de exercício apenas quando a carga utilizada gerasse uma nota equivalente a 4 (“Um pouco fácil”). A nota 4 foi escolhida por estar associada a uma intensidade $\sim 60 \%$ de 1-RM, baseando-se em estudos prévios $(257,258)$. O procedimento foi realizado para cada exercício até o atingimento da nota. Sempre que os ajustes nos pesos $(1 \mathrm{~kg})$ fossem insuficientes para determinar a nota 4 (i.e., permanecessem 3 ou 5), o peso referente à menor nota foi utilizado. A média das cargas determinadas nas duas últimas sessões de familiarização e determinação foi utilizada nas sessões experimentais. 
Em cada sessão de familiarização e determinação de carga, os sujeitos foram apresentados à definição de PSE, à escala e suas instruções, e aos procedimentos de ancoragem (253). O termo "Percepção subjetiva de esforço" foi definido para os sujeitos como "intensidade subjetiva de esforço, estresse, desconforto e/ou fadiga que você sente durante o exercício". As instruções da escala foram lidas e detalhadamente explicadas às voluntárias na primeira sessão de familiarização e determinação; nas três sessões subsequentes, as próprias voluntárias leram por si mesmas as instruções, com as explicações da escala e procedimento de ancoragem repetidos pelos avaliadores. As instruções foram as seguintes: "Nós gostaríamos que você utilizasse estas figuras para descrever como seus músculos se sentem durante o exercício de força. Você irá realizar exercícios para os braços e pernas. Por favor, olhe para a pessoa na parte mais baixa da escala, executando uma repetição com um peso leve. Se você se sentir como esta pessoa imediatamente após levantar os pesos, o esforço será EXTREMAMENTE FÁCIL. Nesse caso, você responderá com o número 0 . Agora olhe a pessoa no topo da escala, que mal consegue executar uma repetição, utilizando um peso muito pesado. Se você se sentir como esta pessoa imediatamente após levantar os pesos, o esforço será EXTREMAMENTE DIFÍCIL. Nesse caso, você responderá com o número 10. Se o esforço estiver entre "extremamente fácil" (0) e "extremamente difícil" (10), dê um número entre 0 e 10. Nós pediremos que você dê um número que descreva como seus músculos ativos (os músculos que estão fazendo força) se sentem. Lembre-se, não há números certos ou errados. Utilize tanto as figuras quanto o que está escrito para ajudar na seleção dos números".

Para ancoragem, os sujeitos foram orientados a estabelecer uma associação cognitiva entre a PSE (evocação de memória do maior e menor esforço já efetuado ao levantar qualquer peso) com as figuras apresentadas na escala, para criação de uma conexão cognitivo-visual. Lagally and Costigan (259) compararam os procedimentos de ancoragem por meio de exercício (1-RM) e evocação de memória, demonstrando que a inclusão da ancoragem por meio de exercício não produziu melhoras na confiabilidade das notas apontadas na escala de percepção de esforço 
em comparação ao procedimento mnemônico, cuja utilização foi apontada como preferida pelos benefícios de tempo, esforço e praticidade que apresenta.

A PSE da sessão foi mensurada por meio de uma escala de percepção de esforço (Borg CR-10) adaptada por Foster, Florhaug (260) (Figura 8), em concordância com procedimentos descritos por Sweet, Foster (261), que demonstraram que a PSE da sessão é um método viável para quantificar a intensidade de uma sessão de ER. Para melhor compreensão das voluntárias, a escala foi traduzida para a língua portuguesa. Trinta minutos após o término da sessão, os sujeitos foram apresentados às escalas e foram inquiridos pelo avaliador: "Como foi o seu treino?"; em seguida, os sujeitos foram orientados a responder à pergunta apontando uma nota na escala que refletisse a intensidade de toda a sessão de ER (261).

\begin{tabular}{cc}
\hline Classificação & Descrição \\
\hline $\mathbf{0}$ & Repouso \\
$\mathbf{1}$ & Muito, muito fácil \\
$\mathbf{2}$ & Fácil \\
$\mathbf{3}$ & Moderado \\
$\mathbf{4}$ & Um pouco difícil \\
$\mathbf{5}$ & Difícil \\
$\mathbf{6}$ & - \\
$\mathbf{7}$ & Muito difícil \\
$\mathbf{8}$ & - \\
$\mathbf{9}$ & - \\
$\mathbf{1 0}$ & Máximo \\
\hline
\end{tabular}

Figura 8. Escala de percepção subjetiva de esforço Category Ratio (Borg CR-10) modificada por Foster, Florhaug (260). Versão traduzida para a língua portuguesa. 
Todos os sujeitos foram orientados a realizar uma avaliação global da sessão, não se atendo a possíveis percepções mais ou menos intensas decorrentes de exercícios divergentes (261). Imediatamente após a mensuração da PSE da sessão pela escala Borg CR-10, os indivíduos avaliaram novamente a PSE da sessão por meio da escala OMNI-RES, uma escala desenvolvida especificamente para mensurar o esforço subjetivo no ER (253). A eficácia da avaliação da PSE da sessão por meio da escala OMNI-RES foi verificada previamente em uma amostra de mulheres idosas (262). Os procedimentos de avaliação foram semelhantes na utilização das duas escalas.

\subsubsection{Modulação autonômica do sistema nervoso}

A modulação do sistema nervoso autônomo foi realizada por meio da avaliação da variabilidade da frequência cardíaca, com a utilização de um monitor cardíaco Polar $\AA$ (modelo RS800CX, Polar Electro Oy, Kempele, Finland), em concordância com as recomendações do Task Force of the European Society of Cardiology and the North American Society of Pacing and Electrophysiology (153). Antes da colocação da cinta de transmissão, esta foi previamente umedecida e um gel ultrassônico transmissor foi aplicado às áreas elétricas para otimizar o contato entre o transmissor e a pele dos indivíduos, minorando a ocorrência de ruído na aquisição do sinal. Antes das medidas de repouso e pós-exercício, os indivíduos permaneceram em repouso, na posição sentada, por pelo menos 10 minutos. As leituras foram realizadas em intervalos de 5 minutos com respiração espontânea, nos momentos de repouso e nos 60 minutos pós-ER (de 10-15, 25-30, 40-45 e 55-60 minutos). Todos os indivíduos permaneceram em repouso na posição sentada durante as leituras, sendo orientados a não conversaram antes ou durante as medidas. Medidas adicionais da VFC foram realizadas durante o teste de Stroop, nos momentos pré e pós-exercício, e comparados ao repouso.

O software Polar ProTrainer 5 (Polar Electro Oy, Kempele, Finland) foi utilizado para a transferência dos dados e correção dos erros na aquisição do sinal 
(filtro de alto poder). O software Kubios HRV 2.2 (Biosignal Analysis and Medical Imaging Group, Joensuu, Finland) foi utilizado para tratamento dos dados, que foram analisados pelos métodos lineares no domínio de frequência e tempo, e por método não-linear da VFC.

Para o domínio de frequência, o tacograma gerado pela análise foi processado pelo método auto regressivo (256s; ordem do modelo $=16)$, que decompôs a VFC em componentes de baixa frequência ( $L F$, de 0,04 a $0,15 \mathrm{~Hz}$ ) e alta frequência $(H F$, de 0,15 a $0,4 \mathrm{~Hz}$ ), utilizados como indicadores da atividade simpática e parassimpática do coração, respectivamente. O componente de muito baixa frequência (Very low frequency, VLF) não foi considerado para análise, por se tratar de uma medida de curto-prazo (153). A relação LF/HF foi utilizada para aferir o balanço simpato-vagal sobre o coração. Os dados foram normalizados por meio da divisão da potência de cada componente (LF ou HF) pelo espectro de potência total, valor que foi subtraído do componente VLF e multiplicado por 100 (263). Análises no domínio tempo foram realizadas, por não terem a estacionariedade como uma de suas premissas, como as análises no domínio de frequência. A raiz quadrada da média da soma dos quadrados das diferenças entre intervalos RR normais (Square root of the mean of the sum of the squares of differences between adjacent NN intervals, RMSSD) foi utilizada para tanto (153).

Adicionalmente, uma análise da complexidade da FC (método não-linear) foi realizada por meio da entropia amostral (Sample Entropy, SampEn). A SampEn é caracterizada pela probabilidade de sequências (e.g., intervalos $R R$ ) serem similares durante uma série temporal curta, com valores variando entre 0 e 2. Quanto maior a previsibilidade da sequência (i.e., mais regular), menor sua complexidade, com o valor se aproximando de 0. Quanto menor a previsibilidade da sequência (i.e., mais irregular), maior sua complexidade, com o valor se aproximando de 2. Uma redução na complexidade do controle cardíaco pode denotar uma adaptação insuficiente às diversas demandas confrontadas pelo sistema (227). 


\subsubsection{Reatividade da pressão arterial ao estresse mental}

A RPA ao estresse mental foi avaliada por meio da aplicação do teste de Stroop (264) (Figura 9) adaptado, conforme realizado em estudos prévios (5). O teste de Stroop foi realizado antes e após 60 minutos das sessões experimentais, com os indivíduos na posição sentada. O teste consistiu na apresentação de slides com nomes de cores, apresentadas em cores diferentes da indicada na palavra (e.g., a palavra "verde" escrita em vermelho). Os indivíduos foram instruídos a responder em voz alta a cor em que a palavra estava escrita e foram estimulados a acertar o maior número de cores, sendo alertados que o número de respostas certas estava sendo anotado por um avaliador.
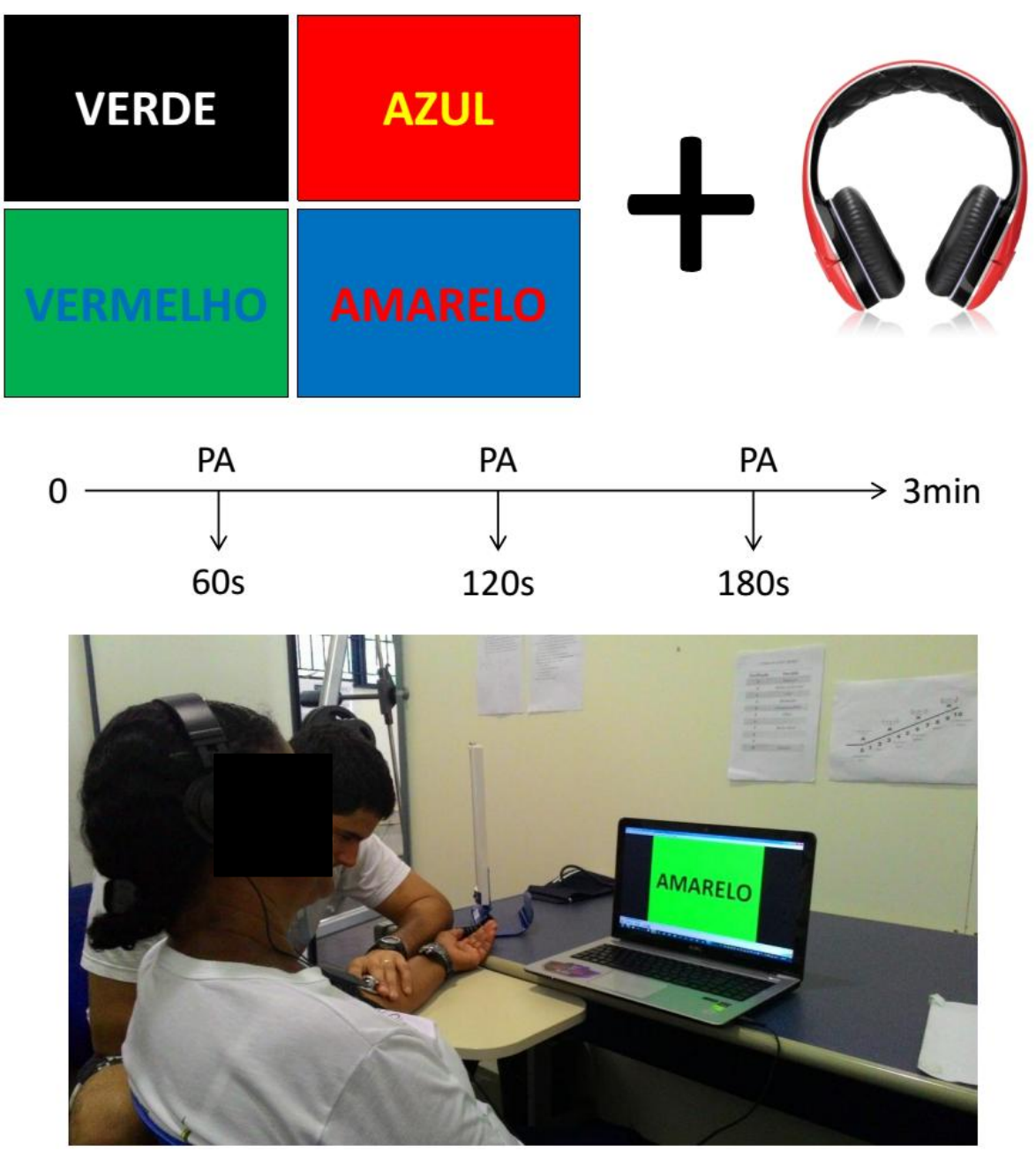

Figura 9. Esquema de aplicação do teste de Stroop. Abaixo, registro fotográfico de uma voluntária durante a realização do teste. 
O procedimento do teste de Stroop teve duração total de 9 minutos (3 minutos de repouso, 3 minutos de teste e 3 minutos de recuperação), e cada slide foi apresentado por tempo <1 segundo. Para potencializar o estresse causado, os indivíduos utilizaram um fone de ouvidos durante o teste para geração de conflito auditivo (e.g., uma voz gravada falando nomes de cores diferentes). Adicionalmente, um feedback constante foi oferecido pelos avaliadores para que os sujeitos aumentassem a velocidade das respostas, dando-se ênfase às respostas incorretas. Apresentações com ordens diferentes para os slides foram utilizadas em cada teste, minorando um possível efeito de memorização.

Um monitor auscultatório de coluna de mercúrio foi utilizado para as mensurações da PA (Unitec Ind. Com. de aparelhos hospitalares LTDA.); estas foram realizadas por um indivíduo treinado, nos 3 minutos que antecederam o teste, nos 3 minutos durante a realização do teste, e nos 3 minutos imediatos à realização do teste. Imediatamente ao final do teste, os sujeitos foram inquiridos sobre o nível de estresse percebido, por meio de escala utilizada em estudos prévios (5) (Figura 10). Para melhor compreensão das voluntárias, a escala foi traduzida para a língua portuguesa.

\begin{tabular}{|l|l|}
\hline 0 & Não estressante \\
\hline 1 & Pouco estressante \\
\hline 2 & Estressante \\
\hline 3 & Muito estressante \\
\hline 4 & Extremamente estressante \\
\hline
\end{tabular}

Figura 10. Escala de estresse percebido. Versão traduzida para a língua portuguesa. 


\subsection{Análise estatística}

Estatística descritiva foi utilizada para apresentação dos dados de caracterização da amostra, expressos em média \pm desvio-padrão (DP). Foi aplicado o teste de Shapiro-Wilk para verificação da normalidade na distribuição dos dados. Um teste $t$ pareado foi utilizado para as comparações das variáveis hemodinâmicas e autonômicas de repouso e demais características das sessões experimentais. A confiabilidade das cargas determinadas pela OMNI-RES (sessões 3 e 4) foi calculada por meio do coeficiente de correlação intraclasse ( $\alpha$ de Cronbach; IC de 95\%).

Análises de variância (ANOVA) de medidas repetidas foram executadas para verificação dos efeitos das duas sessões de ER na PA pós-exercício [2 (Sessão: ERT e ERC) x 5 (Tempo: repouso, 15, 30, 45 e 60 minutos)], RPA [2 (Sessão: ERT e ERC) x 2 (Tempo: pré e pós-ER)] e VFC [2 (Sessão: ERT e ERC) x 5 (Tempo: repouso, $\mathrm{T} 1=10-15^{\circ}$ minuto, $\mathrm{T} 2=25-30^{\circ}$ minuto, $\mathrm{T} 3=40-45^{\circ}$ minuto, e T4 = 55-60응 minuto); e 2 (Sessão: ERT e ERC) x 3 (Tempo: repouso, teste de Stroop pré e pósER)]. Adicionalmente, uma ANOVA de medidas repetidas foi realizada para verificar a eficácia do estímulo estressor antes da realização das sessões de ER [2 (Sessão: ERT e ERC) x 2 (PA pré-teste de Stroop e PA de pico durante o Stroop)]. A correção de Greenhouse-Geisser utilizada em casos de violação do pressuposto da esfericidade dos dados.

Uma análise de correlação de Pearson foi realizada para verificar a existência de uma associação da PA de repouso com a mudança de PA pós-exercício (i.e., PA pré-exercício - PA pós-exercício). $O$ valor de PA de repouso considerado nesse cálculo representa a média pré-exercício das duas sessões, de forma a evitar-se a ocorrência de uma correlação espúria (265). Os resultados da estatística inferencial estão apresentados como média \pm erro-padrão (EP) A significância estatística adotada foi de $p<0.05$, e todas as análises foram realizadas pelo software SPSS, versão 20.0. 


\section{Resultados}

\subsection{Características dos sujeitos e das sessões experimentais}

A Tabela 1 apresenta as características de base da amostra. Todos os indivíduos da amostra eram hipertensos controlados (e.g., PA sistólica e diastólica < 140/90 mm Hg, respectivamente), com um tempo médio de diagnóstico da HA de $11,6 \pm 9,5$ anos.

Tabela 1. Características dos sujeitos $(n=10)$.

\begin{tabular}{lc}
\hline Variável & Média \pm DP \\
\hline Idade (anos) & $71,1 \pm 5,5$ \\
Estatura $(\mathrm{m})$ & $1,5 \pm 0,1$ \\
Massa corporal $(\mathrm{kg})$ & $56,1 \pm 9,8$ \\
IMC $\left(\mathrm{kg} / \mathrm{m}^{2}\right)$ & $24,2 \pm 3,9$ \\
PAS $(\mathrm{mm} \mathrm{Hg})$ & $119,3 \pm 4,6$ \\
PAD $(\mathrm{mm} \mathrm{Hg})$ & $68,5 \pm 5,0$ \\
PAM (mm Hg) & $85,4 \pm 3,5$ \\
FC (bpm) & $69,9 \pm 9,2$ \\
Tempo pós-menopausa & $20,8 \pm 5,5$ \\
\hline IMC = Índice de massa corporal; PAS = Pressão \\
arterial sistólica; PAD $=$ Pressão arterial \\
diastólica; PAM = Pressão arterial média; FC = \\
Frequência cardíaca.
\end{tabular}

A Tabela 2 apresenta as distribuições de frequência e percentuais para as variáveis categóricas. Por meio da aplicação do IPAQ, todos os sujeitos da amostra foram classificados como "Ativos" ou "Muito ativos". Os sujeitos praticantes de treinamento de força (50\%) apresentaram um tempo médio de prática de 6,4 anos, e frequência semanal de treino equivalente a 2 sessões. 
Tabela 2. Distribuições de frequência e percentual de informações de saúde.

\begin{tabular}{lcc}
\hline Variável & Frequência (n) & $\%$ \\
\hline IPAQ & 6 & 60 \\
Ativo & 4 & 40 \\
Muito ativo & & \\
Ingere bebida alcoólica? & 3 & 30 \\
Sim & 7 & 70 \\
Não & & 0 \\
É fumante? & 0 & 100 \\
Sim & 10 & 60 \\
Não & & 60 \\
Medicamentos* & 6 & 70 \\
Bloqueadores dos canais de cálcio & 6 & \\
Diuréticos & 7 & 50 \\
Bloqueadores do receptor AT1 da Angiotensina II & & 50 \\
Pratica musculação? & 5 & \\
Sim & 5 & \\
Não & 5 &
\end{tabular}

$\mathrm{IPAQ}=$ International Physical Activity Questionnaire. *Bloqueadores dos canais de cálcio = Anlodipino; Diuréticos = Indapamida e Hidroclorotiazida; Bloqueadores do receptor AT1 da Angiotensina II = Losartana, Candesartana, Valsartana e Olmesartana.

Os dados referentes às cargas utilizadas nas sessões experimentais e 0 volume total da sessão podem ser observados na Tabela 3. Os coeficientes de correlação intraclasse ( $\alpha$ de Cronbach; IC de 95\%) para as cargas encontradas com a escala OMNI-RES foram de 92,1\% (pressão de pernas), 93,3\% (remada sentado), 98,5\% (extensão de joelhos), 97,6\% (supino sentado), 87,1\% (flexão de joelhos), $93,2 \%$ (elevação lateral) e $98 \%$ (flexão plantar).

Conforme demonstrado na Tabela 4, não houve diferença nas variáveis hemodinâmicas e autonômicas de repouso entre as sessões experimentais. Cinco sujeitos iniciaram o protocolo experimental com a sessão ERT, e cinco com a sessão ERC. 
Tabela 3. Cargas e volume total dos exercícios resistidos.

\begin{tabular}{lc}
\hline Exercício & Média \pm DP \\
\hline Leg-press $(\mathrm{kg})$ & $27,8 \pm 8,8$ \\
Remada sentado $(\mathrm{kg})$ & $20,5 \pm 4,6$ \\
Cadeira extensora $(\mathrm{kg})$ & $22,9 \pm 4,4$ \\
Supino sentado $(\mathrm{kg})$ & $17,7 \pm 4,0$ \\
Cadeira flexora $(\mathrm{kg})$ & $23,4 \pm 3,8$ \\
Elevação lateral $(\mathrm{kg})$ & $1,8 \pm 0,4$ \\
Flexão plantar sentado $(\mathrm{kg})$ & $11,5 \pm 4,2$ \\
Volume total (séries $\mathrm{x}$ repetições $\times$ carga) & $4521,6 \pm 906,5$ \\
\hline
\end{tabular}

Tabela 4. Variáveis hemodinâmicas e autonômicas de repouso no dia das sessões experimentais (média \pm EP).

\begin{tabular}{lcc}
\hline Variável & ERT & ERC \\
\hline PAS (mm Hg) & $120,1 \pm 2,4$ & $117,7 \pm 2,4$ \\
PAD (mm Hg) & $68,9 \pm 1,6$ & $69,6 \pm 1,6$ \\
PAM (mm Hg) & $85,9 \pm 1,5$ & $85,6 \pm 1,5$ \\
FC (bpm) & $69,6 \pm 3,2$ & $71,6 \pm 3,4$ \\
In TP (ms $\left.{ }^{2}\right)$ & $6,2 \pm 0,3$ & $6,2 \pm 0,2$ \\
In LF (ms $\left.{ }^{2}\right)$ & $4,8 \pm 0,4$ & $4,8 \pm 0,3$ \\
LF (nu) & $60,1 \pm 7,1$ & $61,4 \pm 6,6$ \\
In HF (ms $\left.{ }^{2}\right)$ & $4,3 \pm 0,2$ & $4,3 \pm 0,3$ \\
HF (nu) & $39,8 \pm 7,1$ & $38,6 \pm 6,6$ \\
Razão LF/HF & $1,1 \pm 0,1$ & $1,2 \pm 0,1$ \\
SampEn & $1,51 \pm 0,08$ & $1,52 \pm 0,10$ \\
\hline
\end{tabular}

$E R T=$ Exercício resistido tradicional; ERC = Exercício resistido em circuito; PAS = Pressão arterial sistólica; PAD = Pressão arterial diastólica; PAM = Pressão arterial média; FC = Frequência cardíaca; TP = Total power; LF = Low frequency; $\mathrm{HF}=$ High frequency; SampEn = Sample Entropy; In = normalização logarítmica; nu = unidade normalizada.

A Tabela 5 apresenta um quadro comparativo das características das sessões experimentais. Como pode ser observado, houve diferença significativa entre as sessões para o tempo total e FC das sessões. Não obstante, não houve diferenças 
para o tempo sob tensão nem para a PSE entre as sessões, avaliada pelas escalas Borg CR-10 e OMNI-RES.

\begin{tabular}{lcc}
$\begin{array}{l}\text { Tabela 5. Quadro comparativo das } \\
\text { experimentais (média } \pm \text { EP). }\end{array}$ & características & das sessões \\
\hline Variável & $5,1 \pm 0,5$ & $4,5 \pm 0,5$ \\
\hline PSE sessão Omni-Res & $3,7 \pm 0,3$ & $3,4 \pm 0,4$ \\
PSE sessão Borg CR-10 & $29,9 \pm 0,3$ & $20,2 \pm 0,3 \dagger$ \\
Tempo total da sessão (min) & $593,3 \pm 15,6$ & $553,3 \pm 15,2$ \\
Tempo sob tensão (s) & $94,1 \pm 5,4$ & $98,9 \pm 5,5^{*}$ \\
FC média (bpm) & ERC \\
\hline ERT = Exercício resistido tradicional; & ERC $=$ Exercício resistido em \\
circuito; PSE $=$ Percepção subjetiva & de esforço; FC $=$ Frequência \\
cardíaca; ${ }^{*} p<0,05 ; \dagger p<0,001$. &
\end{tabular}

\subsection{Efeitos agudos do exercício resistido sobre a pressão arterial}

Resultados da análise de variância de medidas repetidas não demonstraram efeitos significativos para sessão (ERT e ERC), tempo (Repouso, 15, 30, 45 e 60 minutos) ou interação (sessão $x$ tempo) para PAS, PAD ou pressão arterial média (PAM; Figura 11), não sendo observado um efeito hipotensor mediado pelo ER em nenhuma das sessões experimentais. Para a FC, foi demonstrado um efeito significativo de sessão $(70,5 \pm 2,9$ na sessão ERT vs 73,0 $\pm 3,1$ na sessão ERC; $p=$ $0,046)$ e tempo $(76,4 \pm 3,4$ e $72,3 \pm 3,1$ para nos momentos 15 e 30 minutos pósexercício, vs 70,6 $\pm 3,2$ no momento pré-exercício; $p=0,001$ e $p=0,011$, respectivamente); não foi observado efeito de interação (sessão $x$ tempo) para esta variável. 
A

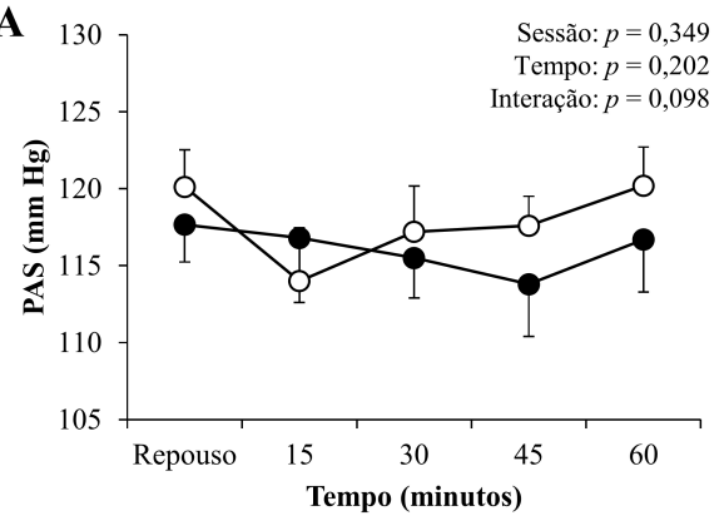

C

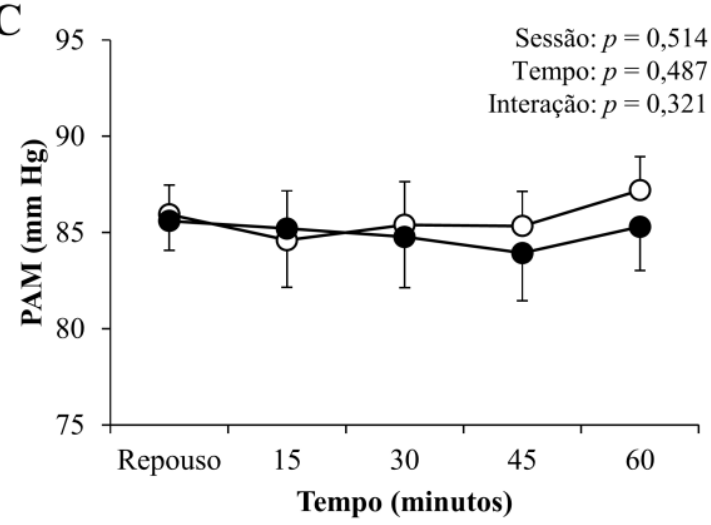

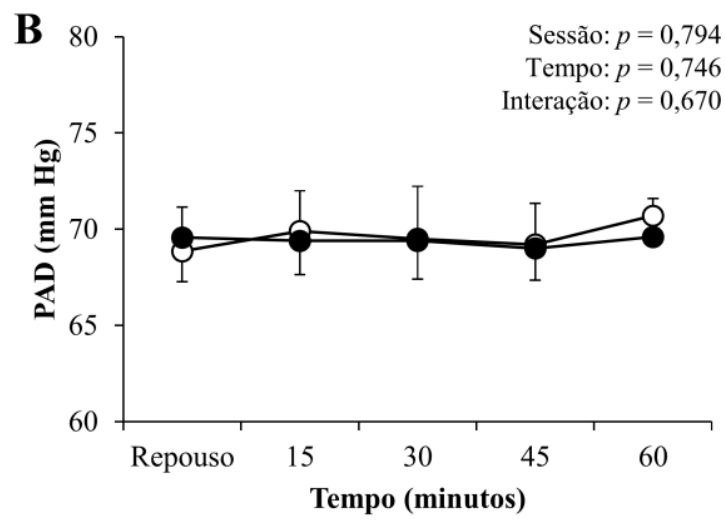

D

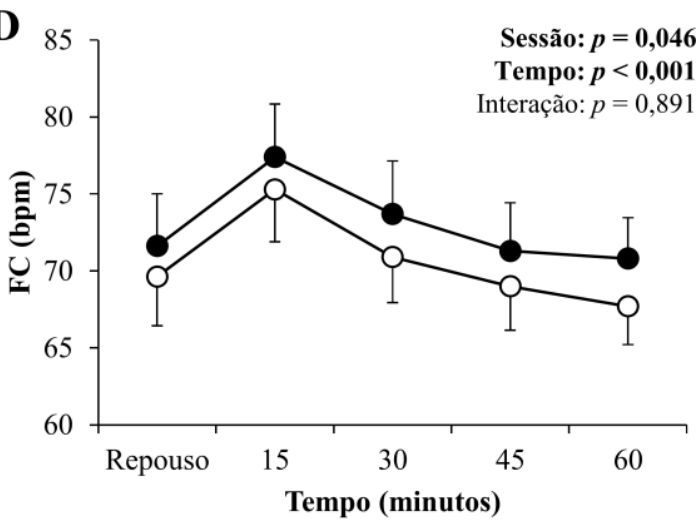

Figura 11. Média \pm EP da pressão arterial sistólica (PAS; Painel A), diastólica (PAD; Painel B), média (PAM, Painel C) e frequência cardíaca (FC; Painel D) antes e após as sessões de exercício resistido tradicional (ERT) e exercício resistido em forma de circuito (ERC). $\left(^{*}\right)$ indica efeito significativo de tempo, na ANOVA.

Para uma melhor compreensão do leitor, os valores de $\Delta \mathrm{mm} \mathrm{Hg}$ para PAS, PAD e PAM estão apresentados na Figura 12. É interessante notar que, para PAS, embora não tenha sido observada significância estatística, houve uma depressão nos valores médios de PA pós-exercício em relação ao momento pré-exercício (mais pronunciada na sessão ERT), valores que retornaram aos níveis de repouso após 60 minutos. 
Tempo
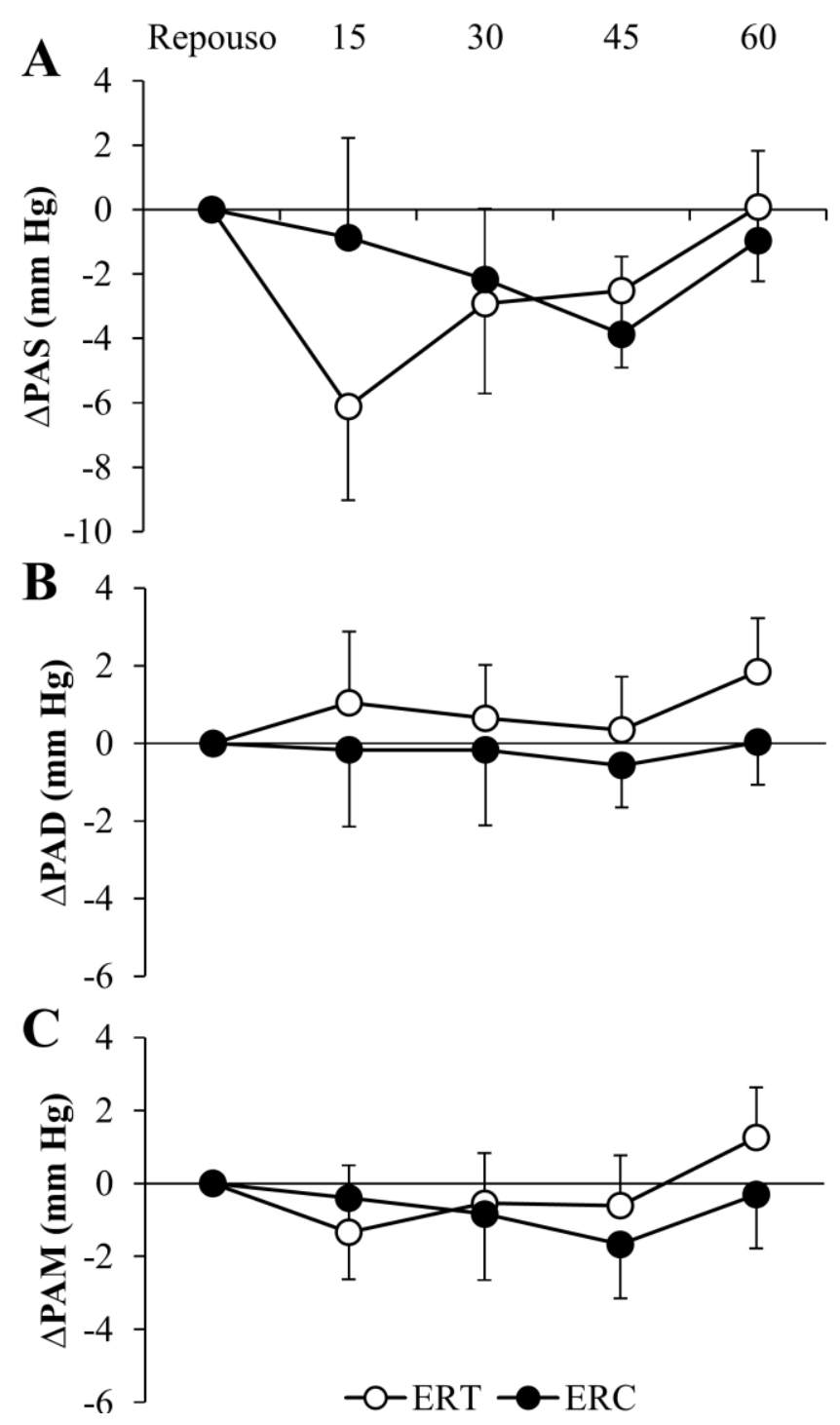

Figura 12. Média \pm EP da pressão arterial sistólica (PAS; Painel A), diastólica (PAD; Painel B) e média (PAM; Painel C) expressa em $\triangle \mathrm{mm} \mathrm{Hg}$ (i.e., valor da PAS em cada tempo pós-exercício - PAS préexercício), antes e após as sessões de exercício resistido tradicional (ERT) e exercício resistido em circuito (ERC).

Não foram observadas correlações significativas entre as mudanças de PA pós-ER e a PA pré-exercício. Portanto, não foram realizadas análises de regressão para verificar o poder preditivo da PA pré-exercício no comportamento da PA pósexercício. 


\subsection{Efeitos agudos do exercício resistido sobre a modulação autonômica}

Devido a problemas técnicos ocorridos durante as coletas, os dados de 2 voluntárias foram perdidos. Dessa forma, todos os resultados apresentados para a VFC representam os dados de 8 voluntárias, tanto no repouso pós-exercício quanto durante o teste de Stroop.

Em decorrência da distribuição dos dados de VFC, as variáveis de referência foram transformadas logaritmicamente. Como se pode ver na Tabela 6 , não foram observadas alterações no poder total (Total power, TP) após nenhuma das sessões experimentais, efeito que também não foi observado para o componente $\operatorname{LF}\left(\mathrm{ms}^{2}\right)$, para os componentes LF e HF (nu), para o balanço simpatovagal (LF/HF), ou para RMSSD. Resultados da ANOVA de medidas repetidas demonstraram um efeito de tempo para o componente $\mathrm{HF}\left(\mathrm{ms}^{2}\right)$, sendo observada uma redução significativa no momento T1 (10-15') em comparação ao repouso $(4,3 \pm 0,2$ vs 3,8 $\pm 0,2 ; p=0,033)$.

Um efeito de tempo também foi observado para a complexidade da FC (SampEn), que apresentou uma redução nos momentos T1, T2 (25-30') e T3 (40-45') em comparação ao repouso $(1,21 \pm 0,13 ; p=0,027 ; 1,21 \pm 0,08 ; p=0,005$; e $1,25 \pm$ 0,$10 ; p=0,015$ vs $1,51 \pm 0,09$, respectivamente); não houve diferença entre as sessões ou interação (sessão $x$ tempo) para esta variável.

5.4 Efeitos agudos do exercício resistido sobre reatividade da pressão arterial ao estresse mental

O estresse percebido do teste de Stroop não foi diferente em nenhuma das sessões experimentais, comparando-se os momentos pré e pós-exercício $(1,7 \pm 0,3$ e 1,9 \pm 0,3 para ERT; $1,8 \pm 0,2$ e 1,7 $\pm 0,3$ para ERC, respectivamente; sessão: $p=$ 0,726; tempo: $p=0,726$; interação: $p=0,081$ ). 
Tabela 6. Média \pm EP dos componentes da análise da VFC antes e após as sessões de exercício resistido tradicional (ERT) e exercício resistido em circuito (ERC).

\begin{tabular}{|c|c|c|c|c|c|c|c|c|}
\hline & In TP $\left(\mathrm{ms}^{2}\right)$ & In LF $\left(\mathrm{ms}^{2}\right)$ & $\operatorname{LF}(\mathrm{nu})$ & In HF $\left(\mathrm{ms}^{2}\right)$ & $\mathrm{HF}(\mathrm{nu})$ & $\mathrm{LH} / \mathrm{HF}$ & RMSSD (ms) & SampEn \\
\hline \multicolumn{9}{|l|}{ Pré } \\
\hline ERT & $6,2 \pm 0,3$ & $4,8 \pm 0,4$ & $60,1 \pm 7,1$ & $4,3 \pm 0,2$ & $39,8 \pm 7,1$ & $1,1 \pm 0,1$ & $14,7 \pm 1,9$ & $1,51 \pm 0,08$ \\
\hline ERC & $6,2 \pm 0,2$ & $4,8 \pm 0,3$ & $61,4 \pm 6,6$ & $4,3 \pm 0,3$ & $38,6 \pm 6,6$ & $1,2 \pm 0,1$ & $15,0 \pm 1,9$ & $1,52 \pm 0,10$ \\
\hline \multicolumn{9}{|l|}{ T1 (10-15') } \\
\hline ERT & $6,4 \pm 0,3$ & $5,0 \pm 0,3$ & $65,0 \pm 7,1$ & $4,1 \pm 0,2$ & $34,9 \pm 7,1$ & $1,2 \pm 0,1$ & $14,3 \pm 1,5$ & $1,26 \pm 0,17$ \\
\hline ERC & $6,2 \pm 0,3$ & $4,5 \pm 0,4$ & $71,3 \pm 6,1$ & $3,5 \pm 0,4$ & $28,6 \pm 6,1$ & $1,3 \pm 0,1$ & $11,7 \pm 2,0$ & $1,16 \pm 0,12$ \\
\hline \multicolumn{9}{|l|}{ T2 (25-30’) } \\
\hline ERT & $6,5 \pm 0,3$ & $5,2 \pm 0,3$ & $70,8 \pm 6,4$ & $4,1 \pm 0,2$ & $29,1 \pm 6,4$ & $1,3 \pm 0,1$ & $14,5 \pm 1,0$ & $1,29 \pm 0,08$ \\
\hline $\mathrm{ERC}$ & $6,5 \pm 0,4$ & $4,9 \pm 0,3$ & $70,9 \pm 6,5$ & $3,9 \pm 0,2$ & $29,0 \pm 6,5$ & $1,3 \pm 0,1$ & $13,7 \pm 1,7$ & $1,13 \pm 0,11$ \\
\hline \multicolumn{9}{|l|}{ T3 (40-45’) } \\
\hline ERT & $6,6 \pm 0,3$ & $5,3 \pm 0,3$ & $71,0 \pm 7,0$ & $4,3 \pm 0,2$ & $29,0 \pm 7,0$ & $1,3 \pm 0,1$ & $14,8 \pm 1,4$ & $1,26 \pm 0,09$ \\
\hline $\mathrm{ERC}$ & $6,3 \pm 0,2$ & $4,8 \pm 0,3$ & $64,7 \pm 8,0$ & $4,1 \pm 0,3$ & $35,2 \pm 8,0$ & $1,2 \pm 0,1$ & $13,3 \pm 1,3$ & $1,23 \pm 0,12$ \\
\hline \multicolumn{9}{|l|}{ T4 (55-60’) } \\
\hline ERT & $6,6 \pm 0,1$ & $5,3 \pm 0,2$ & $61,8 \pm 5,8$ & $4,7 \pm 0,2$ & $38,1 \pm 5,8$ & $1,1 \pm 0,1$ & $17,5 \pm 1,5$ & $1,40 \pm 0,05$ \\
\hline ERC & $6,5 \pm 0,2$ & $5,1 \pm 0,3$ & $70,1 \pm 7,4$ & $4,2 \pm 0,2$ & $29,8 \pm 7,5$ & $1,3 \pm 0,1$ & $14,2 \pm 1,6$ & $1,31 \pm 0,07$ \\
\hline \multicolumn{9}{|l|}{$p$ (ANOVA) } \\
\hline Sessão & 0,569 & 0,181 & 0,462 & 0,148 & 0,461 & 0,264 & 0,209 & 0,085 \\
\hline Tempo & 0,299 & 0,216 & 0,166 & $0,020^{*}$ & 0,165 & 0,112 & 0,210 & $0,007^{*}$ \\
\hline Interação & 0,775 & 0,503 & 0,228 & 0,153 & 0,225 & 0,245 & 0,150 & 0,730 \\
\hline
\end{tabular}

$\mathrm{ERT}=$ Exercício resistido tradicional; ERC = Exercício resistido em circuito; TP = Total power; LF = Low frequency; HF = High frequency; $\mathrm{RMSSD}=$ Square root of the mean of the sum of the squares of differences between adjacent NN intervals; SampEn = Sample Entropy; In = normalização logarítmica; nu = unidade normalizada. 
Os valores absolutos das medidas de PA durante a realização do teste de Stroop podem ser observados na Tabela 7, a título descritivo. Resultados da ANOVA de medidas repetidas, realizada para verificar a eficácia do estímulo estressor, não demonstraram efeitos significativos para sessão ( $p=0,832$ para PAS, $p=0,583$ para PAD e $p=0,948$ para PAM) ou interação ( $p=0,586$ para PAS, $p=0,808$ para PAD e $p=0,957$ para PAM) no momento pré-exercício. Entretanto, houve efeito significativo de tempo $(127,1 \pm 2,2$ valor pré vs $144,5 \pm 4,7$ valor pico, $p=0,001$ para PAS; 71,9 \pm 2,0 valor pré vs $85,7 \pm 2,5$ valor pico, $p<0,001$ para $P A D$; e 90,3 $\pm 1,6$ valor pré vs $104,3 \pm 2,5$ valor pico, $p<0,001$ para PAM). As elevações significativas na PA observadas durante o teste de Stroop, no momento pré-exercício, demonstram que o estímulo foi satisfatoriamente estressante e equivalente entre as sessões experimentais.

Tabela 7. Valores absolutos das leituras de PA durante o teste de Stroop (média \pm DP).

\begin{tabular}{cccc}
\hline & PAS $(\mathrm{mm} \mathrm{Hg})$ & PAD $(\mathrm{mm} \mathrm{Hg})$ & PAM $(\mathrm{mm} \mathrm{Hg})$ \\
\hline Pré-exercício & & & \\
ERT (repouso) & $127,9 \pm 8,0$ & $71,6 \pm 7,3$ & $90,4 \pm 6,1$ \\
ERT (pico) & $144,3 \pm 16,2$ & $85,1 \pm+8,0$ & $104,4 \pm 8,1$ \\
ERC (repouso) & $126,2 \pm 9,5$ & $72,2 \pm 6,0$ & $90,2 \pm 5,6$ \\
ERC (pico) & $144,6 \pm 15,8$ & $86,2 \pm 9,4$ & $104,3 \pm 9,5$ \\
Pós-exercício & & & \\
ERT (repouso) & $125,5 \pm 9,4$ & $73,2 \pm 7,6$ & $90,6 \pm 6,7$ \\
ERT (pico) & $138,4 \pm 17,0$ & $82,6 \pm 6,3$ & $100,7 \pm 7,1$ \\
ERC (repouso) & $122,7 \pm 11,0$ & $74,4 \pm 7,1$ & $90,5 \pm 6,5$ \\
ERC (pico) & $134,7 \pm 12,1$ & $82,5 \pm 5,5$ & $99,1 \pm 6,1$ \\
\hline
\end{tabular}

$E R T=$ Exercício resistido tradicional; ERC = Exercício resistido em circuito; PAS $=$ Pressão arterial sistólica; PAD = Pressão arterial diastólica; PAM = Pressão arterial média.

As figuras 13, 14 e 15 ilustram o comportamento da PA pré-teste (média das leituras dos minutos 1 a 3 ) e a cada minuto durante o estresse mental (painel A), e a 
respectiva comparação dos deltas de PAS, PAD e PAM $(\Delta \mathrm{mm} \mathrm{Hg})$ na situação de repouso e após o exercício (painel $\mathrm{B}$ ). Resultados da análise de variância de medidas repetidas para a RPA $(\Delta \mathrm{mm} \mathrm{Hg})$ demonstraram efeitos significativos para tempo (Pré e Pós-ER), mas não para sessão (ERT e ERC) ou interação (sessão $x$ tempo). Os resultados foram semelhantes para PAS $(17,4 \pm 3,7 \Delta$ pré versus $12,5 \pm$ 2,6 $\Delta$ pós, $p=0,14)$, PAD $(13,7 \pm 2,0 \Delta$ pré versus $8,8 \pm 1,3 \Delta$ pós, $p=0,11)$ e PAM $(14,0 \pm 2,2 \Delta$ pré versus 9,3 $\pm 1,6 \Delta$ pós, $p=0,007)$. Em conjunto, essas observações indicam que ambos os arranjos das sessões de ER (tradicional e circuito) induziram atenuação da RPA ao estresse mental, sem diferença entre as sessões.
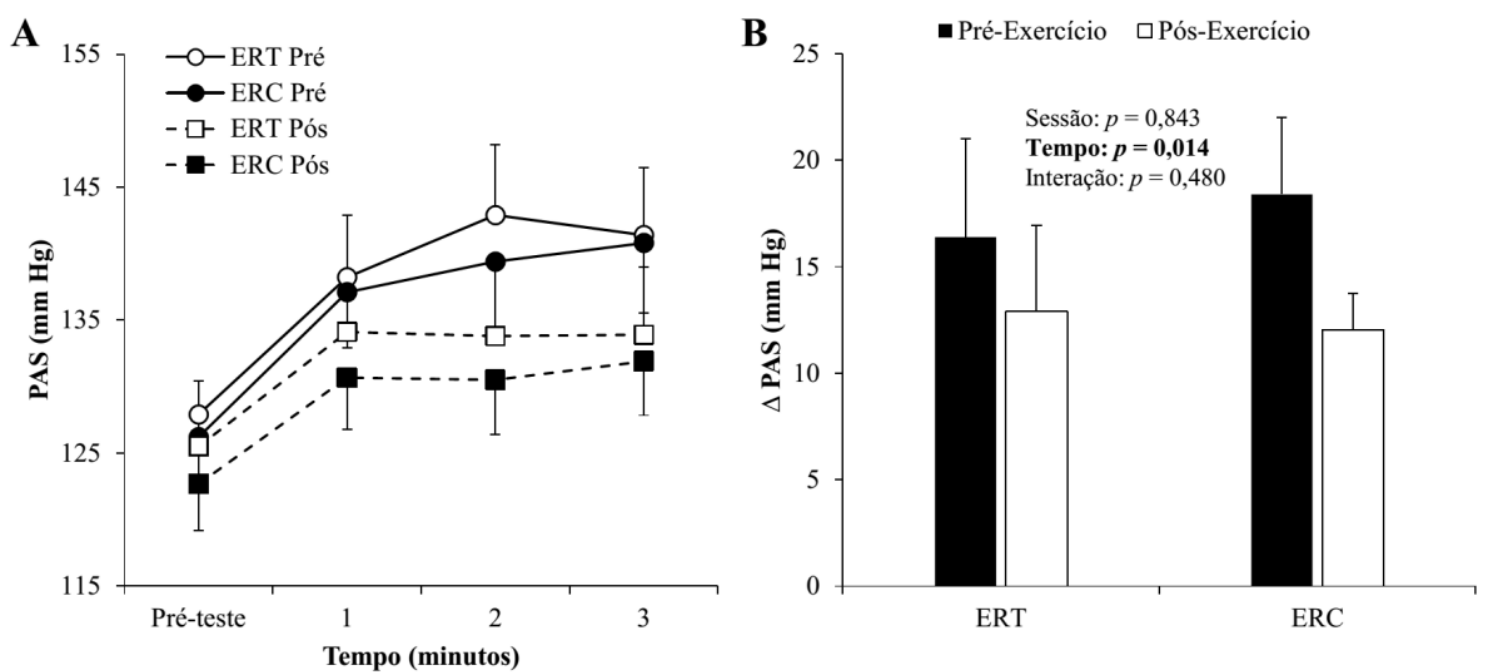

Figura 13. Comportamento da PA pré-teste e a cada minuto durante o estresse mental (painel A) e valores de reatividade da pressão arterial sistólica (PAS) ao estresse mental antes e após as sessões de exercício resistido tradicional (ERT) e exercício resistido em circuito (ERC; painel B). Dados apresentados como média \pm EP. 

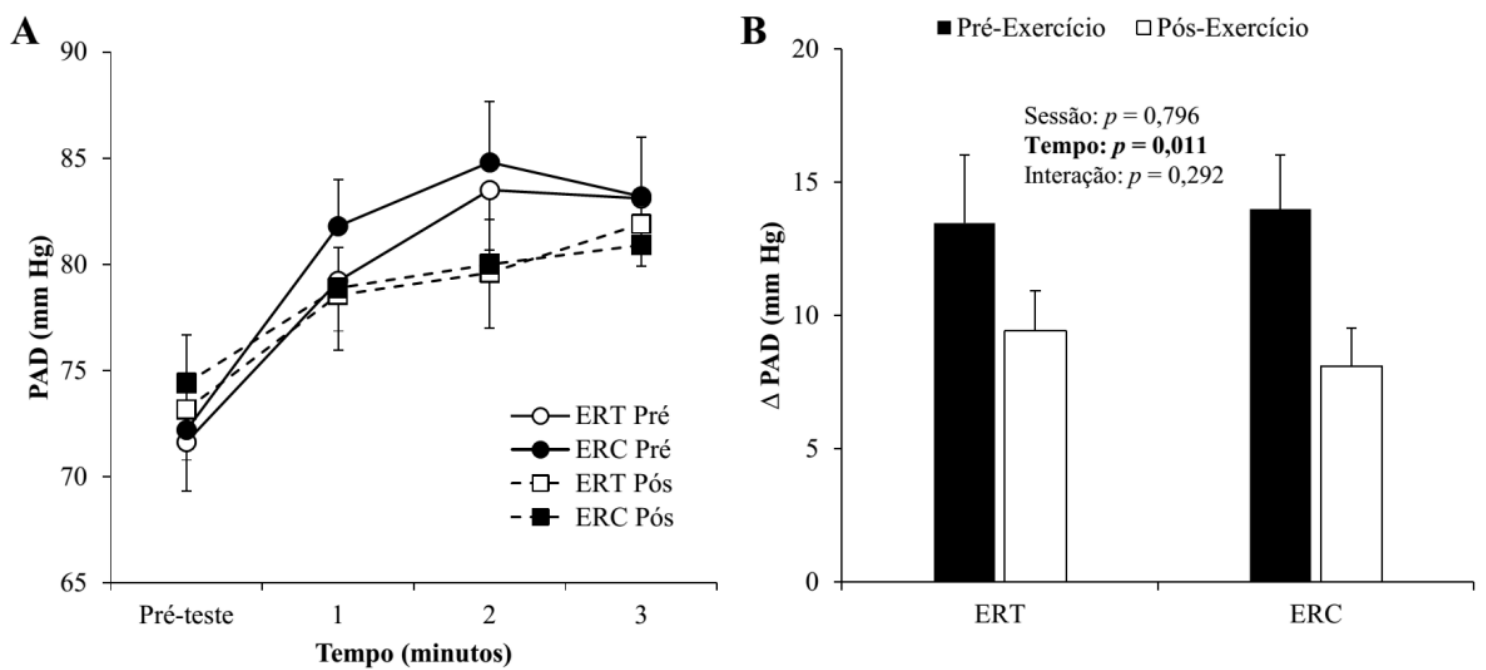

Figura 14. Comportamento da PA pré-teste e a cada minuto durante o estresse mental (painel A) e valores de reatividade da pressão arterial diastólica (PAD) ao estresse mental antes e após as sessões de exercício resistido tradicional (ERT) e exercício resistido em circuito (ERC; painel B). Dados apresentados como média \pm EP.
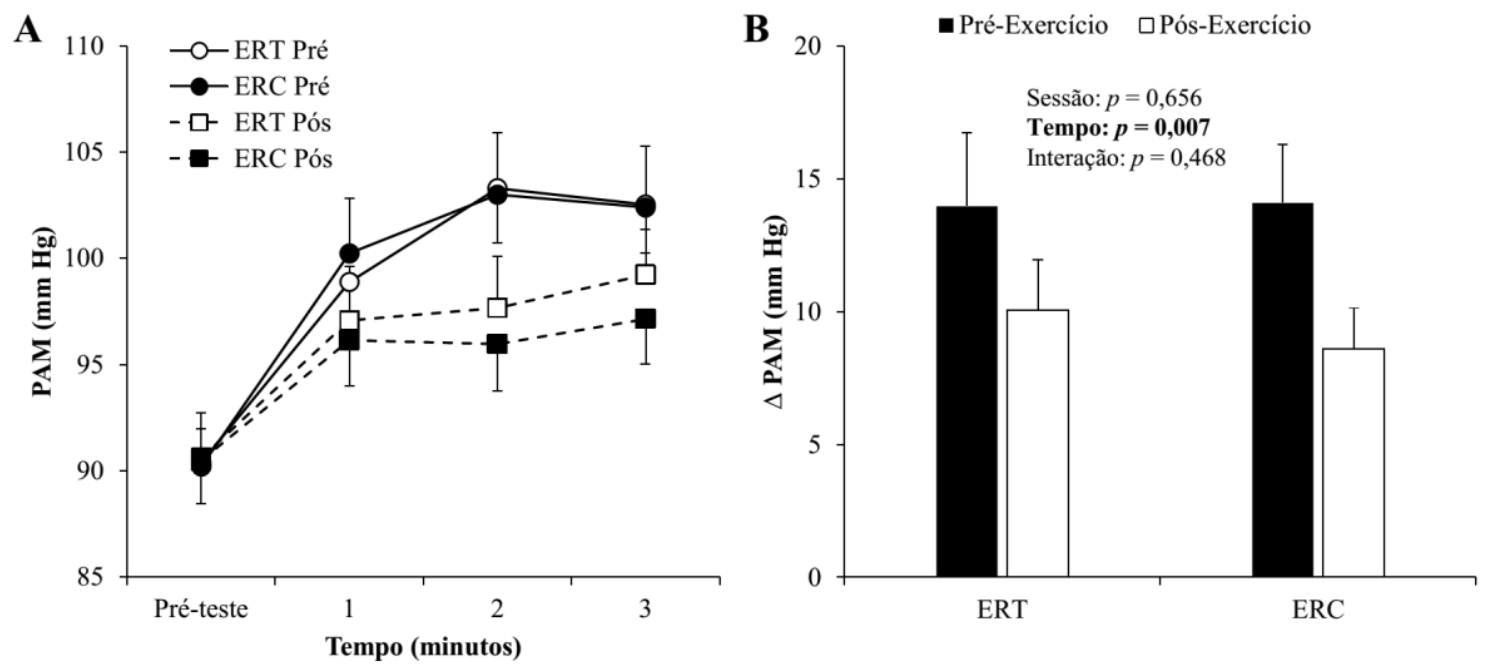

Figura 15. Comportamento da PA pré-teste e a cada minuto durante o estresse mental (painel A) e valores de reatividade da pressão arterial média (PAM) ao estresse mental antes e após as sessões de exercício resistido tradicional (ERT) e exercício resistido em circuito (ERC; painel B). Dados apresentados como média \pm EP. 
Os resultados do estresse mental na $\mathrm{FC}(\Delta \mathrm{bpm})$, provocado pelo teste de Stroop, antes e após as sessões ERT e ERC, podem ser observados na Figura 16. Não foram observados efeitos para sessão, tempo, ou interação (sessão x tempo).

- Pré-Exercício 口Pós-Exercício

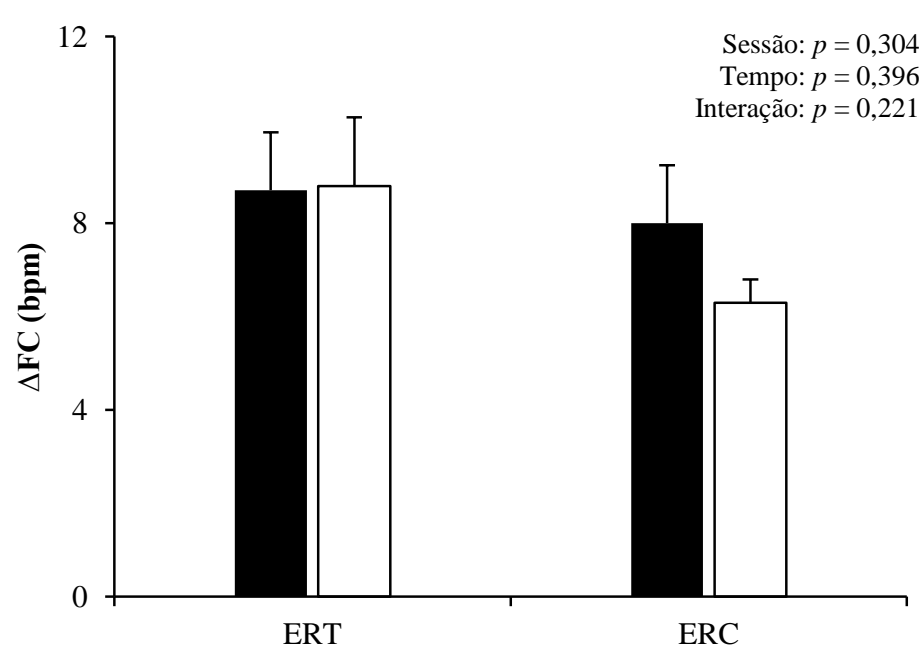

Figura 16. Média \pm EP dos valores de reatividade da frequência cardíaca (FC) ao estresse mental antes e após as sessões de exercício resistido tradicional (ERT) e exercício resistido em circuito (ERC).

5.5 Efeitos agudos do exercício resistido na modulação autonômica durante o estresse mental

Os resultados obtidos para a análise espectral da VFC, durante o estresse mental, estão apresentados na tabela 8. Em decorrência da distribuição dos dados de VFC (domínio de frequência), as variáveis de referência foram transformadas logaritmicamente. Todas as variáveis de análise da VFC já haviam retornado aos valores de repouso no momento T4 (55-60'). A Figura 17 apresenta um tacograma de um sujeito em repouso, durante a realização do teste de estresse mental e nos 3 minutos de recuperação que se seguiram ao teste. Como é possível observar, há 
uma redução expressiva nos intervalos RR imediatamente após o início do teste, seguida por uma elevação súbita dessa variável após o término do estresse mental; também é possível observar um aumento na dominância simpática durante 0 estímulo estressor, conforme indicado pela análise autorregressiva.

Um efeito de tempo foi demonstrado para os componentes TP $\left(\mathrm{ms}^{2}\right)$; LF $\left(\mathrm{ms}^{2}\right)$ durante o teste de Stroop pré-exercício em comparação ao repouso $(5,3 \pm 0,3$ valor pré-exercício versus $4,8 \pm 0,3$ valor de repouso, $p=0,023$ ), sem diferenças entre 0 Stroop pré e pós-exercício; LF (nu) durante o teste de Stroop pré e pós-exercício em comparação ao repouso $(76,8 \pm 4,2$ valor pré-exercício versus $61,4 \pm 6,8$ valor de repouso, $p=0,032$; e 7,91 $\pm 3,3$ valor pós-exercício versus $61,4 \pm 6,8$ valor de repouso, $p=0,011)$; $\mathrm{HF}(\mathrm{nu})$ durante o teste de Stroop pré e pós-exercício em comparação ao repouso $(22,9 \pm 4,2$ valor pré-exercício versus $38,5 \pm 6,8$ valor de repouso, $p=0,032$; e 20,8 $\pm 3,3$ valor pós-exercício versus $38,5 \pm 6,8$ valor de repouso, $p=0,011$ ); e LF/HF durante o teste de Stroop pré e pós-exercício em comparação ao repouso $(1,4 \pm 0,1$ valor pré-exercício versus $1,1 \pm 0,1$ valor de repouso, $p=0,025$; e 1,4 $\pm 0,1$ valor pós-exercício versus $1,1 \pm 0,1$ valor de repouso, $p=0,010)$. Não foi observado efeito de tempo para o componente $\mathrm{HF}\left(\mathrm{ms}^{2}\right)$. Os resultados para a análise espectral da VFC demonstram que a realização de uma sessão de ER não alterou a modulação autonômica durante o estresse mental. Não foram observados efeitos para sessão ou interação (sessão $x$ tempo) para nenhuma variável. 
Tabela 8. Média \pm DP dos componentes da análise da VFC no repouso e durante o estresse mental, antes e após as sessões de exercício resistido tradicional (ERT) e exercício resistido em circuito (ERC).

\begin{tabular}{|c|c|c|c|c|c|c|c|c|}
\hline & $\begin{array}{l}\text { In TP } \\
\left(\mathrm{ms}^{2}\right)\end{array}$ & $\begin{array}{l}\text { In LF } \\
\left(\mathrm{ms}^{2}\right)\end{array}$ & $\begin{array}{l}\text { LF } \\
(\mathrm{nu})\end{array}$ & $\begin{array}{l}\text { In HF } \\
\left(\mathrm{ms}^{2}\right)\end{array}$ & $\begin{array}{l}\mathrm{HF} \\
(\mathrm{nu})\end{array}$ & $\mathrm{LH} / \mathrm{HF}$ & RMSSD & SampEn \\
\hline \multicolumn{9}{|l|}{ ERT } \\
\hline Repouso & $6,3 \pm 0,2$ & $5,0 \pm 0,4$ & $62,2 \pm 7,6$ & $4,4 \pm 0,2$ & $37,7 \pm 7,5$ & $1,1 \pm 0,1$ & $15,1 \pm 1,9$ & $1,62 \pm 0,08$ \\
\hline Stroop-pré & $6,6 \pm 0,2$ & $5,4 \pm 0,3$ & $79,8 \pm 3,0$ & $3,9 \pm 0,2$ & $20,2 \pm 3,0$ & $1,4 \pm 0,0$ & $13,6 \pm 1,1$ & $1,31 \pm 0,08$ \\
\hline Stroop-pós & $6,7 \pm 0,2$ & $5,4 \pm 0,3$ & $78,5 \pm 3,2$ & $4,0 \pm 0,2$ & $21,4 \pm 3,2$ & $1,3 \pm 0,0$ & $14,6 \pm 1,3$ & $1,28 \pm 0,06$ \\
\hline \multicolumn{9}{|l|}{$\mathrm{ERC}$} \\
\hline Repouso & $6,2 \pm 0,3$ & $4,7 \pm 0,3$ & $60,6 \pm 6,9$ & $4,2 \pm 0,3$ & $39,4 \pm 6,9$ & $1,1 \pm 0,1$ & $14,5 \pm 2,1$ & $1,54 \pm 0,07$ \\
\hline Stroop-pré & $6,6 \pm 0,2$ & $5,2 \pm 0,3$ & $73,9 \pm 7,0$ & $4,0 \pm 0,2$ & $25,7, \pm 7,1$ & $1,3 \pm 0,1$ & $13,4 \pm 1,6$ & $1,26 \pm 0,07$ \\
\hline Stroop-pós & $6,8 \pm 0,2$ & $5,4 \pm 0,3$ & $79,8 \pm 3,7$ & $3,9 \pm 0,2$ & $20,2 \pm 3,7$ & $1,4 \pm 0,1$ & $14,3 \pm 1,3$ & $1,09 \pm 0,09$ \\
\hline \multicolumn{9}{|l|}{$p$ (ANOVA) } \\
\hline Sessão & 0,980 & 0,451 & 0,409 & 0,488 & 0,446 & 0,892 & 0,739 & 0,134 \\
\hline Tempo & $0,049^{*}$ & $0,029^{*}$ & $0,006^{*}$ & 0,230 & $0,006^{*}$ & $0,004^{*}$ & 0,611 & $<0,001^{*}$ \\
\hline Interação & 0,677 & 0,754 & 0,651 & 0,456 & 0,680 & 0,581 & 0,951 & 0,518 \\
\hline
\end{tabular}

$\mathrm{ERT}=$ Exercício resistido tradicional; $\mathrm{ERC}=$ Exercício resistido em circuito; $\mathrm{TP}=$ Total power $\mathrm{LF}=$ Low frequency; $\mathrm{HF}=$ High frequency; RMSSD = Square root of the mean of the sum of the squares of differences between adjacent $N N$ intervals; SampEn = Sample Entropy; In = normalização logarítmica; nu = unidade normalizada. 

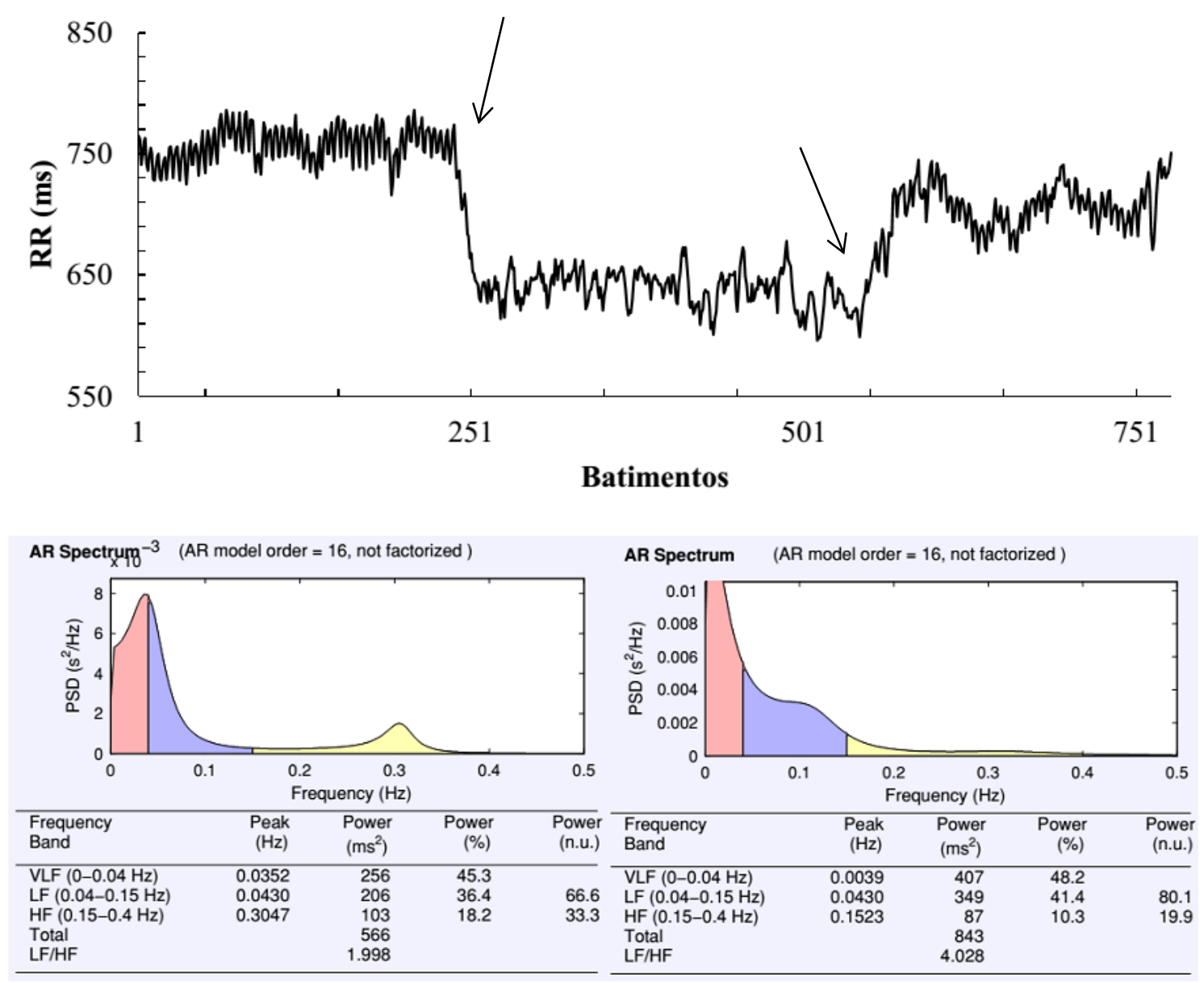

Figura 17. Análise espectral da VFC de um sujeito em repouso e durante o teste de estresse mental (Stroop). A série temporal dos intervalos RR pode ser visualizada no painel superior, com as setas da esquerda e direita indicando o início e final do estímulo estressor, respectivamente. Os painéis inferiores ilustram a saída da análise autorregressiva do Software Kubios HRV 2.2 de um sujeito em repouso (esquerda) e durante o teste de Stroop (direita).

Resultados da ANOVA de medidas repetidas para análise da VFC no domínio de tempo (RMSSD; Figura 18) não demonstraram alterações significativas durante 0 estresse mental em nenhum momento, em comparação ao repouso, tampouco diferenças entre as sessões ou interação (sessão x tempo). Os resultados indicam uma ausência de efeito do estresse mental ou exercício na modulação dessa variável, e confirmam a ausência de alterações observada no componente $\mathrm{HF}\left(\mathrm{ms}^{2}\right)$ por meio de análise espectral da VFC. 


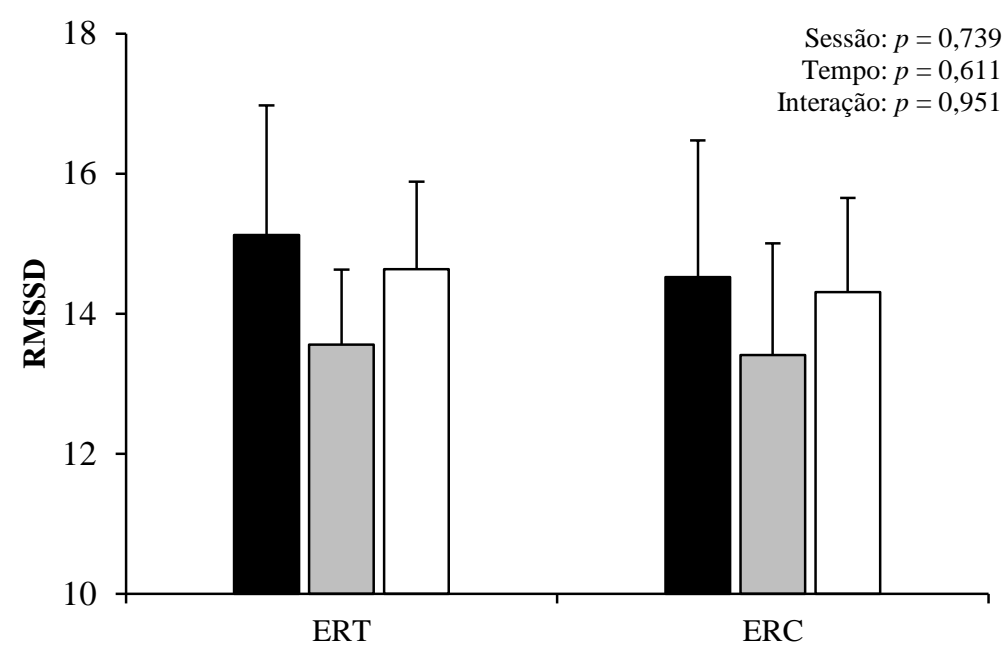

Figura 18. Média \pm EP dos valores de RMSSD em repouso e durante o estresse mental, antes e após as sessões de exercício resistido tradicional (ERT) e exercício resistido em circuito (ERC).

Finalmente, um efeito de tempo durante o teste de Stroop em comparação ao repouso $(1,28 \pm 0,06$ valor pré-exercício versus 1,58 $\pm 0,06$ valor de repouso, $p=$ 0,015 ; e 1,19 $\pm 0,06$ valor pós-exercício versus 1,58 $\pm 0,06$ valor de repouso, $p=$ 0,004 ) foi demonstrado para a complexidade da FC (Figura 19), analisada por meio da entropia amostral (SampEn), sugerindo uma redução mediada pelo estresse mental, sem alterações provocadas pelo exercício. Não foram observados efeitos de sessão ou interação (sessão x tempo) para esta variável. 
- Repouso $\quad \square$ Stroop Pré $\quad \square$ Stroop Pós

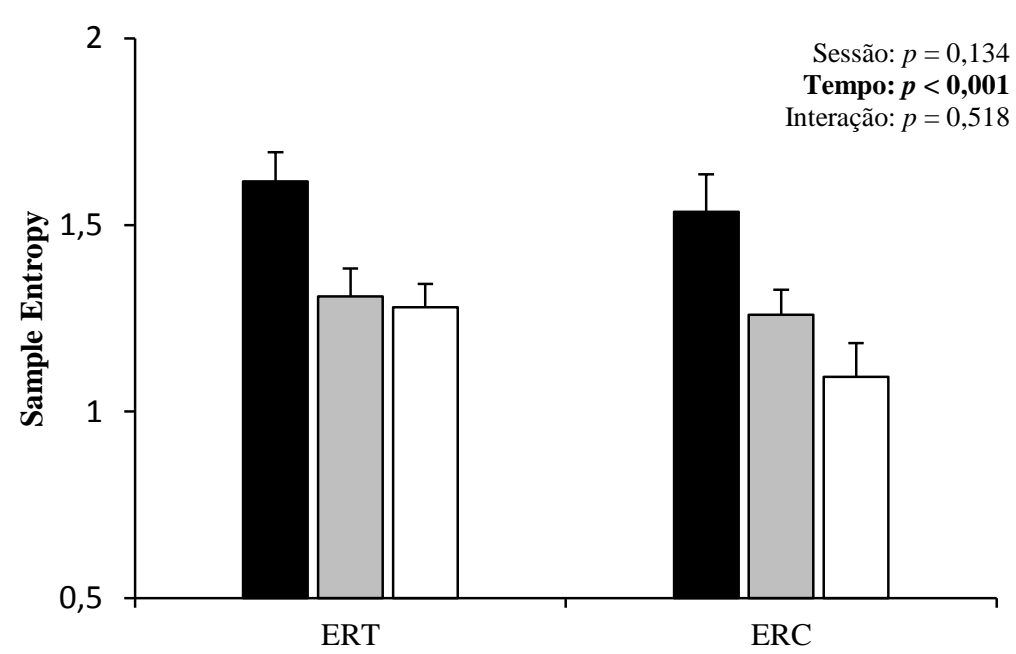

Figura 19. Média \pm EP dos valores de entropia amostral (SampEn) em repouso e durante o estresse mental, antes e após as sessões de exercício resistido tradicional (ERT) e exercício resistido em circuito (ERC). 


\section{DISCUSSÃO}

A utilização do ER como estratégia de redução no risco cardiovascular tem ganhado evidência em estudos recentes $(63,128)$. Enquanto intervenções com o ER têm sido utilizadas no intuito de se estudar o fenômeno da $\operatorname{HPE}(20,22)$, apenas dois estudos compararam as respostas pós-exercício da PA para os arranjos tradicional e em forma de circuito, ambos realizados com indivíduos jovens e normotensos (33, 34). As respostas da modulação autonômica por meio da VFC ao ER também têm sido alvo de estudos recentes $(27,28)$, mas o único estudo que comparou os arranjos supracitados incluiu apenas jovens normotensos como amostra (33).

Ademais, os efeitos de uma sessão de ER na reatividade pressórica ao estresse mental, um importante marcador de risco cardiovascular, ainda são desconhecidos. Considerando as modificações cardiovasculares e nervosas que acompanham tanto o processo de envelhecimento quanto a hipertensão arterial (38, 266) e, principalmente, o desconhecimento dos efeitos do ER na reatividade pressórica ao estresse mental, identifica-se uma lacuna a ser preenchida em relação às respostas hemodinâmicas e autonômicas ao ER em indivíduos idosos e hipertensos. O estudo dessas variáveis é de suma importância, considerando os possíveis benefícios cardiovasculares que o ER pode prover nessa população.

No presente estudo, duas sessões de exercício resistido realizadas em arranjos diferentes (i.e., de forma tradicional e em circuito) foram comparadas para as respostas hemodinâmicas e autonômicas pós-exercício, no repouso e durante o estresse mental, em um grupo de mulheres idosas hipertensas. Os principais achados foram: a) o ER promoveu atenuação na reatividade pressórica ao estresse mental, sendo essa observação similar para os dois arranjos estudados; b) a atenuação na RPA pode ser explicada, em parte, por uma redução na atividade simpática durante o estresse mental, mediada pelo ER; c) o ER não promoveu HPE, independente do arranjo utilizado (considerando os valores de PA pós-ER em relação ao repouso); e d) uma depressão vagal foi observada nos primeiros 15 minutos pós-ER, acompanhada por uma elevação da FC por até 30 minutos pós-ER; também foi observada uma redução na complexidade da FC até 45 minutos pós-ER, 
sem diferença entre a sessão tradicional e em forma de circuito. Para uma melhor compreensão do leitor, a presente discussão segue estruturada em tópicos.

\subsection{Sessões experimentais}

Análise comparativa das características das sessões demonstrou que, a despeito da sessão ERT apresentar um maior tempo de realização e uma FC média reduzida em comparação à sessão $\mathrm{ERC}$, as duas sessões não divergiram quanto à PSE, avaliada por duas escalas distintas. Adicionalmente, o tempo sob tensão também não foi diferente entre as sessões. Dessa forma, é possível inferir que, além da equivalência de volume e intensidade entre os arranjos utilizados, uma velocidade de movimento semelhante foi garantida para as duas sessões.

Estudos prévios que compararam parâmetros cardiovasculares entre sessões de ER na forma tradicional e em circuito apresentaram resultados de FC semelhantes aos observados no presente estudo (267). Alcaraz, Sánchez-Lorente (267) demonstraram que, enquanto parâmetros de desempenho se equipararam entre uma sessão realizada de forma tradicional e uma em circuito, a sobrecarga cardiovascular imposta pela sessão em forma de circuito foi maior (i.e., maior FC), corroborando nossos achados. É possível que as diferenças observadas no presente estudo possam ser explicadas pelo menor intervalo de recuperação utilizado na sessão ERC entre exercícios (30 segundos) em comparação ao utilizado entre séries no arranjo tradicional (60 segundos), associado às trocas frequentes de exercício em cada volta do circuito.

O ajuste de intensidade não se realizou por meio de um teste de força máxima, mas por meio de uma escala de PSE. Entretanto, foi demonstrado que a inclusão de procedimento de ancoragem por meio de um teste de força máximo não produziu melhoras na confiabilidade das notas apontadas na escala de percepção de esforço em comparação ao procedimento mnemônico (259), cuja utilização foi apontada como preferida pelos benefícios de tempo, esforço e praticidade que apresenta. Os valores elevados do $\mathrm{CCl}$ observados no presente estudo corroboram 
esse achado, bem como as notas apontadas pelos sujeitos para a PSE da sessão, que indicam uma intensidade moderada $(261,268)$ após as sessões de ER. Dessa forma, nossos achados reforçam a utilidade da escala OMNI-RES no ajuste de carga para mulheres idosas portadoras de HA.

Avaliações da PSE de uma sessão de ER foram inicialmente realizadas por Sweet, Foster (261), utilizando uma escala modificada de PSE (Category ratio) (260). Os resultados do presente estudo demonstraram valores de 3,7 e 3,4 para as sessões ERT e ERC, respectivamente, na escala Category ratio modificada (valores na faixa de esforço entre "Moderado" e "Um pouco difícil"). Os resultados apresentados por Day, McGuigan (268) e Sweet, Foster (261) indicam que a intensidade utilizada no presente estudo proporcionou um estímulo próximo do desejado. Ao avaliar a PSE de uma sessão de ER realizada a 50\% de 1-RM, Day, McGuigan (268) obtiveram um valor referente a 3,3. Sweet, Foster (261) demonstraram um valor equivalente a 3,8 para a mesma intensidade de exercício.

Importa ressaltar que apenas 1 estudo prévio utilizou a escala OMNI-RES para mensurar a PSE da sessão (262), uma escala desenvolvida especificamente para aplicação no ER. Os autores atestaram a eficácia dessa escala na avaliação da sessão em um grupo de 14 mulheres idosas, e encontraram uma PSE de $\sim 4$ após uma sessão de ER, composta por 5 exercícios realizados a 70\% de 1-RM. Valores superiores aos apresentados por Ferreira, Krinski (262) foram observados no presente estudo (5,1 e 4,5 para as sessões ERT e ERC, respectivamente), se aproximando de um nível de esforço entre "Um pouco fácil" e "Um pouco difícil". É possível especular que as cargas selecionadas no presente estudo por meio da escala OMNI-RES tenham representado um percentual de 1-RM maior do que os valores esperados no delineamento do presente estudo ( $60 \%$ de 1-RM). Entretanto, a escolha de carga (nota 4 na escala para 1 repetição) se baseou em diversos estudos que relacionaram percentuais de 1-RM com diferentes categorias de percepção de esforço nessa escala $(257,258,269)$. Adicionalmente, os valores de PSE da sessão, avaliada por meio da escala Category ratio modificada, ratificam sua proximidade com a intensidade do ER determinada por meio da escala OMNI-RES. 
Dessa forma, é provável que o menor número de exercícios e repetições utilizados por Ferreira, Krinski (262) justifique as diferenças supracitadas.

\subsection{Efeitos agudos do exercício resistido sobre a pressão arterial}

Não foram observadas alterações significativas na PA mensurada até 60 minutos pós-exercício no presente estudo. Não obstante, apesar da divergência desses resultados com os apresentados por estudos prévios, realizados tanto com indivíduos idosos $(18,136,137)$, quanto com indivíduos hipertensos em uso de medicação $(20,134)$ eles estão em concordância parcial com estudos prévios (16, $19,27,126)$.

Fisher (16), ao verificar os efeitos de uma sessão de ER de intensidade moderada (50\% de 1-RM estimado) na forma de circuito, em 16 mulheres normotensas e com hipertensão borderline (PAS de 130-159 e PAD de 85-99 mm $\mathrm{Hg}$ ), não identificou uma redução dos níveis de PA em relação ao repouso, apesar de os valores de PAS serem menores em relação a uma sessão controle no período pós-ER. De forma semelhante, Queiroz, Kanegusuku (27) verificaram os efeitos de uma sessão de ER em 16 indivíduos idosos de ambos os sexos. Os autores não observaram uma redução significativa na PAS pós-ER em relação ao repouso, apesar de haver redução em comparação a uma sessão controle; adicionalmente, um aumento na PAD foi observado no momento pós-exercício. Mota, de Oliveira (19), ao estudarem os efeitos crônicos e agudos do ER em uma amostra composta por 64 mulheres idosas hipertensas, não notaram o fenômeno da HPE (redução da PA em relação ao repouso), quando investigado nos meses 1 e 4 de um programa de TR.

É possível que o nível de PA de repouso justifique, em parte, a ausência de HPE, considerando que há uma associação entre a PA de repouso e a ocorrência desse fenômeno $(16,17,127)$. Foi demonstrado que quanto maiores os níveis de PA observados em uma sessão controle, maiores as reduções na PA pós-ER $(17,127)$. Nessa direção, Fisher (16) demonstrou que $71 \%$ dos sujeitos hipertensos borderline 
experimentaram um decréscimo consistente na PAS $(-7 \mathrm{~mm} \mathrm{Hg})$ em relação ao valor de repouso, quando apenas $33 \%$ dos indivíduos normotensos apresentaram decréscimo semelhante. É importante considerar que em vários estudos que incluíram indivíduos idosos e indivíduos portadores de $\mathrm{HA}$ e em uso de medicação específica $(20,21,134,137)$, o nível de PA de repouso pré-exercício foi consideravelmente maior do que os observados na presente pesquisa, especialmente para a PAS ( 130 mm Hg versus $120 \mathrm{mmHg}$, respectivamente). Todavia, uma correlação entre as alterações da PA e seus valores de repouso não pôde ser observada no presente estudo, em concordância com Moraes, Bacurau (131), indicando que outros fatores podem ter contribuído para a ausência de resposta.

Alternativamente, é possível que o estado de treinamento possa influenciar as alterações na resposta pressórica pós-ER. Conforme demonstrado por Costa, Gerage (134), em estudo que comparou o estado de treinamento em 15 mulheres idosas portadoras de hipertensão, o fenômeno da HPE ocorreu de forma mais consistente no grupo que não tinha experiência em TR. Na presente pesquisa, 50\% das voluntárias eram praticantes de TR; baseando-se nas evidências supracitadas, é possível especular que o estado de treinamento dos sujeitos tenha sido responsável, em parte, pela não observância da HPE. Dessa forma, uma ANOVA de medidas repetidas foi realizada novamente, com os indivíduos separados pela experiência em TR (dados não apresentados). Mesmo considerando a experiência em TR das voluntárias, não foram identificadas diferenças significativas na PA pós-ER em comparação ao repouso.

É possível que a antecipação ao estresse mental - ao qual o sujeito seria exposto no fim do período de repouso - possa ter impedido que maiores reduções na PA tenham sido observadas. De fato, o fenômeno da HPE não foi observado em estudos que utilizaram o exercício aeróbio para verificação da reatividade pressórica ao estresse mental $(9,246,250)$, nem mesmo em indivíduos com altos níveis de PA (9). West, Brownley (9) propuseram que a antecipação dos indivíduos ao teste de estresse mental a ser realizado poderia justificar a ausência de HPE, o que pode ter acontecido no presente estudo. 
A ausência de diferenças no comportamento da PA pós-ER identificada no presente estudo, para os dois arranjos utilizados, está de acordo com resultados de estudos prévios $(33,34)$. É importante considerar, nesse sentido, que Anunciação, Poton (33) e Simao, Fleck (34) utilizaram apenas jovens normotensos como amostra, não encontrando diferenças nas respostas da PA pós-ER entre os métodos tradicional e em forma de circuito. Os resultados do presente estudo estendem esses achados à população de idosos, portadores de HA e em uso de medicação antihipertensiva.

\subsection{Efeitos agudos do exercício resistido sobre a modulação autonômica}

Os resultados do presente estudo demonstraram uma depressão vagal pósER no T1 (10-15), representada por um decréscimo no poder da banda de alta frequência (InHF), além de uma redução na complexidade da FC durante 45 minutos pós-ER. Essa depressão vagal foi acompanhada por um aumento na FC 30 minutos pós-ER. Esses resultados estão em concordância parcial com estudos prévios que avaliaram a modulação autonômica após uma sessão de ER por meio da análise espectral da VFC $(22,23,33,177,179,181)$. Em geral, os autores supracitados observaram aumentos no componente LF e decréscimos no componente HF, com consequente aumento no balanço simpatovagal, indicando uma depressão vagal associada a um aumento da atividade simpática após uma sessão de ER.

Nossos resultados, não obstante demonstrarem uma redução no componente absoluto de alta frequência no $T 1$, não observaram maiores efeitos na modulação autonômica. Entretanto, respostas semelhantes foram observadas em vários estudos (28, 178, 182-184), corroborando parcialmente nossos achados. Lima, Forjaz (183) verificaram os efeitos de duas sessões de ER de diferentes intensidades (50 e 70\% de 1-RM) na VFC, não observando alterações na modulação autonômica após a sessão de menor intensidade. Não obstante haver inconsistência quanto à manipulação da intensidade na resposta da VFC (22), resultados semelhantes aos de Lima, Forjaz (183) foram observados por Okuno, Pedro (182). Dessa forma, a intensidade do ER parece ser fundamental na resposta autonômica pós-exercício. É 
possível que a intensidade utilizada no presente estudo, estimada pela percepção de esforço, não tenha atingido um nível suficiente para desencadear uma resposta mais expressiva na modulação autonômica. Nessa direção, Tibana, Boullosa (132) verificaram os efeitos de uma sessão de ER (10 repetições submáximas a $60 \%$ de 1 RM) na modulação autonômica em 19 indivíduos com e sem síndrome metabólica, durante 60 minutos. Nos sujeitos que não apresentavam esta condição, foi observado um decréscimo no componente HF (absoluto; $\mathrm{ms}^{2}$ ) no período 0-5 minutos pós ER em comparação ao valor de repouso. Nenhum efeito adicional pode ser demonstrado nos outros componentes da análise espectral da VFC, em concordância com os nossos resultados.

Ao considerar os resultados observados por meio da análise da VFC no domínio de tempo, entretanto, não foram observadas alterações significativas no momento pós-exercício. Nossos resultados divergem dos apresentados por Kingsley, Hochgesang (179), que observaram uma redução na RMSSD após sessões de ER realizadas em diferentes segmentos corporais. Considerando que Kingsley, Hochgesang (179) utilizaram uma intensidade de 10-RM - consideravelmente maior que a do presente estudo -, possivelmente essas diferenças se justificam pela manipulação dessa variável do ER. Esses resultados são importantes, considerando que o pressuposto da estacionariedade nas análises no domínio de frequência deve ser respeitado, e que há uma perda de estacionariedade após uma sessão de ER (181).

Tendo em vista que alterações na VFC foram observadas após tratamentos com diuréticos $(106,108)$, bloqueadores dos canais de cálcio $(29,30)$ e bloqueadores dos receptores da angiotensina $(102,104)$, há possibilidade de a ingestão medicamentosa ter alterado os efeitos específicos do ER nessa variável. Nessa direção, é possível que: a) a ingestão regular de medicamentos tenha impedido decréscimos mais pronunciados na VFC, considerando que diuréticos e bloqueadores do receptor da angiotensina eram utilizados por 60 e $70 \%$ da nossa amostra; e b) considerando que $60 \%$ das voluntárias usavam anlodipino, é possível que o uso contínuo deste fármaco tenha reduzido a $\operatorname{VFC}$ a longo-termo $(29,30)$, reduzindo a margem para maiores alterações na modulação autonômica. Nesse 
sentido, é importante considerar que o envelhecimento per se $(173,174)$ e a presença de HA $(72,73)$ podem estar associados a uma VFC reduzida, apesar de haver inconsistência na literatura em relação à ultima condição $(165,166)$.

A análise espectral da VFC pós-ER foi avaliada em indivíduos idosos em apenas um estudo. Queiroz, Rezk (129) verificaram as respostas dessa variável em 16 indivíduos idosos com experiência em TR. Elevações nos componentes LF e no balanço simpatovagal foram observadas após uma sessão de ER, em relação aos valores de repouso. É importante considerar que uma intensidade referente a 8-RM foi utilizada, diferindo da metodologia adotada no presente estudo, que se valeu de séries submáximas de 12 repetições. Dessa forma, considerando a potencial importância da intensidade na resposta autonômica pós-ER (182, 183), é possível que as diferenças observadas nessa variável justifiquem essa divergência.

O único estudo que comparou o nível de PA na modulação autonômica pósER foi realizado por Queiroz, Sousa (28). Os autores verificaram os efeitos de uma sessão de ER comparando-se indivíduos normotensos e hipertensos. Seus resultados demonstraram que o nível de PA parece não interferir na modulação autonômica após uma sessão de ER, já que reduções no componente HF (nu) e elevações no componente LF (nu) e no balanço simpatovagal foram observados nos dois grupos, divergindo dos resultados observados na presente pesquisa. Entretanto, os indivíduos hipertensos que compuseram a amostra de Queiroz, Sousa (28) estavam sob tratamento placebo (i.e., não estavam sob uso de medicamento antihipertensivo), diferentemente das voluntárias que compuseram nossa amostra. Dessa forma, maiores comparações não são possíveis, considerando que a utilização de medicamentos como bloqueadores dos canais de cálcio, diuréticos e bloqueadores do receptor AT1 da angiotensina II podem alterar modulação autonômica $(29,102,106)$. Importa ressaltar que Lima, Farah (184) não observaram alterações na regulação autonômica pós-ER, avaliada por meio da VFC em 15 pacientes com doença arterial periférica. Desses, $84,6 \%$ da amostra era portadora de $\mathrm{HA}$, e a maioria fazia uso regular de medicamentos anti-hipertensivos de classes semelhantes às utilizadas pelas voluntárias do presente estudo. 
Foi encontrado apenas um estudo que comparou os métodos tradicional e de circuito na modulação autonômica pós-ER. Após a realização de 3 séries de 18 repetições a $40 \%$ de $1-\mathrm{RM}$, um aumento significativo no balanço simpatovagal foi observado para os dois métodos, no estudo de Anunciação, Poton (33). Entretanto, o método de circuito provocou uma elevação maior que o tradicional nessa variável, divergindo dos nossos resultados nesse aspecto. Além das diferenças metodológicas, é possível justificar essas discrepâncias pelo fato de as sessões experimentais não terem sido realizadas no mesmo horário do dia no estudo de Anunciação, Poton (33), considerando que a VFC é passível de sofrer variações vinculadas ao ritmo circadiano (35).

Nossos resultados demonstraram uma redução na complexidade da FC por até 45 minutos pós-exercício. Uma redução na entropia amostral também foi demonstrada por Heffernan, Sosnoff (181) 5 minutos após uma sessão de ER. Já Kingsley, Hochgesang (179) observaram uma redução nessa variável apenas quando sessões de ER foram executadas por indivíduos treinados, 25 minutos após sua realização, sugerindo que o estado de treinamento pode influenciar nessa resposta. Contrariamente, Iglesias-Soler, Boullosa (178) não puderam observar alterações significativas na complexidade da FC mensurada 8 minutos após a realização de duas sessões de ER; entretanto, como apenas um exercício com um baixo número de repetições ( 9 ao todo) foi utilizado, é possível que o volume realizado não tenha sido suficiente para desencadear uma resposta mais evidente. Ampliando esses achados, nossos resultados demonstraram que a complexidade da FC permaneceu reduzida por até 45 minutos após o ER em um grupo de mulheres idosas hipertensas.

É importante considerar que a depressão vagal observada após a realização de uma sessão de exercícios pode trazer certas ponderações em relação a esta prática. De fato, há um aumento no risco de morte súbita durante e após a realização de exercícios vigorosos (24), parcialmente explicada por uma redução na atividade parassimpática $(25,26)$. Entretanto, uma redução do componente InHF foi observada apenas por 15 minutos pós-exercício na presente pesquisa, retornando aos níveis de repouso 30 minutos após as sessões. Adicionalmente, esse resultado não foi 
confirmado por análise no domínio de tempo. Considerando que a magnitude de risco associada ao exercício é extremamente pequena (24), a prática do ER não deve ser desencorajada, tendo em vista que os benefícios oferecidos por essa modalidade de treino se sobrepõem, em muito, aos possíveis riscos associados à sua prática, especialmente para a população de idosos $(64,117)$.

6.4 Efeitos agudos do exercício resistido sobre reatividade da pressão arterial ao estresse mental e modulação autonômica

Nossos principais resultados demonstraram, pela primeira vez, que o ER é capaz de atenuar a RPA ao estresse mental. Esse achado se soma aos diversos benefícios já bem estabelecidos acerca da prática dessa modalidade de treinamento $(63,117)$. Sua importância é reforçada, em especial, pela aplicabilidade a populações de risco cardiovascular acentuado, como os indivíduos idosos e portadores de HA. É importante ressaltar que a intensidade foi ajustada por meio de uma escala de percepção de esforço (OMNI-RES), um método prático, simples e validado para o ajuste de intensidade no ER (253) - inclusive para o método de circuito (256) - cuja eficácia foi demonstrada na população de idosos (254).

As reduções apresentadas no presente estudo se assemelham aos valores obtidos por Hamer, Taylor (7), em meta análise que incluiu resultados de 15 intervenções realizadas com sessões de exercício aeróbio. Os autores demonstraram que uma sessão de exercício aeróbio é capaz de promover reduções de 3,0 e $3,9 \mathrm{~mm} \mathrm{Hg}$ para PAS e PAD, respectivamente. Nossos resultados demonstraram reduções equivalentes a 3,5 (PAS) e 4,0 mm Hg (PAD) para a sessão tradicional, e de 6,4 (PAS) e 5,9 (PAD) para a sessão realizada em forma de circuito, sem diferença estatisticamente significativa entre as sessões. No único estudo encontrado que incluiu exercícios resistidos como parte de uma sessão de exercício concorrente, Moreira, Lima (8) verificaram uma atenuação da resposta pressórica (PAS e PAD) mediada pelo exercício em 20 homens e mulheres jovens e saudáveis, durante um teste de estresse (Cold pressor test) aplicado antes e 60 minutos após a 
realização da sessão. Nossos resultados demonstraram que o ER per se é capaz de atenuar a reatividade pressórica ao estresse mental em mulheres idosas hipertensas.

Os resultados do presente estudo não demonstraram alterações significativas na reatividade da FC após o ER. A inexistência de alterações significativas na FC corrobora resultados de estudos prévios (250), evidenciando que a PA é a variável principal a ser modulada durante situações de estresse, e não a FC, conforme apontado por Freyschuss, Hjemdahl (210) e Lindqvist, Melcher (207). De fato, estudos que se basearam apenas na FC como variável de interesse durante 0 estresse mental, para verificar os efeitos de sessões de exercício aeróbio no seu comportamento, falharam em demonstrar resultados consistentes (270).

O comportamento da modulação autonômica durante o estresse mental tem demonstrado ser inconsistente. Aumentos no componente LF associados a reduções no componente HF $(191,222,223)$, manutenção nos componentes absolutos LF e HF $(224,225)$, elevações no componente HF (226), reduções no componente LF (227), ou reduções nos componentes $\operatorname{LF}$ e HF $(228,229)$ foram observados. Nossos resultados, entretanto, demonstraram um comportamento característico de uma elevação na atividade simpática e redução vagal que não divergiu entre os arranjos utilizados, demonstrado por elevação do componente LF (em $\mathrm{ms}^{2}$ e nu), redução do componente HF (nu) e consequente aumento no balanço simpatovagal, similar a estudos prévios $(191,222)$. Adicionalmente, como foi demonstrada uma perda de estacionariedade após uma sessão de ER (uma premissa prima facie da análise espectral) (181), uma análise no domínio de tempo foi realizada. A ausência de alterações se alinha ao comportamento da banda HF $\left(\mathrm{ms}^{2}\right)$, que também não demonstrou alterações significativas durante o estresse mental, considerando que há correspondência aproximada entre essas variáveis (153). Ainda, uma redução na entropia amostral foi observada durante o estresse mental, comportamento que não sofreu alteração após a realização do ER. Esse resultado concorda com estudos prévios que demonstraram uma redução na complexidade da FC durante o estresse mental $(226,227)$. 
A atenuação na RPA, observada após a realização do $E R$, pode ser justificada, em parte, por uma redução na ativação simpática durante o estresse mental mediada pelo ER. Nossos resultados demonstraram que não houve diferença significativa no poder da banda LF $\left(\mathrm{ms}^{2}\right)$ durante o estresse mental pós-exercício em relação ao repouso, enquanto uma elevação significativa foi observada no estresse mental pré-exercício em relação ao repouso. Os resultados supracitados estão em concordância com os apresentados por Brownley, Hinderliter (6), que demonstraram que reduções na reatividade simpática (redução nos níveis de norepinefrina e aumento no período de pré-ejeção) foram responsáveis por $64 \%$ da diminuição observada na RPA média ( $\triangle$ PAM) mediada por uma sessão de exercício aeróbio.

Não obstante Brownley, Hinderliter (6) terem observado uma redução nos níveis de norepinefrina circulante após uma sessão de exercício, imediatamente antes da realização de um teste de estresse mental, o papel das catecolaminas nessa condição apresenta resultados conflitantes (11, 12). Enquanto Péronnet, Massicotte (11) observaram uma redução na epinefrina durante o estresse mental pós-exercício aeróbio, uma redução na reatividade pressórica não foi observada. Já (Ebbesen, Prkachin (12)) verificaram que uma sessão de exercício aeróbio foi capaz de promover uma atenuação nessa variável, que não foi acompanhada por alterações nas catecolaminas circulantes.

Adicionalmente, foi sugerido que uma vasodilatação mediada pelos receptores adrenérgicos $\beta 2$ pode ser responsável pela atenuação na RPA pós-exercício, conforme demonstrado por Brownley, Hinderliter (6). Entretanto, importa considerar que a dose vasodilatadora de isoproterenol necessária para reduzir a resistência vascular periférica em $50 \%$ esteve reduzida em apenas $5 \%$ nos 60 minutos após a realização do exercício, se elevando para 22\% somente após 120 minutos da realização da sessão. Considerando que o teste de estresse mental foi realizado 30 minutos após o exercício, não se pode afirmar que a reatividade pressórica foi atenuada por vasodilatação, no estudo de supracitado. Importa ressaltar que estudos prévios demonstraram que a redução na reatividade pressórica mediada pelo exercício pode ocorrer tanto por meio de uma diminuição na resistência vascular 
periférica (9), quanto por meio de reduções no volume de ejeção e débito cardíaco $(5,10)$.

O fato de que níveis equivalentes de PA foram observados no repouso e 60 após o exercício afirmam a eficácia do exercício resistido como uma importante estratégia de atenuação da reatividade pressórica ao estresse, mesmo sem a ocorrência do fenômeno da HPE. Esses achados são consistentes com os de estudos prévios que aplicaram estímulos estressores após $1 \mathrm{~h}$ da realização de sessões de exercício aeróbio e observaram atenuação da reatividade pressórica, sem observar alterações no nível de PA mediado pelo exercício $(5,6,9)$. Dessa forma, os resultados do presente estudo sugerem que a atenuação da responsividade pressórica ao estresse parece não depender dos níveis basais de $P A$, reforçando a importância da prática do ER mesmo na ausência de reduções na PA pós-ER.

Considerando que a reatividade pressórica apresenta-se exacerbada em indivíduos idosos (4), somado ao risco cardiovascular aumentado com o envelhecimento e a presença de HA $(14,15,94)$, nossos resultados são de relevância clínica, considerando que indivíduos que apresentam resposta hiperreativa ao estresse mental podem estar situados em faixas de maior risco cardiovascular, como para o acidente vascular encefálico (1), doença cerebrovascular silenciosa (2) e mortalidade cardiovascular (3).

\subsection{Limitações}

Reconhecemos limitações no presente estudo. É possível especular que a ausência de uma sessão controle tenha impedido maiores conclusões acerca do efeito do ER nas variáveis em estudo. Entretanto, várias evidências demonstraram que não há alteração na reatividade pressórica ao estresse mental após sessões em que os sujeitos permaneceram em repouso (controle) (6, 8). Adicionalmente, Gotshall, Aten (271) demonstraram que, mesmo após 2 horas de repouso sentado, a 
PAM não sofreu alterações em indivíduos do sexo feminino, em estudo realizado no período da manhã, semelhante ao utilizado no presente estudo.

A avaliação da modulação autonômica, no presente estudo, foi realizada por meio de uma medida indireta. Dessa forma, a VFC não acessa diretamente a descarga simpática central, mas a resposta do nodo sinusal a essa descarga, o que pode ser influenciado por alterações na responsividade à estimulação $\beta$-adrenérgica, como sugerido por Fagard, Stolarz (165). É sabido que alterações na frequência respiratória podem modular o componente HF, devido a modificações na arritmia respiratória sinusal (224), o que implica em limitações do método quando a frequência respiratória não é controlada, como no presente estudo. Entretanto, o controle da respiração para sua sincronização com o componente HF não representa uma respiração fisiologicamente natural, o que pode mudar o balanço simpatovagal para uma predominância vagal artificial, conforme sugerido por Montano, Porta (151).

Durante o estresse mental, estudos prévios sugerem que tanto o componente HF quanto o LF não são adequados para verificar a modulação autonômica no estresse mental $(224,229)$. Entretanto, nossos resultados para a VFC demonstraram uma resposta característica de elevação simpática mimetizada pelo estresse mental. Adicionalmente, é importante considerar que metodologias semelhantes foram utilizadas em vários estudos prévios que se valeram de intervenções com o ER (28, $129,132)$, e a metodologia aplicada apresenta validade externa.

Outra limitação consiste na ingestão de água, imediatamente após o término das sessões experimentais. Foi demonstrado que elevações de até $11 \mathrm{~mm} \mathrm{Hg}$ podem decorrer da ingestão de $\sim 0,5 \mathrm{~L}$ de água em indivíduos idosos (272). A ingestão de água provoca uma aceleração na recuperação vagal pós-exercício (273), alterando o componente HF (274-276). Entretanto, importa considerar que a dose utilizada no presente estudo representou menos da metade utilizada na maioria dos estudos associados à recuperação vagal (273-275). Adicionalmente, o pico da resposta cardiovascular acontece aproximadamente 30 minutos após a ingestão de água $(272,274,275)$, e o teste de estresse mental empregado no presente estudo foi realizado 60 minutos pós-exercício. É também importante considerar que na prática 
diária, nos centros de treinamento físico, os indivíduos frequentemente consomem água após uma sessão de exercício.

Finalmente, nossos resultados estão restritos à população estudada, uma amostra de mulheres idosas hipertensas e em uso de medicação anti-hipertensiva, não podendo ser estendidos a outras populações. É importante ressaltar, ainda, que as voluntárias utilizadas no presente estudo foram classificadas como ativas ou muito ativas pelo IPAQ, além de terem passado por critérios rigorosos de inclusão. Dessa forma, é possível que elas estejam em melhores condições de saúde que a maioria de suas congêneres idosas e hipertensas. 


\section{CONCLUSÃO}

Com base nos resultados observados, é possível concluir uma sessão de ER, realizada pelo método tradicional ou em forma de circuito, não promove redução da PA pós-exercício em idosas com HA controlada, em relação aos valores de repouso. Nossos resultados apontam, ainda, para uma depressão vagal significativa por até 15 minutos pós-exercício que não foi confirmada por análise no domínio de tempo, associada a uma elevação da FC por 30 minutos pós-ER. De forma importante, entretanto, os resultados do presente estudo demonstraram, pela primeira vez, uma atenuação na RPA ao estresse mental após o exercício resistido. Essa atenuação foi similar após os dois métodos de treinamento estudados e pode ser explicada, em parte, por uma diminuição na ativação simpática durante o estresse mental mediada pelo ER. Esses resultados podem apresentar relevante implicação clínica e se agregam a evidências prévias que recomendam o ER como importante componente de um programa de treinamento físico para idosos e para portadores da HA. Digno de nota, o arranjo de circuito, mesmo sendo vantajoso em relação ao tempo gasto para a realização de uma sessão de exercício resistido e não apresentando diferença para percepção de esforço da sessão em relação ao método tradicional, não divergiu desse arranjo nas respostas cardiovasculares e autonômicas observadas durante 60 minutos pós-exercício. 


\section{REFERÊNCIAS}

1. Everson SA, Lynch JW, Kaplan GA, Lakka TA, Sivenius J, Salonen JT. Stress-induced blood pressure reactivity and incident stroke in middle-aged men. Stroke; a journal of cerebral circulation. 2001;32(6):1263-70.

2. Waldstein SR, Siegel EL, Lefkowitz D, Maier KJ, Brown JRP, Obuchowski AM, et al. Stressinduced blood pressure reactivity and silent cerebrovascular disease. Stroke; a journal of cerebral circulation. 2004;35(6):1294-8.

3. Carroll D, Ginty AT, Der G, Hunt K, Benzeval M, Phillips AC. Increased blood pressure reactions to acute mental stress are associated with 16-year cardiovascular disease mortality. Psychophysiology. 2012;49(10):1444-8.

4. Uchino BN, Birmingham W, Berg CA. Are older adults less or more physiologically reactive? A meta-analysis of age-related differences in cardiovascular reactivity to laboratory tasks. The Journals of Gerontology Series B: Psychological Sciences and Social Sciences. 2010;65(2):154-62.

5. Vianna LC, Silva BM, Nóbrega ACL. Sex differences in blood pressure responses to mental stress are abolished after a single bout of exercise: underlying hemodynamic mechanisms. The Journal of Physiological Sciences. 2014;64(3):213-9.

6. Brownley KA, Hinderliter AL, West SG, Girdler SS, Sherwood A, Light KC. Sympathoadrenergic mechanisms in reduced hemodynamic stress responses after exercise. Medicine and science in sports and exercise. 2003;35(6):978-86.

7. Hamer M, Taylor A, Steptoe A. The effect of acute aerobic exercise on stress related blood pressure responses: a systematic review and meta-analysis. Biological psychology. 2006;71(2):183-90.

8. Moreira SR, Lima RM, Silva KE, Simoes HG. Combined exercise circuit session acutely attenuates stress-induced blood pressure reactivity in healthy adults. Brazilian journal of physical therapy. 2014;18(1):38-46.

9. West SG, Brownley KA, Light KC. Postexercise vasodilatation reduces diastolic blood pressure responses to stress. Annals of behavioral medicine : a publication of the Society of Behavioral Medicine. 1998;20(2):77-83.

10. Neves FJ, Carvalho AC, Rocha NG, Silva BM, Sales AR, de Castro RR, et al. Hemodynamic mechanisms of the attenuated blood pressure response to mental stress after a single bout of maximal dynamic exercise in healthy subjects. Brazilian journal of medical and biological research = Revista brasileira de pesquisas medicas e biologicas / Sociedade Brasileira de Biofisica [et al]. 2012;45(7):610-6.

11. Péronnet F, Massicotte D, Paquet J-E, Brisson G, de Champlain J. Blood pressure and plasma catecholamine responses to various challenges during exercise-recovery in man. European journal of applied physiology and occupational physiology. 1989;58(5):551-5.

12. Ebbesen BL, Prkachin KM, Mills DE, Green HJ. Effects of acute exercise on cardiovascular reactivity. Journal of behavioral medicine. 1992;15(5):489-507.

13. MacDonald JR. Potential causes, mechanisms, and implications of post exercise hypotension. J Hum Hypertens. 2002;16(4):225-36.

14. Lakatta EG, Levy D. Arterial and cardiac aging: major shareholders in cardiovascular disease enterprises part I: aging arteries: a "set up" for vascular disease. Circulation. 2003;107(1):139-46.

15. Lakatta EG, Levy D. Arterial and cardiac aging: major shareholders in cardiovascular disease enterprises part II: the aging heart in health: links to heart disease. Circulation. 2003;107(2):346-54.

16. Fisher MM. The effect of resistance exercise on recovery blood pressure in normotensive and borderline hypertensive women. Journal of strength and conditioning research / National Strength \& Conditioning Association. 2001;15(2):210-6. 
17. Queiroz AC, Gagliardi JF, Forjaz CL, Rezk CC. Clinic and ambulatory blood pressure responses after resistance exercise. Journal of strength and conditioning research / National Strength \& Conditioning Association. 2009;23(2):571-8.

18. Mediano MFF, Paravidino V, Simão R, Pontes FL, Polito MD. Comportamento subagudo da pressão arterial após o treinamento de força em hipertensos controlados. Rev Bras Med Esporte. 2005;11(6):337-40.

19. Mota MR, de Oliveira RJ, Dutra MT, Pardono E, Terra DF, Lima RM, et al. Acute and chronic effects of resistive exercise on blood pressure in hypertensive elderly women. Journal of strength and conditioning research / National Strength \& Conditioning Association. 2013;27(12):3475-80.

20. de Freitas Brito A, de Oliveira CVC, do Socorro Brasileiro-Santos M, da Cruz Santos A. Resistance exercise with different volumes: blood pressure response and forearm blood flow in the hypertensive elderly. Clinical interventions in aging. 2014;9:2151.

21. Jannig PR, Cardoso AC, Fleischmann E, Coelho CW, Carvalho Td. Influência da ordem de execução de exercícios resistidos na hipotensão pós-exercício em idosos hipertensos; Influence of resistance exercises order performance on post-exercise hypotension in hypertensive elderly. Rev bras med esporte. 2009;15(5):338-41.

22. Rezk CC, Marrache RC, Tinucci T, Mion D, Jr., Forjaz CL. Post-resistance exercise hypotension, hemodynamics, and heart rate variability: influence of exercise intensity. European journal of applied physiology. 2006;98(1):105-12.

23. Teixeira L, Ritti-Dias RM, Tinucci T, Mion Junior D, Forjaz CL. Post-concurrent exercise hemodynamics and cardiac autonomic modulation. European journal of applied physiology. 2011;111(9):2069-78.

24. Albert CM, Mittleman MA, Chae CU, Lee I-M, Hennekens CH, Manson JE. Triggering of sudden death from cardiac causes by vigorous exertion. New England Journal of Medicine. 2000;343(19):1355-61.

25. Kannankeril PJ, Goldberger JJ. Parasympathetic effects on cardiac electrophysiology during exercise and recovery. American Journal of Physiology-Heart and Circulatory Physiology. 2002;282(6): H2091-H8.

26. Smith LL, Kukielka M, Billman GE. Heart rate recovery after exercise: a predictor of ventricular fibrillation susceptibility after myocardial infarction. American Journal of Physiology-Heart and Circulatory Physiology. 2005;288(4):H1763-H9.

27. Queiroz AC, Kanegusuku H, Chehuen MR, Costa LA, Wallerstein LF, Dias da Silva VJ, et al. Cardiac work remains high after strength exercise in elderly. International journal of sports medicine. 2013;34(5):391-7.

28. Queiroz AC, Sousa JC, Cavalli AA, Silva ND, Jr., Costa LA, Tobaldini E, et al. Post-resistance exercise hemodynamic and autonomic responses: Comparison between normotensive and hypertensive men. Scandinavian journal of medicine \& science in sports. 2014.

29. Karas $M$, Lacourcière $Y$, LeBlanc $A-R$, Nadeau $R$, Dubé $B$, Florescu $M$, et al. Effect of the reninangiotensin system or calcium channel blockade on the circadian variation of heart rate variability, blood pressure and circulating catecholamines in hypertensive patients. Journal of hypertension. 2005;23(6):1251-60.

30. Milovanović $B$, Trifunović $D$, Milićević $N$, Vasić $K$, Krotin $M$. The significance of amlodipine on autonomic nervous system adjustment (ANSA Method): a new approach in the treatment of hypertension. Srpski arhiv za celokupno lekarstvo. 2009;137(7-8):371-8.

31. Romero-Arenas S, Blazevich AJ, Martinez-Pascual M, Perez-Gomez J, Luque AJ, Lopez-Roman $\mathrm{FJ}$, et al. Effects of high-resistance circuit training in an elderly population. Experimental gerontology. 2013;48(3):334-40. 
32. Romero-Arenas S, Martinez-Pascual M, Alcaraz PE. Impact of resistance circuit training on neuromuscular, cardiorespiratory and body composition adaptations in the elderly. Aging and disease. 2013;4(5):256-63.

33. Anunciação PG, Poton R, Szytko A, Polito MD. Comportamento cardiovascular após o exercício resistido realizado de diferentes formas e volumes de trabalho. Rev bras med esporte. 2012;18(2):117-21.

34. Simao R, Fleck SJ, Polito M, Monteiro W, Farinatti P. Effects of resistance training intensity, volume, and session format on the postexercise hypotensive response. Journal of strength and conditioning research / National Strength \& Conditioning Association. 2005;19(4):853-8.

35. Furlan R, Guzzetti S, Crivellaro W, Dassi S, Tinelli M, Baselli G, et al. Continuous 24-hour assessment of the neural regulation of systemic arterial pressure and RR variabilities in ambulant subjects. Circulation. 1990;81(2):537-47.

36. Kirkwood TB. Understanding the odd science of aging. Cell. 2005;120(4):437-47.

37. Farinatti PdT. Teorias biológicas do envelhecimento: do genético ao estocástico. Rev bras med esporte. 2002;8(4):129-38.

38. Ferrari AU, Radaelli A, Centola M. Invited review: aging and the cardiovascular system. Journal of Applied Physiology. 2003;95(6):2591-7.

39. Cheitlin MD. Cardiovascular physiology-changes with aging. The American journal of geriatric cardiology. 2003;12(1):9-13.

40. United Nations U. World Population Prospects: The 2012 Revision 2013 [cited 2014 Mai 07]. Available from: http://esa.un.org/wpp/.

41. Nóbrega ACLd, Freitas EVd, Oliveira MABd, Leitão MB, Lazzoli JK, Nahas RM, et al. Posicionamento oficial da Sociedade Brasileira de Medicina do Esporte e da Sociedade Brasileira de Geriatria e Gerontologia: atividade física e saúde no idoso. Revista Brasileira de Medicina do Esporte. 1999;5(6):207-11.

42. IBGE. Projeção da população do Brasil por sexo e idade para o período 2000/2060: Projeção da população por sexo e idades 2013 [cited 2014 Mai 07]. Available from: http://www.ibge.gov.br/home/estatistica/populacao/projecao da populacao/2013/default tab.sht

m.

43. IBGE. Tábua completa de mortalidade - 20132014 [cited 2014 Dec 09]. Available from: http://downloads.ibge.gov.br/downloads estatisticas.htm.

44. IBGE. Projeção da população do Brasil por sexo e idade para o período 2000/2060: Tábuas de mortalidade 2013 [cited 2014 Mai 07]. Available from: http://www.ibge.gov.br/home/estatistica/populacao/projecao da populacao/2013/default tab.sht

$\underline{\mathrm{m}}$.

45. IBGE. Pesquisa Nacional por Amostra de Domicílios (PNAD). Um panorama da saúde no Brasil: acesso, utilização dos serviços, condições de saúde e fatores de risco e proteção à saúde 2008 . In: Rendimento DdP-CdTe, editor. Rio de Janeiro2010.

46. IBGE. Pesquisa Nacional de Saúde 2013 (PNS). Percepção do estado de saúde, estilos de vida e doenças crônicas: Brasil, grandes regiões e unidades da federação. Rio de Janeiro2014.

47. Lin Y-P, Huang Y-H, Lu F-H, Wu J-S, Chang C-J, Yang Y-C. Non-leisure time physical activity is an independent predictor of longevity for a Taiwanese elderly population: an eight-year follow-up study. BMC public health. 2011;11(1):428.

48. Gregg EW, Cauley JA, Stone K, Thompson TJ, Bauer DC, Cummings SR, et al. Relationship of changes in physical activity and mortality among older women. Jama. 2003;289(18):2379-86.

49. Chodzko-Zajko WJ, Proctor DN, Fiatarone Singh MA, Minson CT, Nigg CR, Salem GJ, et al. American College of Sports Medicine position stand. Exercise and physical activity for older adults. Medicine and science in sports and exercise. 2009;41(7):1510-30. 
50. Atlantis E, Martin SA, Haren MT, Taylor AW, Wittert GA. Lifestyle factors associated with agerelated differences in body composition: the Florey Adelaide Male Aging Study. The American journal of clinical nutrition. 2008;88(1):95-104.

51. Shaw K, Srikanth V, Fryer J, Blizzard L, Dwyer T, Venn A. Dual energy X-ray absorptiometry body composition and aging in a population-based older cohort. International journal of obesity. 2007;31(2):279-84.

52. St-Onge M-P, Gallagher D. Body composition changes with aging: the cause or the result of alterations in metabolic rate and macronutrient oxidation? Nutrition. 2010;26(2):152-5.

53. Delmonico MJ, Harris TB, Visser M, Park SW, Conroy MB, Velasquez-Mieyer $P$, et al. Longitudinal study of muscle strength, quality, and adipose tissue infiltration. The American journal of clinical nutrition. 2009;90(6):1579-85.

54. Newman AB, Lee JS, Visser M, Goodpaster BH, Kritchevsky SB, Tylavsky FA, et al. Weight change and the conservation of lean mass in old age: the Health, Aging and Body Composition Study. The American journal of clinical nutrition. 2005;82(4):872-8.

55. Goodpaster BH, Park SW, Harris TB, Kritchevsky SB, Nevitt M, Schwartz AV, et al. The loss of skeletal muscle strength, mass, and quality in older adults: the health, aging and body composition study. The Journals of Gerontology Series A: Biological Sciences and Medical Sciences. 2006;61(10):1059-64.

56. Reid KF, Pasha E, Doros G, Clark DJ, Patten C, Phillips EM, et al. Longitudinal decline of lower extremity muscle power in healthy and mobility-limited older adults: influence of muscle mass, strength, composition, neuromuscular activation and single fiber contractile properties. European journal of applied physiology. 2014;114(1):29-39.

57. Clark DJ, Pojednic RM, Reid KF, Patten C, Pasha EP, Phillips EM, et al. Longitudinal decline of neuromuscular activation and power in healthy older adults. The Journals of Gerontology Series A: Biological Sciences and Medical Sciences. 2013;68(11):1419-25.

58. Fielding RA, Vellas B, Evans WJ, Bhasin S, Morley JE, Newman AB, et al. Sarcopenia: an undiagnosed condition in older adults. Current consensus definition: prevalence, etiology, and consequences. International working group on sarcopenia. Journal of the American Medical Directors Association. 2011;12(4):249-56.

59. Chin SO, Rhee SY, Chon S, Hwang Y-C, Jeong I-K, Oh S, et al. Sarcopenia is independently associated with cardiovascular disease in older Korean adults: the Korea National Health and Nutrition Examination Survey (KNHANES) from 2009. PloS one. 2013;8(3):e60119.

60. Arango-Lopera V, Arroyo P, Gutiérrez-Robledo LM, Perez-Zepeda M, Cesari M. Mortality as an adverse outcome of sarcopenia. The journal of nutrition, health \& aging. 2013;17(3):259-62.

61. Janssen I, Shepard DS, Katzmarzyk PT, Roubenoff R. The healthcare costs of sarcopenia in the United States. Journal of the American Geriatrics Society. 2004;52(1):80-5.

62. Nelson ME, Rejeski WJ, Blair SN, Duncan PW, Judge JO, King AC, et al. Physical activity and public health in older adults: recommendation from the American College of Sports Medicine and the American Heart Association. Circulation. 2007;116(9):1094.

63. Williams MA, Haskell WL, Ades PA, Amsterdam EA, Bittner V, Franklin BA, et al. Resistance exercise in individuals with and without cardiovascular disease: 2007 update a scientific statement from the american heart association council on clinical cardiology and council on nutrition, physical activity, and metabolism. Circulation. 2007;116(5):572-84.

64. Hunter GR, McCarthy JP, Bamman MM. Effects of resistance training on older adults. Sports medicine (Auckland, NZ). 2004;34(5):329-48.

65. Vaitkevicius PV, Fleg JL, Engel JH, O'Connor FC, Wright JG, Lakatta LE, et al. Effects of age and aerobic capacity on arterial stiffness in healthy adults. Circulation. 1993;88(4):1456-62. 
66. O'Leary DH, Polak JF, Kronmal RA, Manolio TA, Burke GL, Wolfson Jr SK. Carotid-artery intima and media thickness as a risk factor for myocardial infarction and stroke in older adults. New England Journal of Medicine. 1999;340(1):14-22.

67. Nagai Y, Metter EJ, Earley CJ, Kemper MK, Becker LC, Lakatta EG, et al. Increased carotid artery intimal-medial thickness in asymptomatic older subjects with exercise-induced myocardial ischemia. Circulation. 1998;98(15):1504-9.

68. Tanaka H, Dinenno FA, Monahan KD, Clevenger CM, DeSouza CA, Seals DR. Aging, habitual exercise, and dynamic arterial compliance. Circulation. 2000;102(11):1270-5.

69. Fleg JL. Alterations in cardiovascular structure and function with advancing age. The American journal of cardiology. 1986;57(5):33c-44c.

70. Christou DD, Seals DR. Decreased maximal heart rate with aging is related to reduced $\beta$ adrenergic responsiveness but is largely explained by a reduction in intrinsic heart rate. Journal of Applied Physiology. 2008;105(1):24-9.

71. Seals DR, Esler MD. Human ageing and the sympathoadrenal system. The Journal of physiology. 2000;528(Pt 3):407-17.

72. Paschoal M, Volanti V, Pires C, Fernandes F. Variabilidade da freqüência cardíaca em diferentes faixas etárias. Revista Brasileira de Fisioterapia. 2006;10(4):413-9.

73. Melo R, Santos MDBd, Silva E, Quitério R, Moreno M, Reis M, et al. Effects of age and physical activity on the autonomic control of heart rate in healthy men. Brazilian journal of medical and biological research. 2005;38(9):1331-8.

74. Monahan KD. Effect of aging on baroreflex function in humans. American Journal of Physiology-Regulatory, Integrative and Comparative Physiology. 2007;293(1):R3-R12.

75. Seals DR, Dinenno FA. Collateral damage: cardiovascular consequences of chronic sympathetic activation with human aging. American Journal of Physiology-Heart and Circulatory Physiology. 2004;287(5):H1895-H905.

76. Sociedades Brasileiras de Cardiologia HeN. VI Diretrizes Brasileiras de Hipertensão. Arq Bras Cardiol. 2010;95(1 (Supl 1)):1-51.

77. Fisher J, Paton J. The sympathetic nervous system and blood pressure in humans: implications for hypertension. Journal of human hypertension. 2012;26(8):463-75.

78. Fazan Jr R, Silva V, Salgado HC. Modelos de hipertensão arterial. Rev Bras Hipertens. 2001;8:19-29.

79. Mancia G, Fagard R, Narkiewicz K, Redon J, Zanchetti A, Bohm M, et al. 2013 ESH/ESC Guidelines for the management of arterial hypertension: the Task Force for the management of arterial hypertension of the European Society of Hypertension (ESH) and of the European Society of Cardiology (ESC). J Hypertens. 2013;31(7):1281-357.

80. Mayet J, Hughes A. Cardiac and vascular pathophysiology in hypertension. Heart. 2003;89(9):1104-9.

81. Santos $M$, Shah AM. Alterations in cardiac structure and function in hypertension. Current hypertension reports. 2014;16(5):1-10.

82. Kearney PM, Whelton M, Reynolds K, Muntner P, Whelton PK, He J. Global burden of hypertension: analysis of worldwide data. The Lancet. 2005;365(9455):217-23.

83. Pereira M, Lunet $\mathrm{N}$, Azevedo A, Barros H. Differences in prevalence, awareness, treatment and control of hypertension between developing and developed countries. Journal of hypertension. 2009;27(5):963-75.

84. Jardim PCBV, Gondim MdRP, Monego ET, Moreira HG, Vitorino PVdO, Souza WKSB, et al. Hipertensão arterial e alguns fatores de risco em uma capital brasileira. Arquivos Brasileiros de Cardiologia. 2007;88(4):452-7. 
85. Castro RAAd, Moncau JEC, Marcopito LF. Prevalência de hipertensão arterial sistêmica na cidade de Formiga, MG. Arquivos Brasileiros de Cardiologia. 2007;88(3):334-9.

86. Cipullo JP, Martin JFV, Ciorlia L, Godoy M, Cação JC, Loureiro AAC, et al. Prevalência e fatores de risco para hipertensão em uma população urbana brasileira. Arq Bras Cardiol. 2010;94(4):519-26.

87. World Health Organization W. A Global Brief on Hypertension. 2013.

88. Franklin SS, Gustin W, Wong ND, Larson MG, Weber MA, Kannel WB, et al. Hemodynamic patterns of age-related changes in blood pressure The Framingham Heart Study. Circulation. 1997;96(1):308-15.

89. Esperandio EM, Espinosa MM, Martins MSA, Guimarães LV, Lopes M, Scala LCN. Prevalência e fatores associados à hipertensão arterial em idosos de municípios da Amazônia Legal, MT. Rev Bras Geriatr Gerontol. 2013;16(3):481-93.

90. Aronow WS, Fleg JL, Pepine CJ, Artinian NT, Bakris G, Brown AS, et al. ACCF/AHA 2011 expert consensus document on hypertension in the elderly: a report of the American College of Cardiology Foundation Task Force on clinical expert consensus documents developed in collaboration with the American Academy of Neurology, American Geriatrics Society, American Society for Preventive Cardiology, American Society of Hypertension, American Society of Nephrology, Association of Black Cardiologists, and European Society of Hypertension. Journal of the American College of Cardiology. 2011;57(20):2037-114.

91. Chobanian AV, Bakris GL, Black HR, Cushman WC, Green LA, Izzo Jr JL, et al. The seventh report of the joint national committee on prevention, detection, evaluation, and treatment of high blood pressure: the JNC 7 report. Jama. 2003;289(19):2560-71.

92. Franklin SS, Larson MG, Khan SA, Wong ND, Leip EP, Kannel WB, et al. Does the relation of blood pressure to coronary heart disease risk change with aging? The Framingham Heart Study. Circulation. 2001;103(9):1245-9.

93. Sesso HD, Stampfer MJ, Rosner B, Hennekens CH, Gaziano JM, Manson JE, et al. Systolic and diastolic blood pressure, pulse pressure, and mean arterial pressure as predictors of cardiovascular disease risk in men. Hypertension. 2000;36(5):801-7.

94. Lewington S, Clarke R, Qizilbash N, Peto R, Collins R. Age-specific relevance of usual blood pressure to vascular mortality: a meta-analysis of individual data for one million adults in 61 prospective studies. Lancet. 2002;360(9349):1903-13.

95. Mikkola TS, Gissler M, Merikukka M, Tuomikoski P, Ylikorkala O. Sex differences in age-related cardiovascular mortality. PloS one. 2013;8(5):e63347.

96. Chen GJ, Yang MS. The effects of calcium channel blockers in the prevention of stroke in adults with hypertension: a meta-analysis of data from 273,543 participants in 31 randomized controlled trials. PLoS One. 2013;8(3):e57854.

97. van Vark LC, Bertrand M, Akkerhuis KM, Brugts JJ, Fox K, Mourad J-J, et al. Angiotensinconverting enzyme inhibitors reduce mortality in hypertension: a meta-analysis of randomized clinical trials of renin-angiotensin-aldosterone system inhibitors involving 158998 patients. European heart journal. 2012;33(16):2088-97.

98. Yusuf S, Teo KK, Pogue J, Dyal L, Copland I, Schumacher H, et al. Telmisartan, ramipril, or both in patients at high risk for vascular events. The New England journal of medicine. 2008;358(15):154759.

99. Sica DA, Carter B, Cushman W, Hamm L. Thiazide and loop diuretics. Journal of clinical hypertension (Greenwich, Conn). 2011;13(9):639-43.

100. Fretheim A, Odgaard-Jensen J, Brors O, Madsen S, Njolstad I, Norheim OF, et al. Comparative effectiveness of antihypertensive medication for primary prevention of cardiovascular disease: systematic review and multiple treatments meta-analysis. BMC medicine. 2012;10:33. 
101. Friedrich S, Schmieder RE. Review of direct renin inhibition by aliskiren. Journal of the reninangiotensin-aldosterone system : JRAAS. 2013;14(3):193-6.

102. Shehab A, Elnour AA, Struthers AD. A randomised, controlled, double-blind, cross-over pilot study assessing the effects of spironolactone, losartan and their combination on heart rate variability and QT dispersion in patients with chronic heart failure: cardiovascular topic. Cardiovascular journal of Africa. 2008;19(6):292-6.

103. De Tommasi E, lacoviello M, Romito R, Ceconi C, Guida P, Massari F, et al. Comparison of the effect of valsartan and lisinopril on autonomic nervous system activity in chronic heart failure. American heart journal. 2003;146(5):854.

104. Keković G, Milovanović B, Davidović D, Raković D, Ćulić M. Comparative effect of bisoprolol and losartan in the treatment of essential hypertension. Journal of research in medical sciences: the official journal of Isfahan University of Medical Sciences. 2012;17(11):1027.

105. Chern C-M, Hsu H-Y, Hu H-H, Chen Y-Y, Hsu L-C, Chao A-C. Effects of atenolol and losartan on baroreflex sensitivity and heart rate variability in uncomplicated essential hypertension. Journal of cardiovascular pharmacology. 2006;47(2):169-74.

106. Osakwe CE, Jacobs L, Anisiuba BC, Ndiaye MB, Lemogoum D, ljoma CK, et al. Heart rate variability on antihypertensive drugs in black patients living in sub-Saharan Africa. Blood pressure. 2014;23(3):174-80.

107. Sahin I, Kosar F, Altunkan S, Günaydin M. Comparison of the effects of amlodipine and verapamil on autonomic activity in hypertensive patients. European journal of internal medicine. 2004;15(4):225-30.

108. Pavithran P, Prakash ES, Dutta TK, Madanmohan T. Effect of antihypertensive drug therapy on short-term heart rate variability in newly diagnosed essential hypertension. Clinical and Experimental Pharmacology and Physiology. 2010;37(2):e107-e13.

109. Ylitalo A, Airaksinen KJ, Sellin L, Huikuri HV. Effects of combination antihypertensive therapy on baroreflex sensitivity and heart rate variability in systemic hypertension. The American journal of cardiology. 1999;83(6):885-9.

110. Kakhramanova S, Bakhshaliev A. Optimization of pharmacotherapy in patients with essential hypertension with neurohumoral modulators with consideration of data on heart rate variability [Abstract]. Kardiologiia. 2012;53(12):25-32.

111. Egan BM, Bandyopadhyay D, Shaftman SR, Wagner CS, Zhao Y, Yu-Isenberg KS. Initial monotherapy and combination therapy and hypertension control the first year. Hypertension. 2012;59(6):1124-31.

112. Liu Y, Chen K, Kou X, Han Y, Zhou L, Zeng C. Aliskiren and amlodipine in the management of essential hypertension: meta-analysis of randomized controlled trials. PLoS One. 2013;8(7):e70111.

113. Gus I, Harzheim E, Zaslavsky C, Medina C, Gus M. Prevalência, reconhecimento e controle da hipertensão arterial sistêmica no estado do Rio Grande do Sul. Arq Bras Cardiol. 2004;83(5):424-8.

114. Strelec M, Pierin AM, Mion Júnior D. A influência do conhecimento sobre a doença ea atitude frente à tomada dos remédios no controle da hipertensão arterial. Arq Bras Cardiol. 2003;81(4):34954.

115. Miranda RD, Perrotti TC, Bellinazzi VR, Nóbrega TM, Cendoroglo MS, Toniolo Neto J. Hipertensão arterial no idoso: peculiaridades na fisiopatologia, no diagnóstico e no tratamento. Rev Bras Hipertens. 2002;9(3):293-300.

116. Artero EG, Lee DC, Lavie CJ, Espana-Romero V, Sui X, Church TS, et al. Effects of muscular strength on cardiovascular risk factors and prognosis. Journal of cardiopulmonary rehabilitation and prevention. 2012;32(6):351-8.

117. Pollock ML, Franklin BA, Balady GJ, Chaitman BL, Fleg JL, Fletcher B, et al. Resistance exercise in individuals with and without cardiovascular disease benefits, rationale, safety, and prescription an 
advisory from the committee on exercise, rehabilitation, and prevention, council on clinical cardiology, American Heart Association. Circulation. 2000;101(7):828-33.

118. Pescatello LS, Franklin BA, Fagard R, Farquhar WB, Kelley GA, Ray CA. American College of Sports Medicine position stand. Exercise and hypertension. Medicine and science in sports and exercise. 2004;36(3):533-53.

119. Cornelissen VA, Smart NA. Exercise Training for Blood Pressure: A Systematic Review and Meta-analysis. Journal of the American Heart Association. 2013;2(1):e004473.

120. Moraes MR, Bacurau RF, Casarini DE, Jara ZP, Ronchi FA, Almeida SS, et al. Chronic conventional resistance exercise reduces blood pressure in stage 1 hypertensive men. Journal of strength and conditioning research / National Strength \& Conditioning Association. 2012;26(4):11229.

121. Queiroz ACC, Kanegusuku H, Forjaz CLdM. Efeitos do treinamento resistido sobre a pressão arterial de idosos. Arq Bras Cardiol. 2010;95(1):135-40.

122. Fleck SJ. Cardiovascular adaptations to resistance training. Medicine and science in sports and exercise. 1988;20(5 Suppl):S146-51.

123. Moraes MR, Bacurau RF, Simoes HG, Campbell CS, Pudo MA, Wasinski F, et al. Effect of 12 weeks of resistance exercise on post-exercise hypotension in stage 1 hypertensive individuals. J Hum Hypertens. 2012;26(9):533-9.

124. O'Connor PJ, Bryant CX, Veltri JP, Gebhardt SM. State anxiety and ambulatory blood pressure following resistance exercise in females. Medicine and science in sports and exercise. 1993;25(4):51621.

125. Focht BC, Koltyn KF. Influence of resistance exercise of different intensities on state anxiety and blood pressure. Medicine and science in sports and exercise. 1999;31(3):456-63.

126. Prista A, Macucule CF, Queiroz AC, Silva ND, Jr., Cardoso CG, Jr., Tinucci T, et al. A bout of resistance exercise following the 2007 AHA guidelines decreases asleep blood pressure in Mozambican men. Journal of strength and conditioning research / National Strength \& Conditioning Association. 2013;27(3):786-92.

127. Melo CM, Alencar Filho AC, Tinucci T, Mion D, Jr., Forjaz CL. Postexercise hypotension induced by low-intensity resistance exercise in hypertensive women receiving captopril. Blood pressure monitoring. 2006;11(4):183-9.

128. Cornelissen VA, Fagard RH, Coeckelberghs E, Vanhees L. Impact of resistance training on blood pressure and other cardiovascular risk factors: a meta-analysis of randomized, controlled trials. Hypertension. 2011;58(5):950-8.

129. Queiroz A, Rezk C, Teixeira L, Tinucci T, Mion D, Forjaz C. Gender influence on post-resistance exercise hypotension and hemodynamics. International journal of sports medicine. 2013;34(11):93944.

130. MacDonald JR, MacDougall JD, Interisano SA, Smith KM, McCartney N, Moroz JS, et al. Hypotension following mild bouts of resistance exercise and submaximal dynamic exercise. European journal of applied physiology and occupational physiology. 1999;79(2):148-54.

131. Moraes MR, Bacurau RF, Ramalho JD, Reis FC, Casarini DE, Chagas JR, et al. Increase in kinins on post-exercise hypotension in normotensive and hypertensive volunteers. Biological chemistry. 2007;388(5):533-40.

132. Tibana RA, Boullosa DA, Leicht AS, Prestes J. Women with metabolic syndrome present different autonomic modulation and blood pressure response to an acute resistance exercise session compared with women without metabolic syndrome. Clinical physiology and functional imaging. 2013;33(5):364-72. 
133. Moreno MR, Cunha GA, Braga PL, Lizardo JHF, Campbell CSG, Denadai MLDR, et al. Effects of exercise intensity and creatine loading on post-resistance exercise hypotension. Brazilian Journal of Kinanthropometry and Human Performance. 2009;11(4):373.

134. Costa JBY, Gerage AM, Gonçalves CGS, Pina FLC, Polito MD. Influência do estado de treinamento sobre o comportamento da pressão arterial após uma sessão de exercícios com pesos em idosas hipertensas. Revista Brasileira de Medicina do Esporte. 2010;16(2):103-6.

135. Cucato GG, Ritti-Dias RM, Wolosker N, Santarem JM, Jacob Filho W, Forjaz CL. Post-resistance exercise hypotension in patients with intermittent claudication. Clinics (Sao Paulo, Brazil). 2011;66(2):221-6.

136. de Salles BF, Maior AS, Polito M, Novaes J, Alexander J, Rhea M, et al. Influence of rest interval lengths on hypotensive response after strength training sessions performed by older men. Journal of strength and conditioning research / National Strength \& Conditioning Association. 2010;24(11):3049-54.

137. Scher LM, Ferriolli E, Moriguti JC, Scher R, Lima NK. The effect of different volumes of acute resistance exercise on elderly individuals with treated hypertension. Journal of strength and conditioning research / National Strength \& Conditioning Association. 2011;25(4):1016-23.

138. Mutti LC, Simão R, Dias I, Figueiredo T, Salles BFd. Efeito hipotensivo do treinamento de força em homens idosos. Rev Bras Cardiol. 2010;23(2):111-5.

139. Lizardo JdF, Simões $\mathrm{H}$. Efeitos de diferentes sessões de exercícios resistidos sobre a hipotensão pós-exercício. Rev Bras Fisioter. 2005;9(3):249-55.

140. Polito MD, Simão R, Senna GW, Farinatti PdTV. Hypotensive effects of resistance exercises performed at different intensities and same work volumes. Revista Brasileira de Medicina do Esporte. 2003;9(2):74-7.

141. Simoes GC, Moreira SR, Kushnick MR, Simoes HG, Campbell CS. Postresistance exercise blood pressure reduction is influenced by exercise intensity in type-2 diabetic and nondiabetic individuals. Journal of strength and conditioning research / National Strength \& Conditioning Association. 2010;24(5):1277-84.

142. Veloso J, Polito MD, Riera T, Celes R, Vidal JC, Bottaro M. Efeitos do intervalo de recuperação entre as séries sobre a pressão arterial após exercícios resistidos. Arq Bras Cardiol. 2010;94(4):512-8.

143. Dutra MT, Lima RM, Mota MR, de Oliveira PFA, Veloso JHCL. Hipotensão pos-exercício resistido: uma revisão da literatura. 2013.

144. Brentano MA, Cadore EL, Da Silva EM, Ambrosini AB, Coertjens M, Petkowicz R, et al. Physiological adaptations to strength and circuit training in postmenopausal women with bone loss. Journal of strength and conditioning research / National Strength \& Conditioning Association. 2008;22(6):1816-25.

145. Bocalini DS, Lima LS, de Andrade S, Madureira A, Rica RL, Dos Santos RN, et al. Effects of circuit-based exercise programs on the body composition of elderly obese women. Clinical interventions in aging. 2012;7:551-6.

146. Harris KA, Holly RG. Physiological response to circuit weight training in borderline hypertensive subjects. Medicine and science in sports and exercise. 1987;19(3):246-52.

147. Kelemen MH, Stewart KJ, Gillilan RE, Ewart CK, Valenti SA, Manley JD, et al. Circuit weight training in cardiac patients. Journal of the American College of Cardiology. 1986;7(1):38-42.

148. Morais PK, Campbell CS, Sales MM, Motta DF, Moreira SR, Cunha VN, et al. Acute resistance exercise is more effective than aerobic exercise for $24 \mathrm{~h}$ blood pressure control in type 2 diabetics. Diabetes \& metabolism. 2011;37(2):112-7.

149. Saccomani MG, Casonatto J, Christofaro D, Gonçalves CS, Simão R, Salles BFd, et al. Impacto do treinamento de força em circuito na pressão arterial de jovens. Rev SOCERJ. 2008;21(5):305-10. 
150. Pumprla J, Howorka K, Groves D, Chester M, Nolan J. Functional assessment of heart rate variability: physiological basis and practical applications. International journal of cardiology. 2002;84(1):1-14.

151. Montano N, Porta A, Cogliati C, Costantino G, Tobaldini E, Casali KR, et al. Heart rate variability explored in the frequency domain: a tool to investigate the link between heart and behavior. Neuroscience \& Biobehavioral Reviews. 2009;33(2):71-80.

152. Kristal-Boneh E, Raifel M, Froom P, Ribak J. Heart rate variability in health and disease. Scandinavian journal of work, environment \& health. 1995:85-95.

153. Task Force T. Heart rate variability. Standards of measurement, physiological interpretation, and clinical use. Task Force of the European Society of Cardiology and the North American Society of Pacing and Electrophysiology. Eur Heart J. 1996;17(3):354-81.

154. Hirsch JA, Bishop B. Respiratory sinus arrhythmia in humans: how breathing pattern modulates heart rate. American Journal of Physiology-Heart and Circulatory Physiology. 1981;241(4):H620-H9.

155. Pagani M, Lombardi F, Guzzetti S, Rimoldi O, Furlan R, Pizzinelli P, et al. Power spectral analysis of heart rate and arterial pressure variabilities as a marker of sympatho-vagal interaction in man and conscious dog. Circulation research. 1986;59(2):178-93.

156. Akselrod S, Gordon D, Ubel FA, Shannon DC, Berger AC, Cohen RJ. Power spectrum analysis of heart rate fluctuation: a quantitative probe of beat-to-beat cardiovascular control. Science (New York, NY). 1981;213(4504):220-2.

157. Pomeranz B, Macaulay RJ, Caudill MA, Kutz I, Adam D, Gordon D, et al. Assessment of autonomic function in humans by heart rate spectral analysis. The American journal of physiology. 1985;248(1 Pt 2):H151-3.

158. Lanfranchi PA, Somers VK. Arterial baroreflex function and cardiovascular variability: interactions and implications. American Journal of Physiology-Regulatory, Integrative and Comparative Physiology. 2002;283(4):R815-R26.

159. Pagani M, Montano N, Porta A, Malliani A, Abboud FM, Birkett C, et al. Relationship between spectral components of cardiovascular variabilities and direct measures of muscle sympathetic nerve activity in humans. Circulation. 1997;95(6):1441-8.

160. Yoo CS, Lee K, Yi SH, Kim J-S, Kim H-C. Association of heart rate variability with the Framingham risk score in healthy adults. Korean journal of family medicine. 2011;32(6):334-40.

161. Gujjar AR, Sathyaprabha TN, Nagaraja D, Thennarasu K, Pradhan N. Heart rate variability and outcome in acute severe stroke: role of power spectral analysis. Neurocritical care. 2004;1(3):347-53.

162. Kleiger RE, Miller JP, Bigger JT, Moss AJ. Decreased heart rate variability and its association with increased mortality after acute myocardial infarction. The American journal of cardiology. 1987;59(4):256-62.

163. Bigger JT, Jr., Fleiss JL, Steinman RC, Rolnitzky LM, Kleiger RE, Rottman JN. Frequency domain measures of heart period variability and mortality after myocardial infarction. Circulation. 1992;85(1):164-71.

164. Aono T, Sato T, Nishinaga M, Kawamoto A, Ozawa T. Power spectral analysis of spontaneous blood pressure and heart rate variability in elderly hypertensives. Hypertension research. 1996;19(1):9-16.

165. Fagard RH, Stolarz K, Kuznetsova T, Seidlerova J, Tikhonoff V, Grodzicki T, et al. Sympathetic activity, assessed by power spectral analysis of heart rate variability, in white-coat, masked and sustained hypertension versus true normotension. Journal of hypertension. 2007;25(11):2280-5.

166. Schroeder EB, Liao D, Chambless LE, Prineas RJ, Evans GW, Heiss G. Hypertension, blood pressure, and heart rate variability the Atherosclerosis Risk In Communities (ARIC) study. Hypertension. 2003;42(6):1106-11. 
167. Singh JP, Larson MG, Tsuji H, Evans JC, O'Donnell CJ, Levy D. Reduced Heart Rate Variability and New-Onset Hypertension Insights Into Pathogenesis of Hypertension: The Framingham Heart Study. Hypertension. 1998;32(2):293-7.

168. Virtanen R, Jula A, Kuusela T, Helenius H, Voipio-Pulkki L-M. Reduced heart rate variability in hypertension: associations with lifestyle factors and plasma renin activity. Journal of human hypertension. 2003;17(3):171-9.

169. Lucini D, Mela GS, Malliani A, Pagani M. Impairment in cardiac autonomic regulation preceding arterial hypertension in humans insights from spectral analysis of beat-by-beat cardiovascular variability. Circulation. 2002;106(21):2673-9.

170. Guzzetti S, Piccaluga E, Casati R, Cerutti S, Lombardi F, Pagani M, et al. Sympathetic predominance an essential hypertension: a study employing spectral analysis of heart rate variability. Journal of hypertension. 1988;6(9):711-7.

171. Fagard RH, Pardaens K, Staessen JA. Relationships of heart rate and heart rate variability with conventional and ambulatory blood pressure in the population. J Hypertens. 2001;19(3):389-97.

172. Liao D, Cai J, Barnes RW, Tyroler HA, Rautaharju P, Holme I, et al. Association of cardiac autonomic function and the development of hypertension: the ARIC study. American journal of hypertension. 1996;9(12 Pt 1):1147-56.

173. Agelink MW, Malessa R, Baumann B, Majewski T, Akila F, Zeit T, et al. Standardized tests of heart rate variability: normal ranges obtained from 309 healthy humans, and effects of age, gender, and heart rate. Clinical autonomic research : official journal of the Clinical Autonomic Research Society. 2001;11(2):99-108.

174. Liao D, Barnes RW, Chambless LE, Simpson RJ, Jr., Sorlie P, Heiss G. Age, race, and sex differences in autonomic cardiac function measured by spectral analysis of heart rate variability--the ARIC study. Atherosclerosis Risk in Communities. The American journal of cardiology. 1995;76(12):906-12.

175. Voss A, Heitmann A, Schroeder R, Peters A, Perz S. Short-term heart rate variability-age dependence in healthy subjects. Physiological measurement. 2012;33(8):1289.

176. Stein PK, Barzilay JI, Chaves PH, Domitrovich PP, Gottdiener JS. Heart rate variability and its changes over 5 years in older adults. Age and ageing. 2009;38(2):212-8.

177. Heffernan KS, Kelly EE, Collier SR, Fernhall B. Cardiac autonomic modulation during recovery from acute endurance versus resistance exercise. European journal of cardiovascular prevention and rehabilitation : official journal of the European Society of Cardiology, Working Groups on Epidemiology \& Prevention and Cardiac Rehabilitation and Exercise Physiology. 2006;13(1):80-6.

178. Iglesias-Soler E, Boullosa DA, Carballeira E, Sánchez-Otero T, Mayo X, Castro-Gacio X, et al. Effect of set configuration on hemodynamics and cardiac autonomic modulation after high-intensity squat exercise. Clinical physiology and functional imaging. 2014.

179. Kingsley JD, Hochgesang S, Brewer A, Buxton E, Martinson M, Heidner G. Autonomic modulation in resistance-trained individuals after acute resistance exercise. International journal of sports medicine. 2014;35(10):851-6.

180. de Souza JC, Tibana RA, Cavaglieri CR, Vieira DC, De Sousa NM, Mendes FA, et al. Resistance exercise leading to failure versus not to failure: effects on cardiovascular control. BMC cardiovascular disorders. 2013;13:105.

181. Heffernan KS, Sosnoff JJ, Jae SY, Gates GJ, Fernhall B. Acute resistance exercise reduces heart rate complexity and increases QTc interval. International journal of sports medicine. 2008;29(4):28993.

182. Okuno NM, Pedro RE, Leicht AS, de Paula Ramos S, Nakamura FY. Cardiac autonomic recovery after a single session of resistance exercise with and without vascular occlusion. Journal of strength and conditioning research / National Strength \& Conditioning Association. 2014;28(4):1143-50. 
183. Lima AHRdA, Forjaz CLdM, Silva GQdM, Menêses AL, Silva AJMR, Ritti-Dias RM. Efeito agudo da intensidade do exercício de força na modulação autonômica cardíaca pós-exercício. Arq bras cardiol. 2011;96(6):498-503.

184. Lima AH, Farah BQ, Rodrigues LB, Miranda AS, Rodrigues SL, de A Correia M, et al. Lowintensity resistance exercise does not affect cardiac autonomic modulation in patients with peripheral artery disease. Clinics. 2013;68(5):632-7.

185. Kingsley JD, Figueroa A. Acute and training effects of resistance exercise on heart rate variability. Clinical physiology and functional imaging. 2014.

186. Tsuji H, Venditti FJ, Manders ES, Evans JC, Larson MG, Feldman CL, et al. Determinants of heart rate variability. Journal of the American College of Cardiology. 1996;28(6):1539-46.

187. Júnior M, da Silva A, Moreira HG, Daher MT. Analysis of heart rate variability in hypertensive patients before and after treatment with angiotensin II-converting enzyme inhibitors. Arquivos brasileiros de cardiologia. 2004;83(2):165-8.

188. Pickering TG. Mental stress as a causal factor in the development of hypertension and cardiovascular disease. Current hypertension reports. 2001;3(3):249-54.

189. Chida Y, Steptoe A. Greater cardiovascular responses to laboratory mental stress are associated with poor subsequent cardiovascular risk status a meta-analysis of prospective evidence. Hypertension. 2010;55(4):1026-32.

190. Carter JR, Ray CA. Sympathetic neural responses to mental stress: responders, nonresponders and sex differences. American Journal of Physiology-Heart and Circulatory Physiology. 2009;296(3):H847-H53.

191. Uchino BN, Uno D, Holt-Lunstad J, Flinders JB. Age-related differences in cardiovascular reactivity during acute psychological stress in men and women. The Journals of Gerontology Series B: Psychological Sciences and Social Sciences. 1999;54(6):P339-P46.

192. Johansson SR, Hjalmarson $\AA$. Age and sex differences in cardiovascular reactivity to adrenergic agonists, mental stress and isometric exercise in normal subjects. Scandinavian Journal of Clinical \& Laboratory Investigation. 1988;48(2):183-91.

193. Steptoe A, Fieldman G, Evans O, Perry L. Cardiovascular risk and responsivity to mental stress: the influence of age, gender and risk factors. Journal of cardiovascular risk. 1996;3(1):83-93.

194. da Nobrega ACL, de Castro RRT, de Souza AC. Estresse mental e hipertensão arterial sistêmica. Rev Bras Hipertens vol. 2007;14(2):94-7.

195. Taggart P, Boyett MR, Logantha SJR, Lambiase PD. Anger, emotion, and arrhythmias: from brain to heart. Frontiers in physiology. 2011;2.

196. Kamarck TW, Everson SA, Kaplan GA, Manuck SB, Jennings JR, Salonen R, et al. Exaggerated blood pressure responses during mental stress are associated with enhanced carotid atherosclerosis in middle-aged Finnish men: findings from the Kuopio Ischemic Heart Disease Study. Circulation. 1997;96(11):3842-8.

197. Salonen JT, Salonen R. Ultrasound B-mode imaging in observational studies of atherosclerotic progression. Circulation. 1993;87(3 Suppl):li56-65.

198. Matthews KA, Zhu S, Tucker DC, Whooley MA. Blood pressure reactivity to psychological stress and coronary calcification in the Coronary Artery Risk Development in Young Adults Study. Hypertension. 2006;47(3):391-5.

199. Ghiadoni L, Donald AE, Cropley M, Mullen MJ, Oakley G, Taylor M, et al. Mental stress induces transient endothelial dysfunction in humans. Circulation. 2000;102(20):2473-8.

200. Carroll D, Ring C, Hunt K, Ford G, Macintyre S. Blood pressure reactions to stress and the prediction of future blood pressure: effects of sex, age, and socioeconomic position. Psychosomatic medicine. 2003;65(6):1058-64. 
201. Matthews KA, Katholi CR, McCreath H, Whooley MA, Williams DR, Zhu S, et al. Blood pressure reactivity to psychological stress predicts hypertension in the CARDIA study. Circulation. 2004;110(1):74-8.

202. Borghi C, Costa F, Boschi S, Mussi A, Ambrosioni E. Predictors of stable hypertension in young borderline subjects: a five-year follow-up study. Journal of Cardiovascular Pharmacology. 1986;8:S138-S41.

203. Carroll D, Smith GD, Sheffield D, Shipley MJ, Marmot MG. Pressor reactions to psychological stress and prediction of future blood pressure: data from the Whitehall II study. Bmj. 1995;310(6982):771-5.

204. Fauvel JP, M'Pio I, Quelin P, Rigaud J-P, Laville M, Ducher M. Neither perceived job stress nor individual cardiovascular reactivity predict high blood pressure. Hypertension. 2003;42(6):1112-6.

205. Light KC, Girdler SS, Sherwood A, Bragdon EE, Brownley KA, West SG, et al. High stress responsivity predicts later blood pressure only in combination with positive family history and high life stress. Hypertension. 1999;33(6):1458-64.

206. Armario P, del Rey RH, Martin-Baranera M, Almendros M, Ceresuela L, Pardell H. Blood pressure reactivity to mental stress task as a determinant of sustained hypertension after 5 years of follow-up. Journal of human hypertension. 2003;17(3):181-6.

207. Lindqvist $M$, Melcher $A$, Hjemdahl P. Hemodynamic and sympathoadrenal responses to mental stress during nitric oxide synthesis inhibition. American Journal of Physiology-Heart and Circulatory Physiology. 2004;287(5):H2309-H15.

208. Fauvel JP, Cerutti C, Quelin P, Laville M, Gustin MP, Paultre CZ, et al. Mental Stress-Induced Increase in Blood Pressure Is Not Related to Baroreflex Sensitivity in Middle-Aged Healthy Men. Hypertension. 2000;35(4):887-91.

209. Halliwill JR, Lawler LA, Eickhoff TJ, Dietz NM, Nauss LA, Joyner MJ. Forearm sympathetic withdrawal and vasodilatation during mental stress in humans. The Journal of physiology. 1997;504(1):211-20.

210. Freyschuss $U$, Hjemdahl P, Juhlin-Dannfelt A, Linde B. Cardiovascular and sympathoadrenal responses to mental stress: influence of beta-blockade. American Journal of Physiology-Heart and Circulatory Physiology. 1988;255(6):H1443-H51.

211. Brod J. Haemodynamic basis of acute pressor reactions and hypertension. British Heart Journal. 1963;25(2):227.

212. Barnes RF, Raskind M, Gumbrecht G, Halter JB. The Effects of Age on the Plasma Catecholamine Response to Mental Stress in Man. The Journal of Clinical Endocrinology \& Metabolism. 1982;54(1):64-9.

213. Esler MD, Thompson JM, Kaye DM, Turner AG, Jennings GL, Cox HS, et al. Effects of aging on the responsiveness of the human cardiac sympathetic nerves to stressors. Circulation. 1995;91(2):351-8.

214. Trueb L, Lepori M, Duplain H, Scherrer U, Sartori C. Nitric oxide mediates the blood pressure response to mental stress in humans. Swiss Med Wkly. 2012;142:w13627.

215. Dietz NM, Rivera JM, Eggener SE, Fix RT, Warner DO, Joyner MJ. Nitric oxide contributes to the rise in forearm blood flow during mental stress in humans. The Journal of physiology. 1994;480(2):361-8.

216. Cardillo C, Kilcoyne CM, Quyyumi AA, Cannon RO, Panza JA. Role of nitric oxide in the vasodilator response to mental stress in normal subjects. The American journal of cardiology. 1997;80(8):1070-4.

217. Harris CW, Edwards JL, Baruch A, Riley WA, Pusser BE, Rejeski WJ, et al. Effects of mental stress on brachial artery flow-mediated vasodilation in healthy normal individuals. American heart journal. 2000;139(3):405-11. 
218. Anderson EA, Wallin BG, Mark AL. Dissociation of sympathetic nerve activity in arm and leg muscle during mental stress. Hypertension. 1987;9(6 Pt 2):III114.

219. Carter JR, Durocher JJ, Kern RP. Neural and cardiovascular responses to emotional stress in humans. American Journal of Physiology-Regulatory, Integrative and Comparative Physiology. 2008;295(6):R1898-R903.

220. Carter JR, Kupiers NT, Ray CA. Neurovascular responses to mental stress. The Journal of physiology. 2005;564(1):321-7.

221. Callister R, Suwarno NO, Seals DR. Sympathetic activity is influenced by task difficulty and stress perception during mental challenge in humans. The Journal of physiology. 1992;454(1):373-87.

222. Moriguchi A, Otsuka A, Kohara K, Mikami H, Katahira K, Tsunetoshi T, et al. Spectral change in heart rate variability in response to mental arithmetic before and after the beta-adrenoceptor blocker, carteolol. Clinical Autonomic Research. 1992;2(4):267-70.

223. Langewitz W, Rüddel H, Schächinger H, Lepper W, Mulder L, Veldman J, et al. Changes in sympathetic and parasympathetic cardiac activation during mental load: an assessment by spectral analysis of heart rate variability. Homeostasis in health and disease: international journal devoted to integrative brain functions and homeostatic systems. 1990;33(1-2):23-33.

224. Sloan R, Korten J, Myers MM. Components of heart rate reactivity during mental arithmetic with and without speaking. Physiology \& Behavior. 1991;50(5):1039-45.

225. Bernardi L, Wdowczyk-Szulc J, Valenti C, Castoldi S, Passino C, Spadacini G, et al. Effects of controlled breathing, mental activity and mental stress with or without verbalization on heart rate variability. Journal of the American College of Cardiology. 2000;35(6):1462-9.

226. Vuksanović V, Gal V. Heart rate variability in mental stress aloud. Medical engineering \& physics. 2007;29(3):344-9.

227. Visnovcova Z, Mestanik M, Javorka M, Mokra D, Gala M, Jurko A, et al. Complexity and time asymmetry of heart rate variability are altered in acute mental stress. Physiological measurement. 2014;35(7):1319.

228. Niizeki K, Saitoh T. Incoherent oscillations of respiratory sinus arrhythmia during acute mental stress in humans. American Journal of Physiology-Heart and Circulatory Physiology. 2012;302(1):H359-H67.

229. Sloan RP, Shapiro P, Bagiella E, Bigger J, Lo E, Gorman J. Relationships between circulating catecholamines and low frequency heart period variability as indices of cardiac sympathetic activity during mental stress. Psychosomatic medicine. 1996;58(1):25-31.

230. Tuomisto MT. Intra-arterial blood pressure and heart rate reactivity to behavioral stress in normotensive, borderline, and mild hypertensive men. Health Psychology. 1997;16(6):554.

231. Georgiades A, Lemne C, de Faire U, Lindvall K, Fredrikson M. Stress-induced laboratory blood pressure in relation to ambulatory blood pressure and left ventricular mass among borderline hypertensive and normotensive individuals. Hypertension. 1996;28(4):641-6.

232. Cardillo C, Kilcoyne CM, Cannon RO, Panza JA. Impairment of the nitric oxide-mediated vasodilator response to mental stress in hypertensive but not in hypercholesterolemic patients. Journal of the American College of Cardiology. 1998;32(5):1207-13.

233. Lindvall K, Kahan T, de Faire U, Ostergren J, Hjemdahl P. Stress-induced changes in blood pressure and left ventricular function in mild hypertension. Clinical cardiology. 1991;14(2):125-32.

234. Tsai P-S, Yucha CB, Nichols WW, Yarandi H. Hemodynamics and arterial properties in response to mental stress in individuals with mild hypertension. Psychosomatic medicine. 2003;65(4):613-9.

235. Langewitz $W$, Rüddel $H$, Schächinger $H$. Reduced parasympathetic cardiac control in patients with hypertension at rest and under mental stress. American heart journal. 1994;127(1):122-8. 
236. Ruediger $H$, Seibt $R$, Scheuch $K$, Krause $M$, Alam S. Sympathetic and parasympathetic activation in heart rate variability in male hypertensive patients under mental stress. Journal of human hypertension. 2004;18(5):307-15.

237. Gintner GG, Hollandsworth JG, Intrieri RC. Age differences in cardiovascular reactivity under active coping conditions. Psychophysiology. 1986;23(1):113-20.

238. Heffernan MJ, Patel HM, Muller MD. Forearm vascular responses to mental stress in healthy older adults. Physiological reports. 2013;1(7):e00180.

239. Steptoe A, Moses J, Edwards S. Age-related differences in cardiovascular reactions to mental stress tests in women. Health Psychology. 1990;9(1):18.

240. Jennings JR, Kamarck T, Manuck S, Everson SA, Kaplan G, Salonen JT. Aging or disease? Cardiovascular reactivity in Finnish men over the middle years. Psychology and aging. 1997;12(2):225.

241. Seals DR, Bell C. Chronic Sympathetic Activation Consequence and Cause of Age-Associated Obesity? Diabetes. 2004;53(2):276-84.

242. Lipman RD, Grossman P, Bridges SE, Hamner J, Taylor JA. Mental stress response, arterial stiffness, and baroreflex sensitivity in healthy aging. The Journals of Gerontology Series A: Biological Sciences and Medical Sciences. 2002;57(7):B279-B84.

243. Bartholomew JB. Stress reactivity after maximal exercise: the effect of manipulated performance feedback in endurance athletes. Journal of sports sciences. 2000;18(11):893-9.

244. Lambiase MJ, Barry HM, Roemmich JN. Effect of a simulated active commute to school on cardiovascular stress reactivity. Medicine and science in sports and exercise. 2010;42(8):1609-16.

245. Medeiros RF, Silva BM, Neves FJ, Rocha NG, Sales AR, Nobrega AC. Impaired hemodynamic response to mental stress in subjects with prehypertension is improved after a single bout of maximal dynamic exercise. Clinics (Sao Paulo, Brazil). 2011;66(9):1523-9.

246. Rejeski WJ, Thompson A, Brubaker PH, Miller HS. Acute exercise: buffering psychosocial stress responses in women. Health Psychology. 1992;11(6):355.

247. Hamer $\mathrm{M}$, Jones $\mathrm{J}$, Boutcher $\mathrm{SH}$. Acute exercise reduces vascular reactivity to mental challenge in offspring of hypertensive families. J Hypertens. 2006;24(2):315-20.

248. Sales AR, Fernandes IA, Rocha NG, Costa LS, Rocha HN, Mattos JD, et al. Aerobic exercise acutely prevents the endothelial dysfunction induced by mental stress among subjects with metabolic syndrome: the role of shear rate. American Journal of Physiology-Heart and Circulatory Physiology. 2014;306(7):H963-H71.

249. Someya N, Ikemura T, Hayashi N. Effect of preceding exercise on cerebral and splanchnic vascular responses to mental task. Journal of physiological anthropology. 2012;31(1):17.

250. Rejeski WJ, Gregg E, Thompson A, Berry M. The effects of varying doses of acute aerobic exercise on psychophysiological stress responses in highly trained cyclists. Journal of Sport and Exercise Psychology. 1991;13:188-99.

251. Alderman BL, Arent SM, Landers DM, Rogers TJ. Aerobic exercise intensity and time of stressor administration influence cardiovascular responses to psychological stress. Psychophysiology. 2007;44(5):759-66.

252. Pickering TG, Hall JE, Appel LJ, Falkner BE, Graves J, Hill MN, et al. Recommendations for blood pressure measurement in humans and experimental animals part 1: blood pressure measurement in humans: a statement for professionals from the Subcommittee of Professional and Public Education of the American Heart Association Council on High Blood Pressure Research. Hypertension. 2005;45(1):142-61.

253. Robertson RJ, Goss FL, Rutkowski J, Lenz B, Dixon C, Timmer J, et al. Concurrent validation of the OMNI perceived exertion scale for resistance exercise. Medicine and science in sports and exercise. 2003;35(2):333-41. 
254. Gearhart Jr RF, Lagally KM, Riechman SE, Andrews RD, Robertson RJ. Strength tracking using the OMNI resistance exercise scale in older men and women. The Journal of Strength \& Conditioning Research. 2009;23(3):1011-5.

255. Brito AdF, Alves NFB, Silva AA, Silva AS. O uso da escala de omni-res em idosas hipertensas. Estud interdiscip envelhec. 2011;16(1):111-25.

256. Aniceto RR, Ritti-Dias RM, dos Prazeres TMP, Farah BQ, de Lima FFM, do Prado WL, et al. Rating of perceived exertion during circuit weight training: a concurrent validation study. The Journal of Strength \& Conditioning Research. 2015.

257. Lagally KM, Robertson RJ. Construct validity of the OMNI resistance exercise scale. The Journal of Strength \& Conditioning Research. 2006;20(2):252-6.

258. Lins-Filho OdL, Robertson RJ, Farah BQ, Rodrigues SL, Cyrino ES, Ritti-Dias RM. Effects of exercise intensity on rating of perceived exertion during a multiple-set resistance exercise session. The Journal of Strength \& Conditioning Research. 2012;26(2):466-72.

259. Lagally KM, Costigan EM. Anchoring procedures in reliability of ratings of perceived exertion during resistance exercise. Perceptual and motor skills. 2004;98(3c):1285-95.

260. Foster C, Florhaug JA, Franklin J, Gottschall L, Hrovatin LA, Parker S, et al. A new approach to monitoring exercise training. The Journal of Strength \& Conditioning Research. 2001;15(1):109-15.

261. Sweet TW, Foster C, McGuigan MR, Brice G. Quantitation of resistance training using the session rating of perceived exertion method. The Journal of Strength \& Conditioning Research. 2004;18(4):796-802.

262. Ferreira SS, Krinski K, Alves RC, Benites ML, Redkva PE, Elsangedy HM, et al. The Use of Session RPE to Monitor the Intensity of Weight Training in Older Women: Acute Responses to Eccentric, Concentric, and Dynamic Exercises. Journal of aging research. 2014;2014:749317.

263. Vanderlei LCM, Pastre CM, Hoshi RA, Carvalho TDd, Godoy MFd. Noções básicas de variabilidade da frequência cardíaca e sua aplicabilidade clínica. Rev Bras Cir Cardiovasc. 2009;24(2):205-17.

264. Stroop JR. Studies of interference in serial verbal reactions. Journal of experimental psychology. 1935;18(6):643.

265. Taylor C, Jones H, Zaregarizi M, Cable N, George K, Atkinson G. Blood pressure status and post-exercise hypotension: an example of a spurious correlation in hypertension research? Journal of human hypertension. 2010;24(9):585-92.

266. Grassi G. Sympathetic neural activity in hypertension and related diseases. American journal of hypertension. 2010;23(10):1052-60.

267. Alcaraz PE, Sánchez-Lorente J, Blazevich AJ. Physical performance and cardiovascular responses to an acute bout of heavy resistance circuit training versus traditional strength training. The Journal of Strength \& Conditioning Research. 2008;22(3):667-71.

268. Day ML, McGuigan MR, BRICE G, Foster C. Monitoring exercise intensity during resistance training using the session RPE scale. The Journal of Strength \& Conditioning Research. 2004;18(2):353-8.

269. Lagally KM, Amorose AJ, Rock B. Selection of resistance exercise intensity using ratings of perceived exertion from the Omni-Res. Perceptual and motor skills. 2009;108(2):573-86.

270. Duda JL, Sedlock DA, Melby CL, Thaman C. The effects of physical activity level and acute exercise on heart rate and subjective response to a psychological stressor. International Journal of Sport Psychology. 1988.

271. Gotshall RW, Aten LA, Yumikura S. Difference in the cardiovascular response to prolonged sitting in men and women. Canadian journal of applied physiology. 1994;19(2):215-25.

272. Jordan J, Shannon JR, Black BK, Ali Y, Farley M, Costa F, et al. The pressor response to water drinking in humans a sympathetic reflex? Circulation. 2000;101(5):504-9. 
273. Vianna LC, Oliveira RB, Silva BM, Ricardo DR, Araújo CGS. Water intake accelerates postexercise cardiac vagal reactivation in humans. European journal of applied physiology. 2008;102(3):283-8.

274. Brown CM, Barberini L, Dulloo AG, Montani J-P. Cardiovascular responses to water drinking: does osmolality play a role? American Journal of Physiology-Regulatory, Integrative and Comparative Physiology. 2005;289(6):R1687-R92.

275. Routledge HC, Chowdhary S, Coote JH, Townend JN. Cardiac vagal response to water ingestion in normal human subjects. Clinical science (London, England : 1979). 2002;103(2):157-62.

276. Callegaro C, Moraes R, Negrao C, Trombetta I, Rondon M, Teixeira M, et al. Acute water ingestion increases arterial blood pressure in hypertensive and normotensive subjects. Journal of human hypertension. 2007;21(7):564-70. 


\section{LISTA DE ANEXOS}

ANEXO I - Termo de consentimento livre e esclarecido .................................115

ANEXO II - Registro de aceite no Comitê de Ética e Pesquisa.........................117

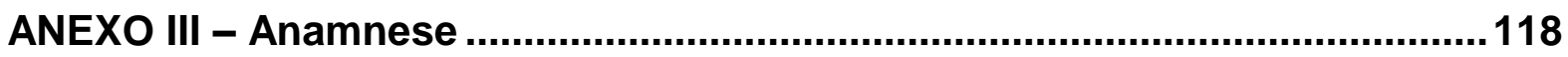

ANEXO IV - Questionário de prontidão para a atividade física (PAR - Q) .....121

ANEXO V - Questionário Internacional de Atividade Física (IPAQ) - Versão curta

ANEXO VI - Artigo publicado: Revista Brasileira de Cineantropometria e Desempenho Humano

ANEXO VII - Artigo aceito para publicação: Clinical Interventions in Aging.125 


\section{ANEXO I \\ Termo de consentimento livre e esclarecido}

Você está sendo convidada a participar da pesquisa intitulada "Efeitos agudos de diferentes métodos de treinamento resistido sobre a pressão arterial, modulação autonômica e reatividade cardiovascular em mulheres idosas hipertensas", orientada para mulheres idosas que possuam hipertensão diagnosticada e façam uso de medicamento anti-hipertensivo, e realizada pelo Grupo de Estudos em Fisiologia do Exercício e Saúde (GEFS). O presente projeto de pesquisa foi aprovado pelo Comitê de Ética em Pesquisa da Faculdade de Ciências da Saúde da UnB (no: 01/13), e tem como objetivo verificar os efeitos de diferentes sessões de exercício resistido (musculação) na pressão arterial, na modulação do sistema nervoso autônomo e na reatividade cardiovascular.

Para a realização da pesquisa, você será submetida a) ao preenchimento de um questionário sobre hábitos de vida e saúde; b) a uma avaliação antropométrica (estatura, massa corporal e circunferência do braço esquerdo); c) a realização de 6 sessões de treino de força (popularmente conhecido como musculação), sendo 4 para familiarização com os exercícios, e 2 sessões experimentais; e) a avaliações da pressão arterial no repouso e após o exercício, por meio de um dispositivo oscilométrico (automático; 2 a 3 leituras no repouso e 4 após o exercício). Para essas avaliações, um manguito será afixado no braço esquerdo, exercendo uma leve pressão no braço quando inflado; f) a avaliações da variabilidade da frequência cardíaca antes e depois das sessões, utilizando-se um frequencímetro. Para isso, um gel será aplicado em uma fita transmissora, que será afixada na linha do processo xifóide (porção mais inferior do osso esterno); e g) a um teste de estresse mental (Teste de Stroop), que também contará com aferições da pressão arterial antes, durante e depois de sua execução, por meio de um dispositivo auscultatório (esfigmomanômetro); o teste consiste em uma série de slides com nomes de cores escritas em cores variadas (por exemplo, "preto" escrito com letras verdes), aonde você deverá acertar a cor em que a palavra foi escrita - serão vários slides, apresentados por 3 minutos. As sessões de familiarização (6) terão duração aproximada de 60 minutos, e as sessões experimentais, de 2 horas e 30 minutos.

O treinamento de força tem sido recomendado como auxiliar no controle não medicamentoso da pressão arterial, e a realização de sessões de treinamento de força não apresentam maiores riscos, desde que as orientações profissionais sejam seguidas. Entretanto, há possibilidade da incidência de dor muscular tardia, que desaparece em poucos dias. Pesquisas recentes demonstraram melhoras na regulação do sistema cardiovascular após a realização de uma sessão de treinamento de força, o que diminui o risco cardiovascular. A 
presente pesquisa contribuirá para um melhor entendimento deste fenômeno, possibilitando a prescrição de treinamentos mais eficientes para o controle da pressão arterial. Os resultados desta pesquisa serão submetidos à publicação em congressos e periódicos científicos, além de serem utilizados para a escrita de uma dissertação de Mestrado. Entretanto, garantimos o sigilo de sua identidade, dados que ficarão guardados apenas pelo pesquisador responsável pelo projeto, podendo ser retirados por você a qualquer momento.

Ressaltamos que você poderá abandonar a pesquisa no momento em que desejar, sem qualquer constrangimento ou ônus, bastando informar sua decisão ao pesquisador responsável. Se necessário, você poderá entrar em contato com o pesquisador responsável [Rafael, (61) 9144-4487] ou com o Comitê de Ética e Pesquisa da Faculdade de Ciências da Saúde da UnB (CEP/FS), pelo telefone (61) 3107-1947. Uma cópia do presente termo será garantida a você.

$$
\text { Eu, }
$$
,abaixo

assinado, após ser devidamente esclarecida sobre os objetivos, riscos e demais condições que envolverão minha participação no presente projeto de pesquisa, realizado sob a responsabilidade do pesquisador Rafael Gauche e supervisionado pelo Prof. Dr. Ricardo Moreno Lima, declaro que tenho total conhecimento e estou ciente e concordante com os direitos e condições que me foram apresentadas e asseguradas e que, livremente, manifesto a minha vontade em participar do projeto supracitado.

BSB, de de

Pesquisador responsável:

Participante voluntário: 


\title{
ANEXO II \\ Registro de aceite no Comitê de Ética e Pesquisa
}

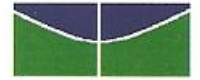 \\ Universidade de Brasília \\ Faculdade de Ciências da Saúde \\ Comitê de Ética em Pesquisa - CEP/FS

\section{PROCESSO DE ANÁLISE DE PROJETO DE PESQUISA}

Registro do Projeto no CEP: 001/13

Título do Projeto: "Estudo compreensivo dos efeitos crônicos do treinamento resistido em mulheres idosas."

Pesquisador Responsável: Ricardo Moreno Lima

Data de Entrada: 06/12/2012

Com base na Resolução 196/96, do CNS/MS, que regulamenta a ética em pesquisa com seres humanos, o Comitê de Ética em Pesquisa com Seres Humanos da Faculdade de Ciências da Saúde da Universidade de Brasília, após análise dos aspectos éticos e do contexto técnico-científico, resolveu APROVAR o projeto 001/13 com o título: "Estudo compreensivo dos efeitos crônicos do treinamento resistido em mulheres idosas.", analisado na $1^{\text {a }}$ Reunião Ordinária, realizada no dia 29 de janeiro de 2013.

O pesquisador responsável fica, desde já, notificado da obrigatoriedade da apresentação de um relatório semestral e relatório final sucinto e objetivo sobre o desenvolvimento do Projeto, no prazo de 1 (um) ano a contar da presente data (item VII.13 da Resolução 196/96).

Brasília, 22 de fevereiro de 2013.

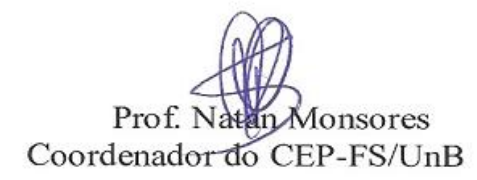




\section{ANEXO III}

\section{Anamnese}

Prezada voluntária,

Muito obrigado pela participação em nossa pesquisa! Solicitamos o preenchimento do questionário abaixo para conhecimento dos seus hábitos de vida e estado de saúde. Por favor, preencha com bastante atenção, estes dados são fundamentais para o êxito do nosso trabalho.

\section{Informações gerais}

Nome:

Data de nascimento: 1

Idade: anos

Nível de escolaridade

Fundamental ( ) Médio ( ) Superior ( ) / Completo ( ) Incompleto ( )

Endereço:

Telefone(s) para contato:

\section{Hábitos de saúde}

Consome bebida alcóolica?

Sim ( ) Não ( ) É fumante?

$\operatorname{Sim}(\quad$ ) Não ( )

Já fumou? Sim ( ) Não ( ) Por quanto tempo?

Parou há:

Faz terapia de reposição hormonal?

$\operatorname{Sim}($ ) Não ( )

Atividade física

\section{Modalidade 1:}

Pratica há quanto tempo?

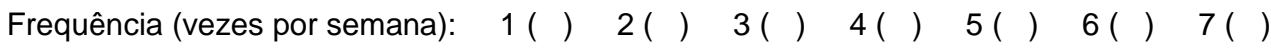

Duração (minutos por sessão): minutos

Modalidade 2:

Pratica há quanto tempo? 
Informações adicionais

Você já fez alguma cirurgia? Sim ( ) Não ( )

De quê?

Há quanto tempo?

Você sente alguma dor? Sim ( ) Não ( )

Em qual parte do corpo?

Há quanto tempo?

Em repouso ( ) Em movimento ( ) Em repouso e em movimento ( )

Quais remédios você toma? Em quais horários?

Data: Avaliador:

ID: 


\section{ANEXO IV \\ Questionário de prontidão para a atividade física (PAR - Q)}

1. Alguma vez um médico lhe disse que você possui um problema no coração e recomendou que só fizesse atividade física sob supervisão médica?

( ) Não ( ) Sim

2. Você sente dor no peito ao fazer atividade física?

( ) Não ( ) Sim

3. Você sentiu dor no peito no último mês?

( ) Não ( ) Sim

4. Você perde o equilíbrio por causa de tontura, ou alguma vez perdeu a consciência?

( ) Não ( ) Sim

5. Você tem algum problema ósseo ou articular que poderia ser agravado com a prática de atividade física?

( ) Não ( ) Sim

6. Algum médico já recomendou uso de medicamento para sua pressão arterial ou problema cardíaco?

( ) Não ( $\quad$ (x) Sim

7. Você tem conhecimento de alguma outra razão que o impeça de praticar atividades físicas?

( ) Não ( ) Sim

Nome:

ID:

Data: Avaliador: 


\section{ANEXO V \\ Questionário Internacional de Atividade Física (IPAQ) - Versão curta}

Nós estamos interessados em saber que tipos de atividade física as pessoas fazem como parte do seu dia a dia. As perguntas estão relacionadas ao tempo que você gasta fazendo atividade física na ÚLTIMA semana. As perguntas incluem as atividades que você faz no trabalho, para ir de um lugar a outro, por lazer, por esporte, por exercício ou como parte das suas atividades em casa ou no jardim. Suas respostas são MUITO importantes. Por favor responda cada questão mesmo que considere que não seja ativo. Obrigado pela sua participação!

Para responder as questões lembre que:

> Atividades físicas VIGOROSAS são aquelas que precisam de um grande esforço físico e que fazem respirar MUITO mais forte que o normal

> Atividades físicas MODERADAS são aquelas que precisam de algum esforço físico e que fazem respirar UM POUCO mais forte que o normal

Para responder as perguntas pense somente nas atividades que você realiza por pelo menos 10 minutos contínuos de cada vez.

1a. Em quantos dias da última semana você CAMINHOU por pelo menos 10 minutos contínuos, em casa ou no trabalho, como forma de transporte para ir de um lugar para outro, por lazer, por prazer ou como forma de exercício?

dias por SEMANA ( ) Nenhum

1b. Nos dias em que você caminhou por pelo menos 10 minutos contínuos, quanto tempo no total você gastou caminhando por dia?

Horas: Minutos:

2a. Em quantos dias da última semana você realizou atividades MODERADAS por pelo menos 10 minutos contínuos, como por exemplo, pedalar leve na bicicleta, nadar, dançar, fazer ginástica aeróbica leve, jogar vôlei recreativo, carregar pesos leves, fazer serviços domésticos na casa, no quintal ou no jardim como varrer, aspirar, cuidar do jardim, ou qualquer atividade que fez aumentar moderadamente sua respiração ou batimentos do coração (POR FAVOR, NÃO INCLUA CAMINHADA).

dias por SEMANA ( ) Nenhum 
2b. Nos dias em que você fez essas atividades moderadas por pelo menos 10 minutos contínuos, quanto tempo no total você gastou fazendo essas atividades por dia?

Horas: Minutos:

3a. Em quantos dias da última semana, você realizou atividades VIGOROSAS por pelo menos 10 minutos contínuos, como por exemplo, correr, fazer ginástica aeróbica, jogar futebol, pedalar rápido na bicicleta, jogar basquete, fazer serviços domésticos pesados em casa, no quintal ou cavoucar no jardim, carregar pesos elevados ou qualquer atividade que fez aumentar MUITO sua respiração ou batimentos do coração.

$$
\text { dias por SEMANA ( ) Nenhum }
$$

3b. Nos dias em que você fez essas atividades vigorosas por pelo menos 10 minutos contínuos, quanto tempo no total você gastou fazendo essas atividades por dia?

Horas: Minutos:

Estas últimas questões são sobre o tempo que você permanece sentado todo dia, no trabalho, na escola ou faculdade, em casa e durante seu tempo livre. Isto inclui o tempo sentado estudando, sentado enquanto descansa, fazendo lição de casa visitando um amigo, lendo, sentado ou deitado assistindo TV. Não inclua o tempo gasto sentando durante o transporte em ônibus, trem, metrô ou carro.

4a. Quanto tempo no total você gasta sentado durante um dia de semana?

Horas: Minutos:

4b. Quanto tempo no total você gasta sentado durante em um dia de final de semana?

Horas: Minutos:

Nome: ID:

Data: Avaliador: 


\section{ANEXO VI \\ Artigo publicado: Revista Brasileira de Cineantropometria e Desempenho Humano}

Strength, muscle quality and markers of cardiometabolic risk in older women

Força, qualidade muscular e marcadores de risco cardiometabólico em mulheres idosas

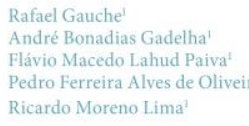

Abstract - The aging process is associated with a decline in physiological functions, including a reduction in muscle quality, as well as changes in cardiometabolic risk factors. Thus, the aim of this study was to verify if a correlation exists between muscle strength and quality and cardiometabolic risk markers in older women. Thirty older women $(66.13 \pm 5.26$ years, $67.33 \pm 12.45 \mathrm{~kg}, 1.54 \pm 0.07 \mathrm{~m}$, body mass index: $28.20 \pm 4.72)$ were submitted to the evaluation of muscle thickness and strength and blood analysis of cardiometabolic risk markers (glucose, basal insulin, C-reactive protein, total cholesterol, HDL-cholesterol, LDL-cholesterol, VLDL-cholesterol, triglycerides, and HOMA-IR). No significant correlations were found between muscle phenotypes and markers of cardiometabolic risk, even after adjustment for confounding factors. The present study indicates that muscle strength or quality is not correlated with markers of cardiometabolic risk.

Key words: Elderly; Muscle strength; Risk factors.

Resumo - O processo de envelhecimento está associado a um declínio nas funções fisiológicas, refletindo em reduções na qualidade muscular, bem como em alteraçôes de marcadores de risco cardiometabólico. Nesse sentido, o objetivo do estudo foi verificar a associação entre qualidade muscular e marcadores de risco cardiometabólico em mulheres idosas. Trinta mulheres idosas $(66,13 \pm 5,26$ anos, $67,33 \pm 12,45 \mathrm{~kg}, 1,54 \pm 0,07 \mathrm{~m}, 28,20 \pm 4,72$ IMC) foram submetidas à avaliação da espessura e força musculares do quadriceps, e à análise sanguínea de marcadores de risco cardiometabólico (glicemia, insulina basal, proteina C-reativa, colesterol total, HDL-colesterol, LDL-colesterol, VLDL-colesterol, triglicerídeos, e índice HOMA-IR). Não foram encontradas correlaçōes significativas entre os fenótipos musculares e os marcadores de risco cardiometabólico estudados, mesmo com controle para fatores de confusão. A presente pesquisa indica não haver correlação entre força e qualidade muscular com os marcadores de risco cardiometabólico estudados. Palavras-chave: Fatores de risco; Força muscular; Idoso.
1 Universidade de Brasilia, Faculdade de Educação Fisica. Brasilia, Distrito Federal, Brasil.

Received: 09 May 2014 Accepted: 17 October 2014 
ANEXO VII

\section{Artigo aceito para publicação: Clinical Interventions in Aging}

\section{Resistance training improves isokinetic strength and metabolic syndrome-related phenotypes in postmenopausal women}

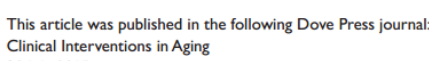

Pedro Ferreira Alves Oliveira'

André Bonadias Gadelha ${ }^{2}$ Rafael Gauche ${ }^{2}$

Flávio Macedo Lahud Paiva ${ }^{2}$ Martim Bottaro ${ }^{2}$

Lauro CVianna ${ }^{2}$

Ricardo Moreno Lima²

'Department of Physical Education, Instituto Federal de Brasilia, ${ }^{2}$ College of Physical Education, University of Brasilia, Brasilia, DF, Braz
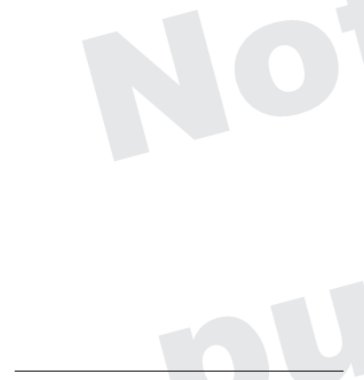

Correspondence: Ricardo Moreno Lim Faculdade de Educação Fisica, Universidade de Brasilia (UnB), Campus Universitário Darcy Ribeiro, Brasilia 70910-900, DF, Brazl

Tel +556181099444

$\mathrm{Fax}+556131072500$

Email ricardomoreno@unb.br
Purpose: To examine the effects of resistance training (RT) on metabolic syndrome-related phenotypes in postmenopausal women.

Patients and methods: Twenty-two postmenopausal women (65.0 \pm 4.2 years) underwent 12 weeks of whole body progressive training with intensity prescribed based on rating of perceived exertion. Dominant knee extension strength was assessed using an isokinetic dynamometer before and after the intervention. Moreover, all volunteers had blood samples collected for lipid profile, glycemic control, and C-reactive protein analyses. Waist circumference and arterial blood pressure were also measured at baseline and after the training period. Student's $t$-tests for paired samples and repeated measures ANOVA were used to compare dependent variables, and statistical significance was set at $P<0.05$.

Results: Isokinetic muscle strength significantly increased $(P<0.01)$ with training. It was observed that waist circumference as well as total and low-density lipoprotein cholesterol levels significantly decreased with training $(P<0.01)$. Total cholesterol/high-density lipoprotein cholesterol ratio, an important marker of cardiovascular disease incidence, was also significantly reduced (from $3.91 \pm 0.91$ to $3.60 \pm 0.74 ; P<0.01$ ) after the program. Blood glucose, basal insulin, and homeostatic model assessment of insulin resistance were also significantly reduced $(P<0.01)$. No significant alterations were observed for resting blood pressure, triglycerides, or $\mathrm{C}$-reactive protein.

Conclusion: Based on the observed results, it can be concluded that a 12-week progressive RT program, besides increasing isokinetic muscle strength, induces beneficial alterations on metabolic syndrome-related phenotypes in postmenopausal women. These findings highlight this mode of exercise as an important component of public health promotion programs for aged women. RT improves isokinetic strength and metabolic syndrome-related phenotypes in postmenopausal women.

Keywords: strength training, cardiometabolic risk, OMNI-RES, aging

\section{Introduction}

Resistance training (RT) has been widely studied in individuals with advanced age, given its well-documented effects in preventing and restoring the decline in muscle mass and strength (ie, sarcopenia) ${ }^{1-3}$ Sarcopenia has been linked to a variety of negative outcomes, and the benefits of the RT introduce its practice in several guidelines from important institutions involved in global physical activity programs for older adults. ${ }^{4-8}$ However, although the effects of RT in improving muscle strength and function are well recognized, its role in managing cardiometabolic risk factors has only lately attracted attention of scientific community. ${ }^{9,10}$ Noteworthy, a plethora of epidemiological studies demonstrate that cardiovascular and metabolic risks

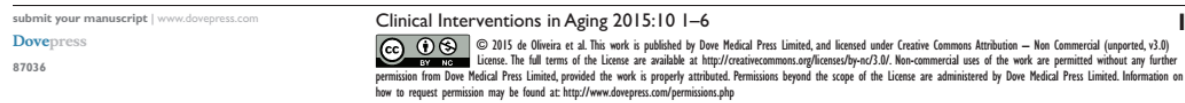

